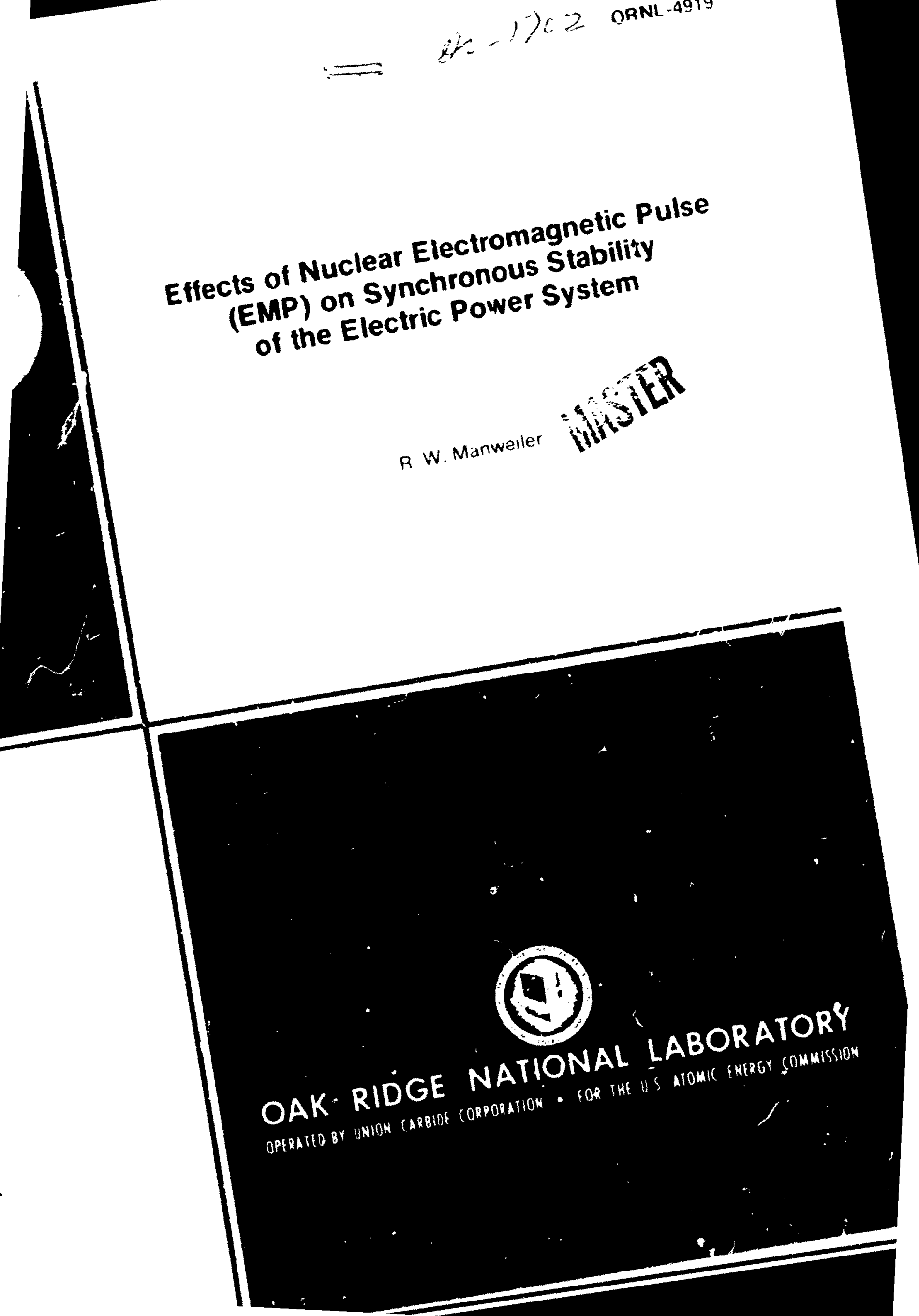



Printed in the United $S$ ates of America. Available from Natınnal Technical Information Service

L.S. Department of Commerce

5785 Port Roval Road. Soringfield. Yirninia 22161

Price: Printed Copy S5.45; Microtir!. \$ 2.25

This report wus prepared as ar accoun! of wcik sponsored by t've Unifed States Government. Neither the United States nor the Energy Research and Development Administation. no: any of their employees. nor any ef their contractors. subconirsctors. Or ingir emoloyees. makes any warranily. expresi or impliect. of assumes any legal liability or responsibility for the accuracy. completeness or usefuliness of any intormatiun, dpparatus, product or prccess tisciosed, or renresents indi is use wouid not infringe privately owned rights. 


$$
\begin{aligned}
& \text { 드-ー9:9 }
\end{aligned}
$$

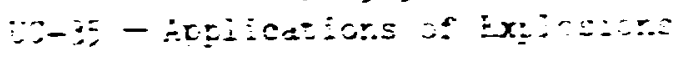

Cortract No. $w-7405-2 n g-26$

HEALTH PHYSICS DTVISION Dmergency Technology Section

EFFECTS OF IUCLEAR ELECTROMAGNETIC PULSE (EXP) ON SYNCHRONOUS STAEILITY OF THE ELECTRIC POWER SYSTEM

R. W. Manweiler

NOVEMBER 1975

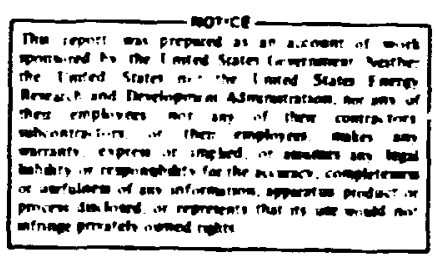

OAK RIDGE NATYONAL LABORATURY

Oak Ridge, Tennessee

operated by

UNION CARBIDE CORPORATION

for the

U.S. ENERGY RESEARCH AND DEV ELORMENT ADMINISTRATION 
CONTFits

Page

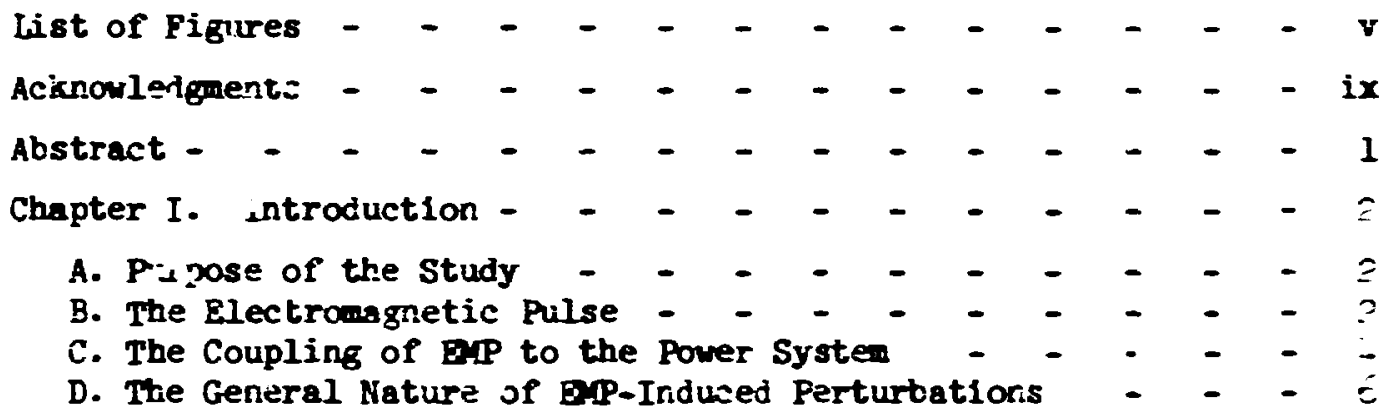

Chapter II. The Stability Problea for the

Sync'ironous Power System - - - - - - - 13

A. Genera] Characteristics of Loss of Stability - - - - 13

1. Historicai Examples - - - - - - - - - - 13

2. Difierences Between EPP and "Natural" Perturtations - - 1-

B. Basic Puysics and ratheatics of the Statility Problen - - lE

1. Basic Equations - - - - - - - - - - - 15

2. Metho of Solution - - - - - - - - - - ?

3. Swing Curves - An Illustrative Bxample - - - - - 2.

Chapter III. Modeling of EMP-Induced Perturbations - - - - $=$

A. The Descripticn of the Multiple-Falit Mojel - - - - $=2$

3. The Modeling of Other Pertirbatiors - - - - - - ?3

Chapter IV. Results of Jumerical Staility Calculationa - - - 35

A. Introduction - - - - - - - - - - - - 3

3. The Respcise fror a Single Set of Multiple Faults - - - 30

1. Faults Applied to the TVA Area Or.ly - - - - - - 39

2. The effect of Increasing the Size of the Perturbed Area - - - - - - - - -

3. Faults Applied to a More Bxtensive Area - - - - - 50

$\therefore$. Dependance of the Response on the

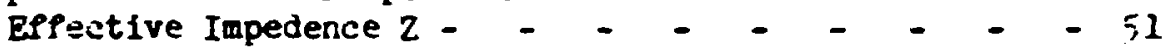

5. Dependence of the Response on the Time Duration of the Faults - - - - - - - 55

C. The Response from Repetitive Sets of Multiple Pulses - - 55

1. A Double Pulse Applied to tine TVA Area - - - - - 5

2. A Double Pulse Applied to a More Bxtensive Area - _ - 5 ;

3. The Bffect of Opening the Tie-tines Before Application of the Perturbation - - - - - 63

$\therefore$ The Dependence of the Response on the Effective Impedence - - - - - - - - - C

5. The Ef fect of Major Load Reduction - - - - - - T

5. Bffect of Changiri, the Fault Density - - . - - 76

7. The Chang? in Average System Freçuency - - . - - 79

D. A Sumbary and Compa-1sen of EMP-Induced and Non-ER-Intured Perturbations - _ _ _ _ - 2,1 
BLANK PAGE

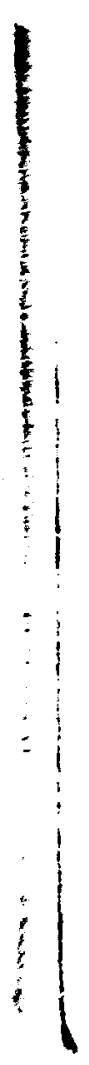




\section{Correns (Cost'd)}

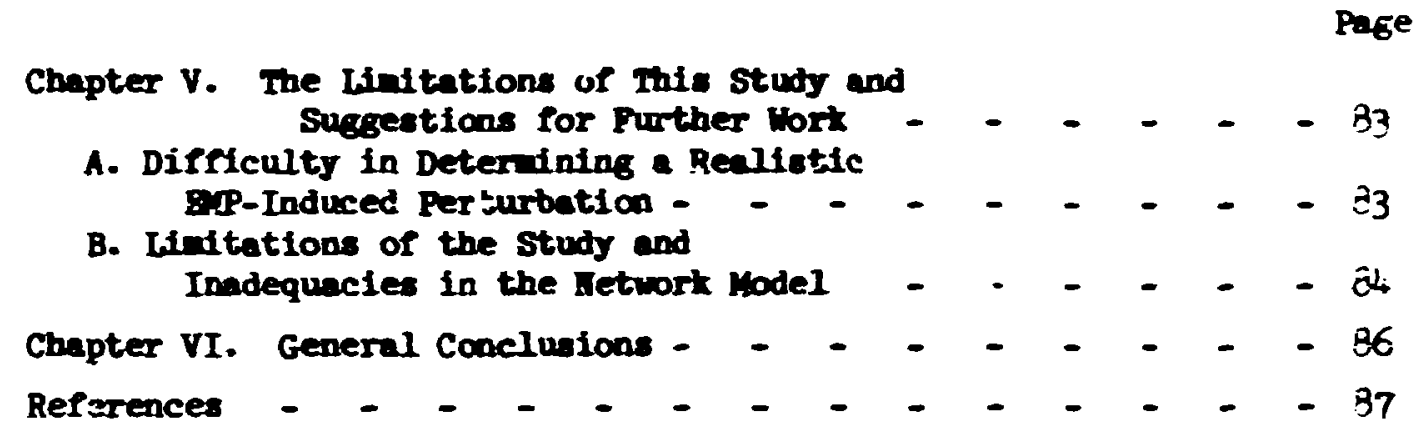


LISE OF FIGIRES

Paze

1. Tre jererative techanis of the Electromgretic Plise

Prodiced by a iigh-Altitude Fuciear Detontios........ ?

$\therefore$ Jpical Area Coverage of $3 P$ for bott: a 100-Tiloseter

Mr.I a iOC-Kilometer ileight of Burst (HOB; .........

j. 드 Iypicel distributior. Syster ............... -

-. The Ferressee Valley iutiority (IVf; Pourer Janseissioc

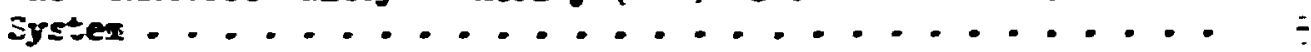

シ. Te Intercorirected ietwori Porer Flon Imediately Before

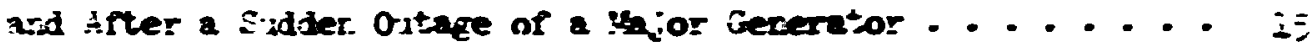

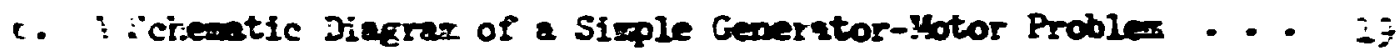

7. Pe as a Fusctios of \& for a Gererntor Jrifirg a yotor . . . 2i

P. S Echematic Diacrar of a Tro-jererator Problem . . . . . ij

9. Ifplcal Sure Cirves for the Torienerator Problez...... $\mathbf{2}^{-}$

20. A :ietwork Diagram Illustratire the Intercorrection of the Irarsud ssion Syster. ard the Distributior. Systew .... I I

11. The rodel ised to Simulate the Perturbation of the Trarsmissior. Syster. from sultiple Sa:ults Occurring or. the Distributfor. Syster. . . . . . . . . . . 3E

12. Switz Cirves for a Sirgle Occurrence of Fault Set $\bar{F}$ of Table 1 for Machire Groxp ío. 1 of Table 2 ........ -

12. Swing Curve for a single Occurrence of Failt Set $\overline{\bar{F}}$ for Machire Grosp ito. 2 . . . . . . . . . . . -2

ib. Swine Curves for a single Occurrence of Fault set $\bar{F}$ for Machine Group lio. 3 .................. ;

15. Swing Curves for a Sinwle Occurrerice of Fault Set $\bar{F}$ for Machire Group No. 4 . . . . . . . . . . . . . . i.

16. Several Groups of ietworks 15 the Vicirity of the JVA Network ....................... .-

27. Suris Curves for a Single Dccurrence of Fault Set F' of Table 1 for Machine Group No. I of Table 2 


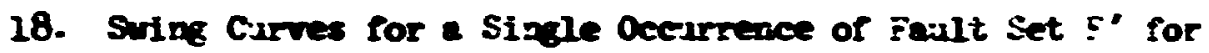
ractive Group 5o.?

19. Suring Curve for a Single Decurrence of Fault Set I” for Inchize Gnvep Jo. 1 ................. $=2$

20. Suing Curves foc a Single vecurrence of Fault Set $\tilde{5}$ for

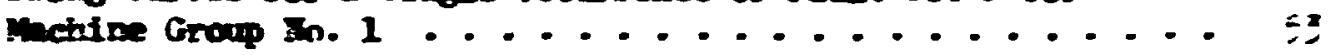

21. Surng Curves for a Single Decarrence of Fault set $\Xi$ for Machine Group $\mathbf{B D}_{0 .} 2 \ldots \ldots \ldots \ldots$

22. Surge Curves for a single decurrence of Fault set $\equiv$ ior

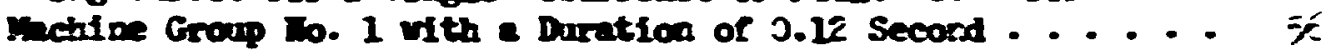

23. Sulf Cirres for 70 occurrences of Fault Set $\equiv$ ior Menine Group to. 1 ................ 59

24. Surfe Curves for two occurrences of Fault set $\equiv$ for sachine Grop 10. $2 \ldots \ldots . . \ldots \ldots$

25. Surirg Curves for $3 w 0$ Ocentrences of sault jet $\bar{E}$ for lacitise

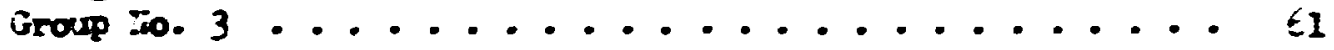

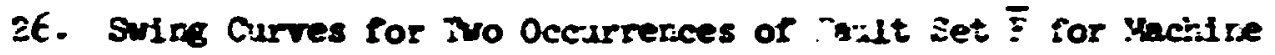

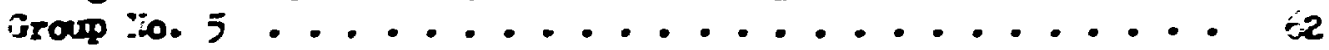

27. Swits Cirves for 2 occurrences of Pault Set I' for Vacinine Group Jo. 1 ................ 6.

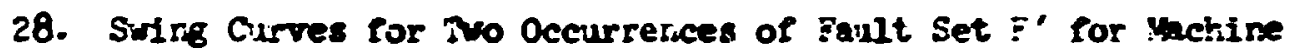

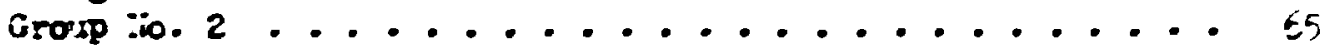

29. Swing Curves for Two Occurrences of Fault Set F' for Yachire

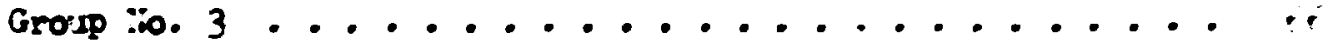

30. Suln Curves for two Occurrences of Fault set $\Xi^{\prime}$ for Machine Group iio. 5 ...................

31. Swing Curves for Two Occurrences of Fault Set $\bar{F}$ with ihajor IV: Tie Ines Initially open for Mchine Group No. $1 \ldots \ldots$

32. Swing Curves for Two Occurrences of Fault Set $\bar{F}$ with Major TVA Tie lines Open for Machine Group No. $3 \ldots \ldots$

33. Swing Curves for Two Occurrences of Fault set $\tilde{F}$ for Machine Group lio. 1 . . . . . . . . . . . . . . 71

34. Swing Curves for Two Occurrerces of Pault Set $\tilde{F}$ for Machine Group 1.o. 2 .................... 


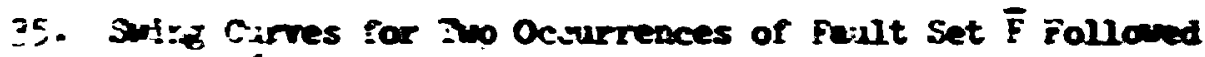
by a 301 Ieduction in iond, for suchice irow bo. 1 .... -

36. Suring Curves for Two Oceurrences of Dault set $\bar{F}$ Followed

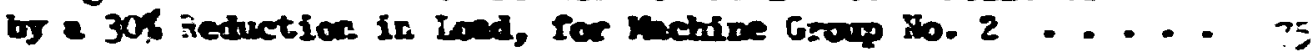

37. Surge Curves for 300 Decarrences of a Pult set of Soller Dersity, Followed by a 30 s letuetioc in Lad, for thehine iroup sio. 1

38. Sulp Curves for To Decurraces of a Penlt set of Smiler Dersity, Followed bs a 30,3 Beduction in iond, for menive

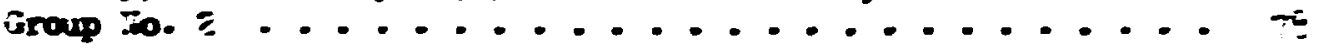




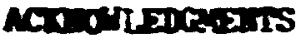

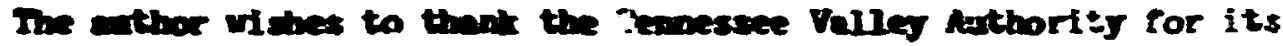

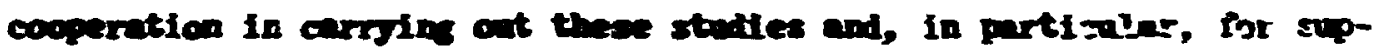

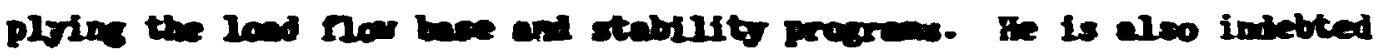

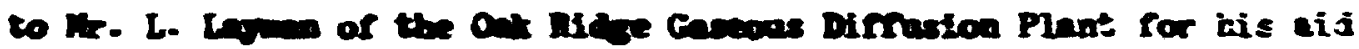

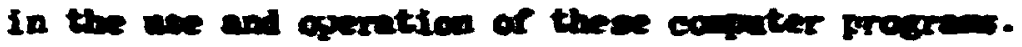




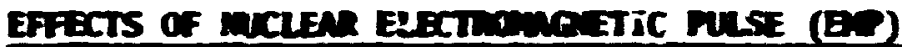

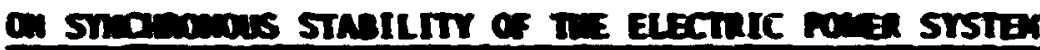

ล. ¿. Baneilex

ABSTMEI

Tie efrects of a melear electrongretic palse 'DP; of the symehrorous stability of the electric pourer transissis and distributioc gstees are evaluated. The various sodes of coupling of EP to the power aster are briefis ilscussed, Ith particular expiesis on thome pertarbations enfecti=e the Jreturorous stablifty of the trareidssios systea. A brief revier of the rudingestal concepts of the stabilits proble: Is giver, Mth a liserssioc of the general characteristics of trarsiezt aralisis. A roiel is developed to represert sifele sets as vell as repetitive sets of antiple raits on the distributio: systens, as =ight be produced io D.P. The resilts of =ar ruserical stability calculatious are fieser:ted to 1ilnstrate the trarised ssion syter's respouse froe differect tspes of pertarbations. Ite important paraseters of bott. altiple and repetitive raults are stodied, irclodice the dependence of the response or the size of the perturbed area, the fault density, and the effective impedance betareer. the ranlt location and the transadsolos syster. Both ajor loed reduction and the effect of the opening of tie lines at the tize of perturbatioc are also studied. ie conclinde that there is a hlgh probability that EP cas induce pertarbations on the distributioc networks culsing a large portion of tise transuission netrork in the perturbed area to lose aschronis. The reaslt would be as imediate and masive power fadlure. 
GHAPIER I

IIIRODUCTIOI

A. FURPOSE OF THE STUDY

A high-altitude ruclear detontion causes currents to flow in the atrosphers. This current generetes an electromenetic pulse (DP) which. propagates to the earth's surface where it induces current and voltage surges on conductors. The purpose of this study is to determine the extent to which such BP-produced surges will disturb the smehronous stability of the electric power arstem through the procuction of multiple and repetitive fouls.

\section{B. THE ELECTROMATETTC PUTSE}

The nuclear BaP field is generated by the action of the primary gamma rays proauced by a high-2ltitude nuclear detonation. The I roductiun meshanisu is 1llustrated in Fig. 1. For a high-altitude burst (approximately $50 \mathrm{~km}$ or more height of burst) tine gamma rays produced will interact with the atmosphere between 20 and $40 \mathrm{~km}$ a.titude, priwarily by compton scattering with electrons of air mole.ules. This scattering cusses the electrons to move dowmars array from the point of bursi in a trajectory which is bent by the earth's geomagnetic field $\mathrm{E}_{\mathrm{g}}$ (shown ixto the page in Fig. 1). These accelcrated electrons radiate the electromagnetic pulse fron the atmospheric umbrella between 20 and $40 \mathrm{~km}$ which is within line of sight of the murst. The primary compton electrons, composing the "primary electron currents" - lso scatter snd produce secondary electrons wich are accelerated in the opposite direction by an electric field prousced by the charge seraration. This secondary electron current flows in roughly the ipposite ilrection as the primary electron cur:erit.

The EMP ffeld can be ealculated from Maxvell's equations using both the primery Compton and the secondary electron currents as tha source 


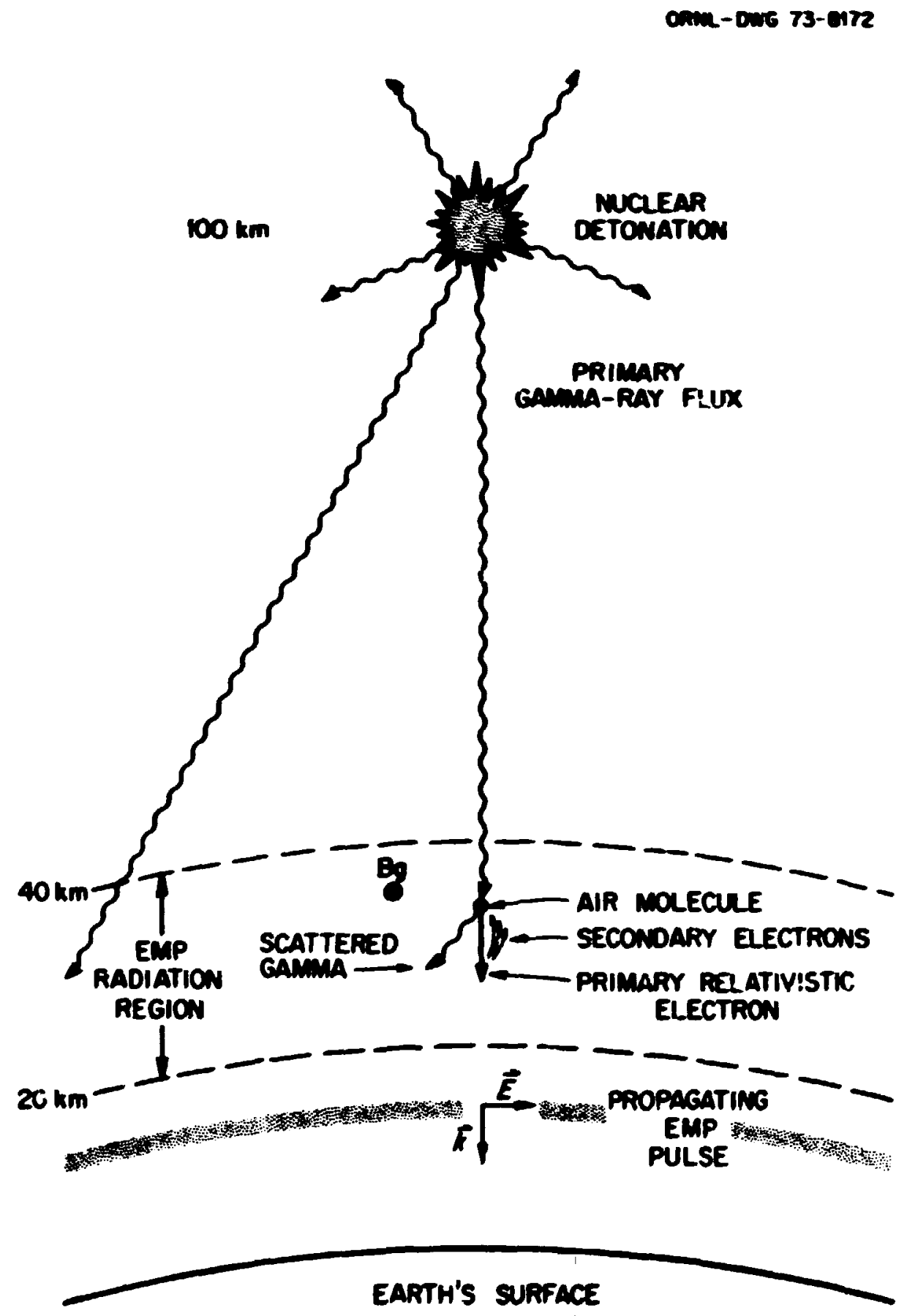

Pig. 1. The Generating Mechanta of the Blectrongnetic Pulce Prodiced by a High-Altitude Nuclear Detonation. 
curzents. This generating mechanisa has been described in detail some tive 480 by Karzas and intter, ${ }^{1}$ and others. A typical BiP oulse from - Iarge Jield detantion ay hare an electric field strength of 50 kilorolts/meter witb a risetime (time to peak vilue) of 10 nanoseconds, and a time to belf the peat value of 30 to 200 nunosecords. Thus, such a pulse has a very inrge fleld trength and produces electrical transients with rapid risetive as compared to those typically occurring on porer grotens, e.8., Iightning.

One distinetive fenture of EMP is its extrenely large geographical extent. For a high-altitude burst, the entire ataospheric umbrella defined above radiates so that the BP field belor this atmospheric umbrella does cot decrease in intensity as $\mathrm{r}^{-1}$ from the burst location. as in the case of Nelds radiated from a small volume. The BaP field occurs everymbere witinin line of sight of the burst, as Fig. 2 illustrates. Clearly BMP differs grently from other perturbations of the power system in its large geographic extent, which has important effects on the systen's stability, as will later be shown.

c. THE COIPLING OF EMP TO THE PONER SYSTEM

The coipling of DMP to the electric power system has been previoisly discissed by Nalson ${ }^{2}$ and in more detall hy Marible, et ․‥ ${ }^{3}$ The EMP field induces currents on exposed conductors. High voltage surges can be produced, particularly at points where lines change direction or branch and at lacations where the impedance is discontinuous. Current and voltage surges of several kiloamps and of nearly a megavolt, respectively, can be produced on unshielded parts of the system, and only a fer hundred meters of length of conductor are necessary for the induction of a significant pules. Distribution, transmission, control, and comminication lines are particularly good examples of conductors which will be affected, and all of the system in the exposed area will be simultaneously affectei. (Âctually the EMP mave front will travel at the speed of light s. But the important time scale for the power system is the 


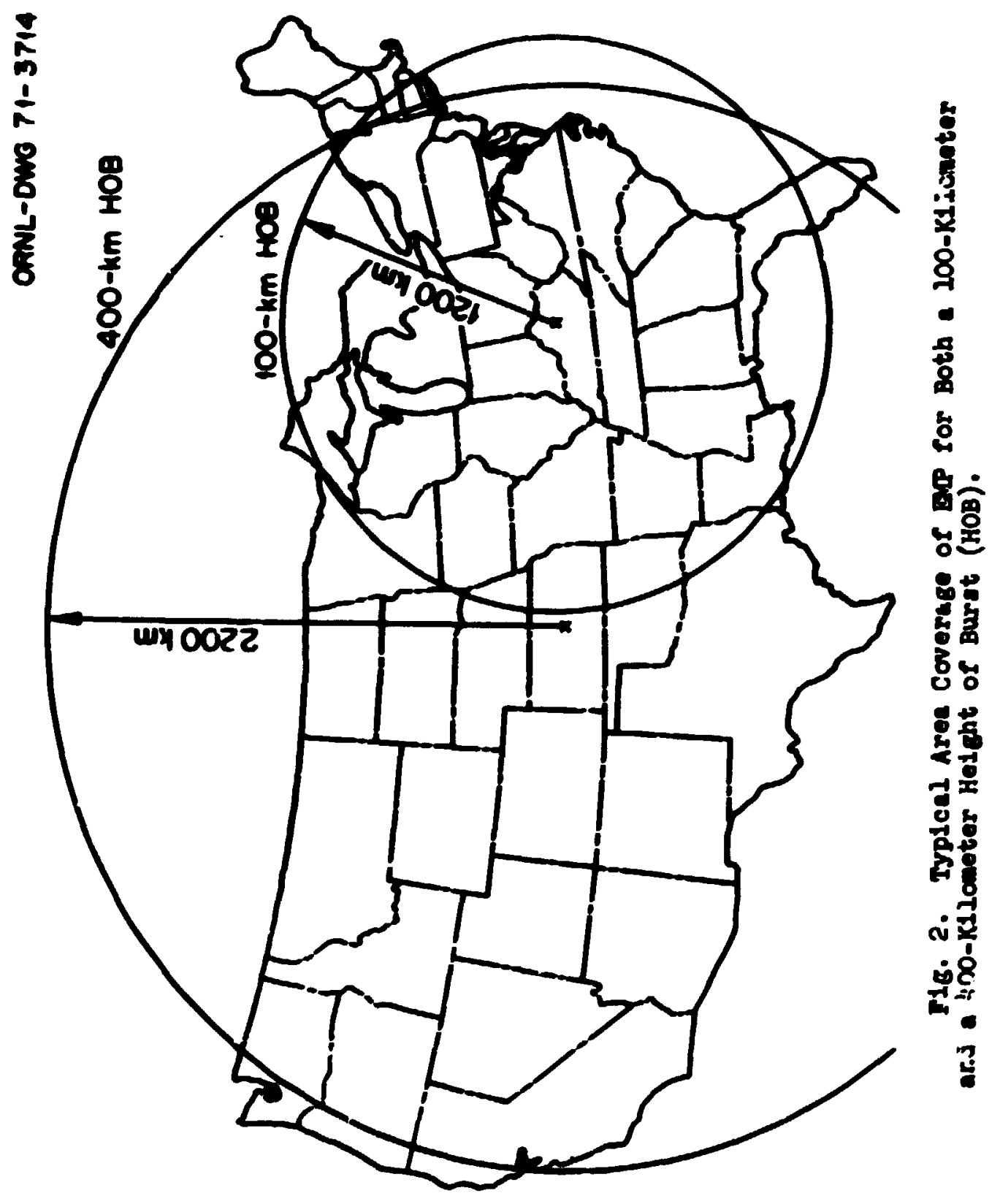


period of the synchronous system, i.e., one-sixtieth second. Thus, the tile difference between arrival of the BP pulse at different locations is of no significant consequence.)

Figure 3 shows a typical distribution system and P16. 4 show a transussion systea (the Termessee Valley Autbority Network) which supplies the connecting distributioc system at wor substations. It is difficult to determine the precise effects of DAP surges on such conlicated systens, but previous work ${ }^{2,3}$ does provide us with rensonable expectations. In the next section ve brieny discuss the effects of Ex which may perturb the power system sufficientiy so that synchronisa will be lost. A more detafled amirsis of the coupling mechanisms is avaliable in Refs. 2 and 3.

\section{THE GEERAL MATURE OF EAP-IIDUCED PERTUREATIONS}

This study is primarily concerned with the effects of BP on the transmission system, rather than on an single distribution syster. However, the dymanical and electrical response of the transmisision systew cannot be separated from that of the distriburtion systems. DRP ray perturb either system in auch a manner as to cause part, or all, of the transmission gretem to lose symchroniss. Fe use the term perturbation in the sense that a synchronous system at equilibrium is being inftielly "disturbed" by some event of finste or contimous duration which wy then affect the suchronisu of the system. Loss of synchronism entalls one or more machines (generstors) falling out of step with its connectine machines, necessitating the rewoval of the machine, or machines, from the electrical system. This study is concerned with determining the likelihood of major machine losses resulting in the transmassion systen's partitioning or complete collapse.

Por correntence of andyais, we partition the groten's reoponse to a perturbation into two tipe intervale the transient and the dynaic response. The first interval (the transient responce) includes up to about the first one and one-half to two seconds and is the result of the 


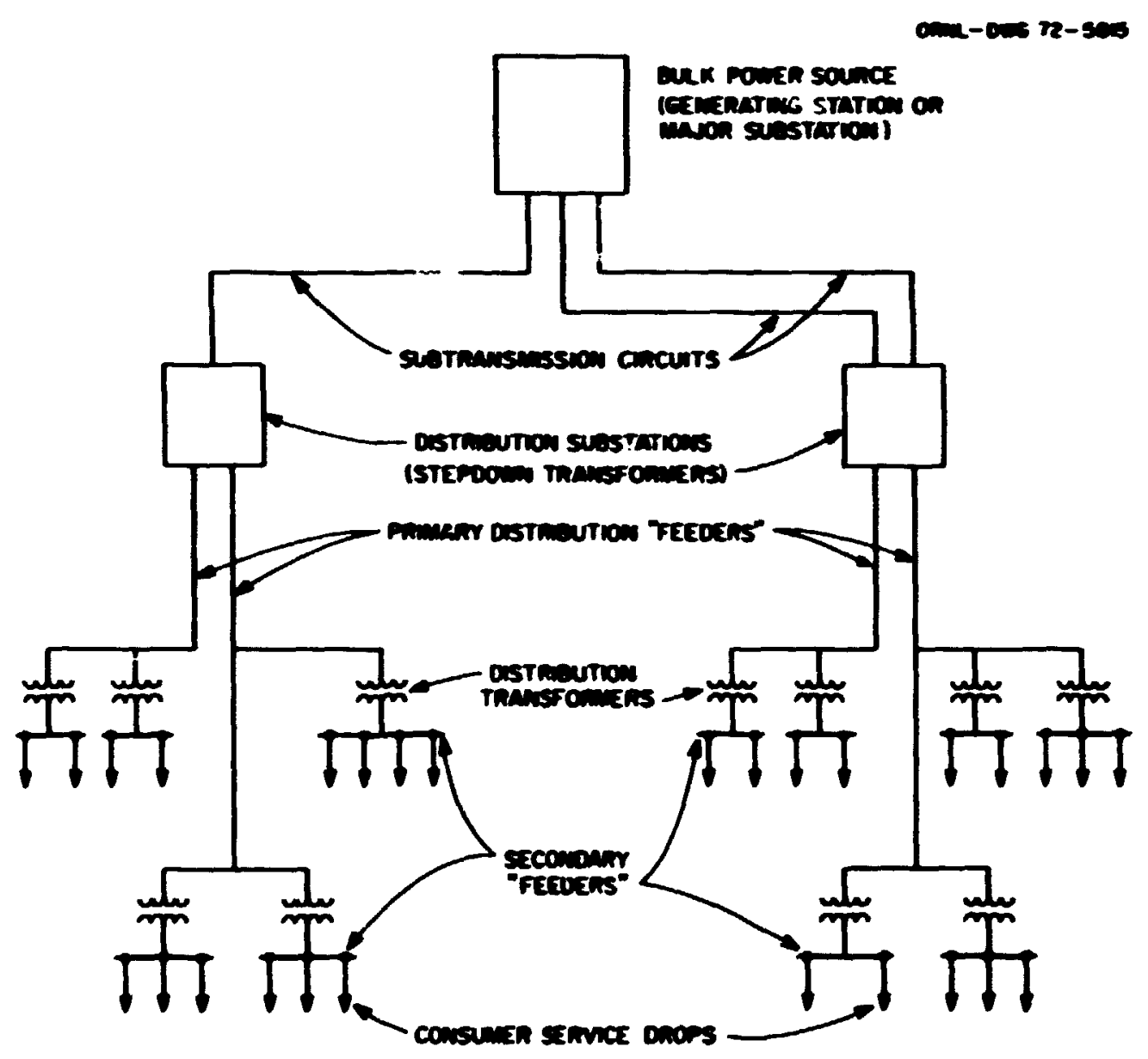

P18. 3. A Typical Diatribution 8juter. 


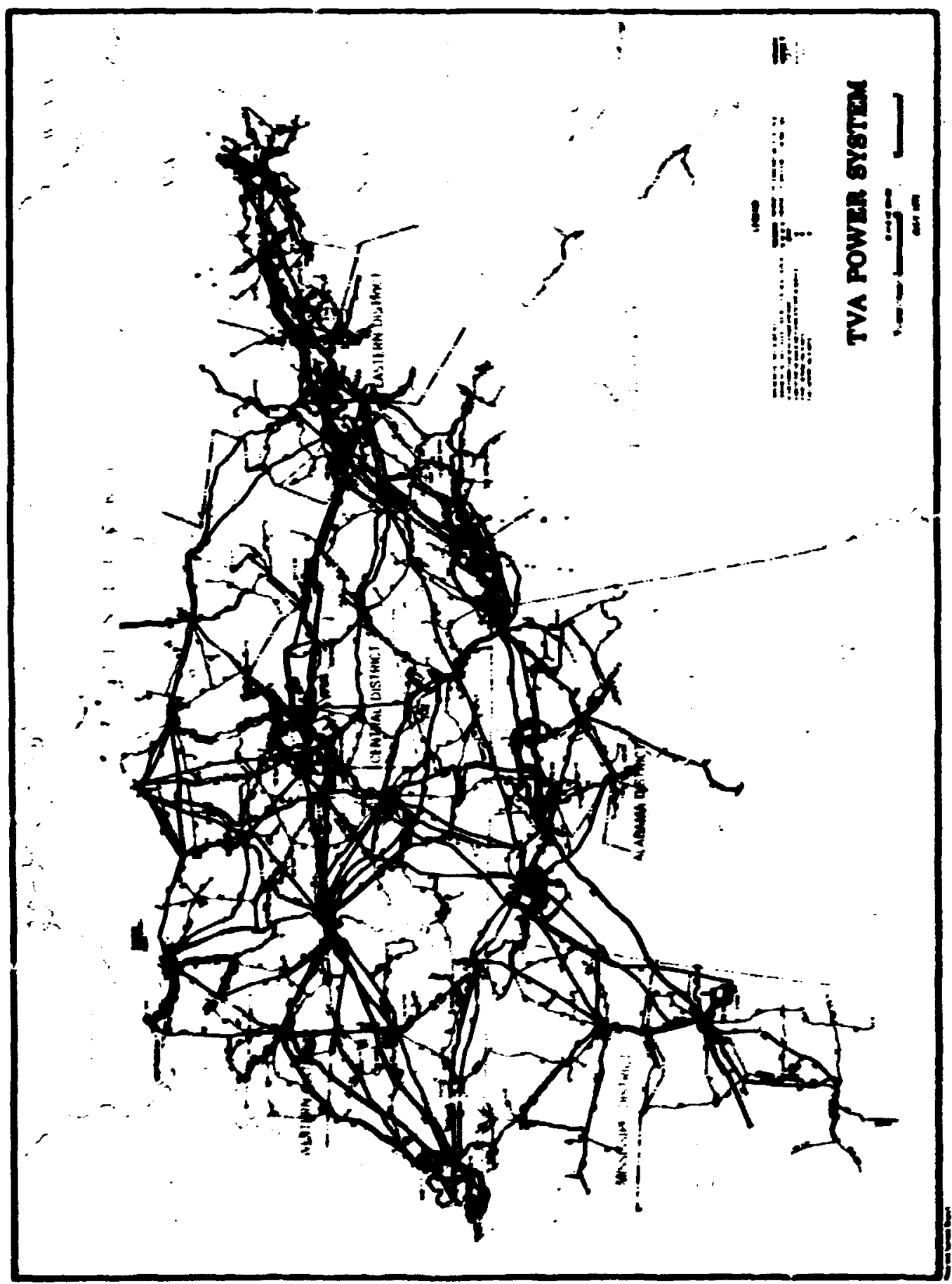

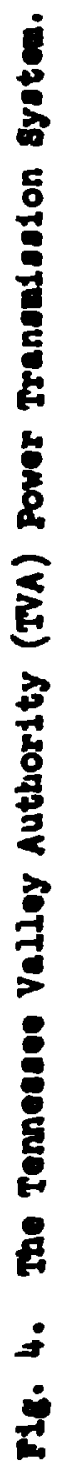


inmediate effects of the perturbation. The secosd interval (the dramic response) starts at aboit 2 seconds and extends to the tiwe when the systen bas reached a new equilibrius, i.e., it is the repponse deteratned by the inter-tine collective effects as vell as by addfional perturbetions triggered arter the firsi second or two following the inftial pertiubation. In the rewainder of this subsection we discuss the nafor types of perturbatiors one nay expect from BP.

Be-induced faults (short circusts betaren lines of frow line to ground) pose a very serious perturbetion for the entire electrical asetem. Beceuse of the transalesion lines' greater insulation, it is ach less lilielis that EMP will cause rwults on these higher voltage ifres. But the tspical distribution astem is probablo insufficientlo inaulated againat Es-induced surges, particularis at discontimities in geosetry, etc., as proviously wentioned (section C). It chould be expected that induced elecirical surges will infinte faults on the distribution lines, in which case the ine roltage mas mintain the faults until the line is opened (disconnected from the electrical grsten) ana cleared in the norwai manner. Such distribution syatem foults would pose no serious threat to the transmigsion system were it not for the fuct that man distribution system faults an be induced simultaneously over a vory large aree (for exanple, see PIg. 2). The chulative enfects of the cultiple foult perturbation on the jintribution ayoten will probably neve a elgaificant effect on the tranalisaion ayotem.

A second important type of EaP-produced perturbation is the poss:bility of repetitive MPP pulses produced from multiple detonations closely spaced in tiwe. It is not the purpose of this paper to discuss possible nuclear scenarios. However, both ofogle and multiple high-altitude detonstions should be considared. Multiple bursta hove two isportant efrecte. Firatly, there will is a sumalitive effect of ropetitive ecte of sulte,

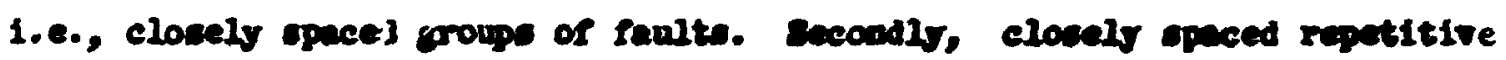
surges ma lock open way relare until thy are manally react. sloce

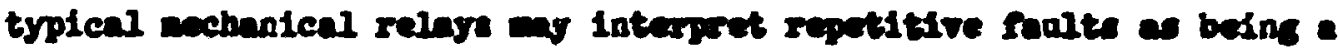
"perwanent fault," three or wore burete elonely goed could loak open wany

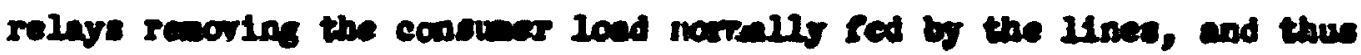


reduce the transidestion network's load. A substantial load reduction could cause the systen to accelerate so rapidy that generation could not be reduced aurficientlo before loss of anchronisa, or before tripping of overspeed relays on generators. The effects of repetitive faults wh th or without subetantial load remetion will be discused in Chapter IV.

A third type of BP-inhuced perturbation wa be the walnuction of inourfiedeutly protseted trandisaton line relass causing either the undecesery opening of lines, or the dectruction of relas circuits. Solid state relage comonly used in very high voltage trangis adou lines wo particularly cenative to Bip-produced transients. However, electromechatical relars typicalls used on distribution arstem and lover voltage tranadiation lines should not he ceriously vulnerable to this type of minunctiot. In this study, we bave asowned thet the tranadission arton circuitry ill not be affected bs the traneients. Otherwise, there is little hope of the groten remining in operation. The poselible munctioning or dange of solid state reluse should be carenilly cominat.

A fourth type of perturbation which an occur is enerrator tripping.

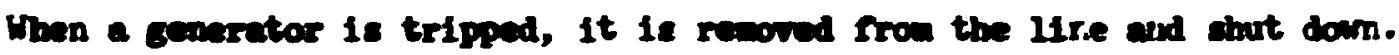
Ore mut distioguleh between two batic categories of genereior tripping. Pirct, generators be ralesly tripped at the tiwe of the burst by electionl eurges induced in the generetor control proten. If a dzable portion of the generation expecity is fulcily tripped, the entire sostem could collepes. Howerer, 19, this stud in have got tripped generators to

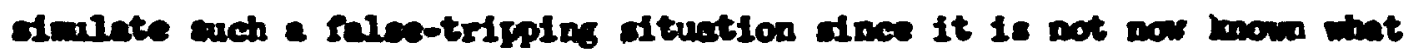

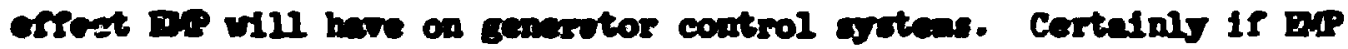
eances corlows problew of this nature, the efrect on the stablity wil

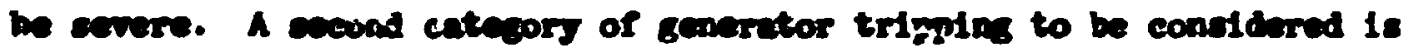

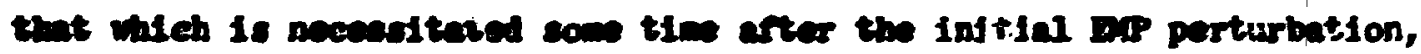

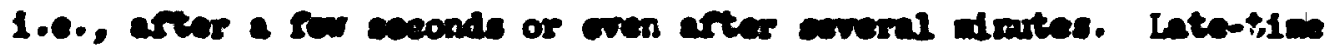

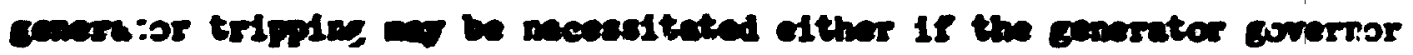

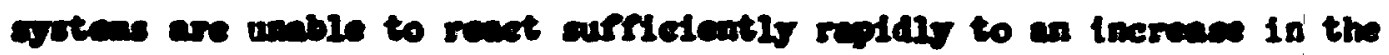

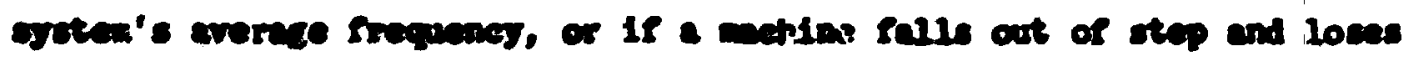

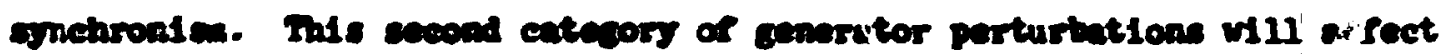


the inter tiwe dynamic response rather than the earlier tixe transiex.t response of the system. He discuss the dymanic response furtiver at the end of this subsection.

An added difficulty in estimating the effects of generator tripging is the possibility of terminating too wuch generation in response to a legitimate need for a reduction. Such a situntion could arise since norwal generator regulation and control procedures un not respond properly to DAP-type perturbations in wich the disturbed aree is very large and is simultaneously affected. Operation and control procechres way need to be reviewed to deterwine whether they respond properly to DAP disturbances.

The various transmission networks are connected by tie lines, where the power flow between networks is controlled. A firth type of perturbation would be direct interference with the tie line wonftoring or control syst.en. The norwal power now between wetworks could be interrupted if tie line control systems were sffected by transient pulses, and the likeltbood of such fallure increases for computerized systens. Additionelly, response of real-tine tie line control av be quite crucial, since significant interactions betiven adjecent transalsolon networks showld be expected, particularis if one network is subjected to the perturbation wore severels than neighborins ones. In sane circum stences it and be desirable to open tie lines, a possibility which will be further discussed in Chapter $\mathrm{I}$.

$A$ sixth perturbation wich sileht realt from DAP would be dange to or interference with computerized load now centers and digpteb otations. Typical computer-controlled pover spotens are deceribed by Rose and

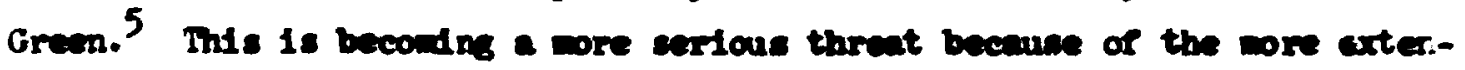
sive use of conputers which, unless sheldad, are particularly vulneroble

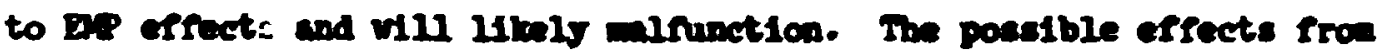
auch perturbations are sidlar to tie line control probleas.

As a consequence of collective efrecte of the varlous DP-intuced perturbation discused above, thare w11 certafily be late-tise dromic effects on the groteins. However, one eannot proefsely deternine what

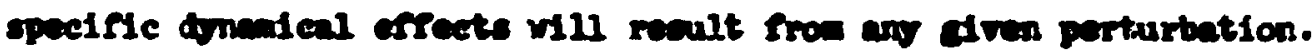


This study was therefore limited to the early-tiwe transient 1 isponse of the systex. But we piesently nention several possible dmand cal effects which DAP could produce, for ore wust keep such possibilities In mind when assessing the total effect of DAP on the power system. If there is a major load loss, an increase in the system's average frequency in the drnanical time period aght occur, which could tax generator control aystems to an extrene. Nnother possible dnamical effect is transdission line overloading realting in the opening of transwission lines and causing cascading fallures sindinr to the Rortheart power falluse of 1365. The power aurges in the transient period were wontored to detect overloading conditions. In this study we assume that trangedssion systems will reanin in operation except for special cases of tie line openings. Certainly loss of major transudssion lines will only magnify the perturbation. Consequently, it should also be expected that major blast damage to the trensidesion astem would have a disastrous effect. Horever, mach of the tranadiasion astem and the generation capacity is outside probable turget areas and therefore not no greatly affected by blast, particularly in a lidited melear engagement. Again, ope cannot at presert eadis calculate the dundical response of the astem, particularly to ach coplicated perturbations as will likely be induced bs BaP. 
Ir. this chapter the general characteristics of stability are described, and two historical examples of perturbel transmission syster:s are presented in Section A. The stebility equations are given and discussed in Section B.

\section{A. GEIERAL CHARACTERISTTCS OF LOSS OF STABILFY}

1. Sistorical Examples

Perhaps the inst nctable historical example of loss o: stability of the transmission network is the lortheast Power Faidure of 1965. Extersive studies $t$ of tiat blacicout of nearly all of the :orthenster. states have beel. zade. Since 1965, the transmission ard gerieratior. systems have beer considerably inproved, yet the failure is a good illustration of cascading faflu es, 1.e., fallures in whsch one ever: triggers a succession of ereuts eventually leadine to the collapse of all or part of the power systen. The sequence of ererts leading to the collapse o: the rortheast perer system was svidently iratiated oj a beckup relay cpenits one of five 230-kilovolt circuits betweer. ti.e Eecis iererating station and Poronto-sanilton, both ir Carada. Inis ever.t resulted ir. nore thar two dozer. artches tripping within the sext five seconds, and producing enornous porer aurges. Generators in wester. iin York and at the Beck Station accelernted until sychrori:-.. wa: lost, recessitating their separation row the reminder of the syste-.. After about 7 seconds from the opening of the first clrcuft, tise trassmission network had oplit into several separate areaz. The frequercy of parts of the system was very 10N, subnomal by as wuch is 106 for raw an nutes. Iven 1solated parts of the gystew which had reasorsably bala:ce: load and zeneration collapeed because of the inftial effects of the 
perturbation. Shing curves of various generators (see Section B of this Chapter for an explanation) are presented in Volume III of Reference 6 . It should be roted that this particular perturbation occurred on the transwission system, not on the distribution system, and trerefore differs from the expected EM-generated perturbations. The collective effect of the series of events resulted in the nearly complete collapse of a major segment of the transmission network.

We wish to consider a second example, wuch less spectacular than the liortheast power failure. In this second case, the pover system did not collapse, primarily because of a strong transmission system. On Jaruary 19, 1964, sudden outage occurred on the TVA Paradise Steur: Plant when generation of 1250 megawatts was abruptly lost. Imediately after the event, the adjacent tie lines supplied the TVA network with additional power. The tie line power flow before and after the loss of generation is shown in Fig. 5. A strong transudssion system provided the generation-deficient TVA network ( "sink" of power after the event) with porer from the adjacent networks (a large "source" of powse), thus preventing loss of synchronism. The system in this case vas stable to this perticular perturbation.

Jumerous porer faflures have occurred since 1965 and conisirue to occur frequently, usually on a state-wide besis. Most, if not all, have been casceuling type of failures initiated by a single event usually associated with the transmission system. The type of initiating events range from stores to mechenical fallure of equipuent.

\section{Differences Between EMP and Miatural" Perturbetions}

EMP-induced perturbations vill differ substartially from "natian" perturbations, such as those mentioned briefly above. As expleined in Chapter I, EAP will most likely induce multiple reults on the distribution systers--not on the transwission systean, and the area coveret by faults cen be extensive. Repetitive sets of faults vould possibly occir for multiple nuclear detonations. PAP effects wa cause the transmission. system's average frequency to increase substentially. Local 


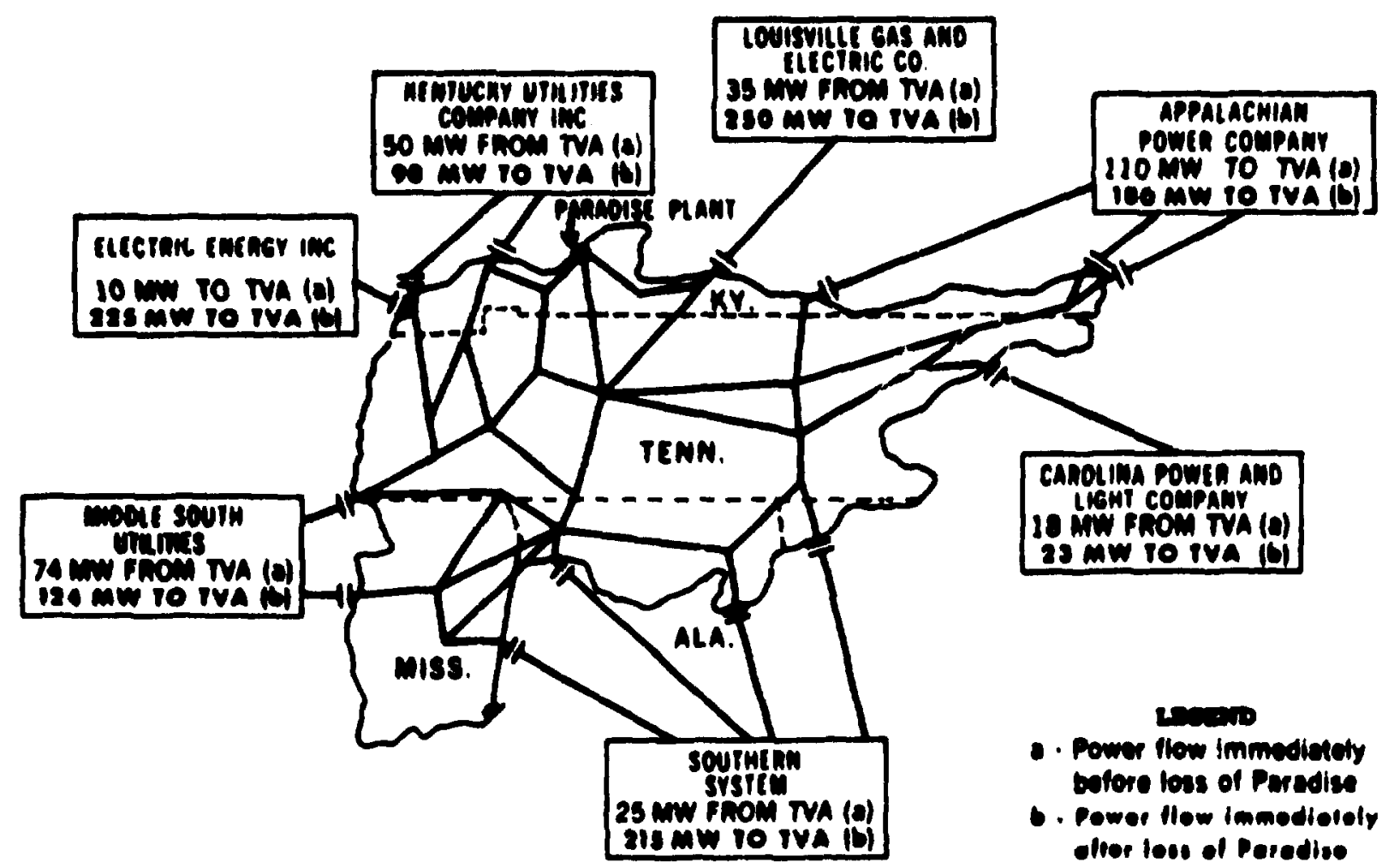

Fig. 5. The Interconnected Netwark Power Flow Imediately Bufore and After a sudden Outage of a Major denerator. 
increases in frequercy do occur at times from "natural" perturbations, but not on the same scale as MP. Additionally, EMP may perturb the transmission s.ystem in many different ways than natural perturbations. The experience which power companies have gained in determinirg tie system response irom natural perturbations may therefore not be directly applicable in determining the response in an EAP environment. Ke further compare the tro historical examples given with the calculated ENP response in Chapter IV, Section $D$.

\section{B. BASIC PHYSICS AND MATHEMATTICS OF THE STABILITY PROBLER?}

The purpose $0_{i}^{*} t_{i=j}=$ section is to introduce the reader to the general pissical and mathematical concepts important in determining the response of the transmission systen to a perturbation such as EMP. It should not be considered as a rigorous treatment. A reader interested in a more rigorous development of the stability problem should refer to standard tex.. $7,8,9$ Reference 7 gives a particularly good physical explanation. The modeling of the transmissicn system and the numerical method for solving the stability equations will be presented in Chapter iII.

\section{Basic Equations}

The transmission system consists basically of: (a) generating devices, or machines; (b) the electrical circuitry which transmits the generated power to the various major substations of the distribution systems (which we refer to as the network in this chapter); and (c) the various contrul and monftoring equipment, with which we are not presertly concerned.

Electrical transients on the network propagate at slightly less than the speed of light. However, the important time scale relevant to the synchronous behavior is in lact not determined by the time of travel of electrical pulses. Rather, there are two important response tines 
(or frequencies) deterwining the system's transient response. One car: relate the respurise time $T$ to a corresponding frequency $f$ by the definitj in

$$
\mathbf{f}=\frac{1}{\mathrm{~T}}
$$

The equilibrium synchronous frequency $f_{0}$ or its inverse perict $T_{n}$ (60 hertz and 16.7 milliseconds respectively in the iJ.S.A.) sets ar. important tire scale. Frequency deviations from the equilibrium syr:chronous frequency :0 which we designate as $\Delta f$ become importent at a time st when ( $A: \Delta t$ ) becomes a significant fraction of a complete cycle. Most of the mechanical relays on both the transmission and distribution neworks operate on this time siale, from one to twenty $\mathrm{s}_{0}$ (approximately 15 to $\$ 50 \mathrm{milliseconds).}$

A second important time scale determining the behavior of the system after being perturbed is the machine response time, or machine period, $\mathrm{T}_{\mathrm{m}}$. A single machine can be modeled as a rotating wass with a large moment of inertia $I$. The mass has an applied torque $\Gamma_{a}$ deliverir $\bar{E}_{E}$ power to it (from stean plants, hydroplants, etc.), and has a back electrical torque $\Gamma_{e}$ opposing $\Gamma_{3}$. Then at equilibrium

$$
r_{a}-r_{e}=r_{d}=0 \text {, }
$$

and the mass rotates at frequency $w_{0}$. However, if a perturbation is applied, the electrical torque $r_{e}$ is changed resulting in a net torque on the mass and from Newton's law

$$
\Gamma_{d}=I \frac{d^{2}}{d t^{2}} \quad \theta(t)=I \frac{d^{2}}{d t^{2}} \quad \theta(t),
$$

where we have defined

$$
g(t)=\theta(t)-w_{0} t+\delta_{0} \cdot
$$

The motivation for defining is the following. $\theta$ is fust the absolute electrical phase angle which. in equilibrium, increases as wot. However the power delivered by machiues depends upon their relative angles. Since the mastines normally cotate tagether it is desirable to define a 
coordinate astem rotating at frequency $g_{0} t$. Then $s(t)$ is the angle of aeparture from equilibriun, measured with respect to souse rotating reference, with all initiei angles fiven with respect to one particular machine at $t=0$.

The thematical difficulties arise from the complicated dependence of $r_{e}$ on the machine angles. For $n$ machines, there are $n$ coupied nonlinear equations; for the $i^{\text {th }}$ machine

$$
I_{i} \bar{\delta}_{1}=r_{2, i}-r_{e, i}\left(\delta_{i}, \delta_{j}, \ldots, i_{i}, \dot{s}_{j}, \ldots\right)
$$

where the $\Gamma^{\prime}$ s are the applied and electrical torques presiously defined for the $i^{\text {th }}$ mechine. A dot means the derivative with respect to time. Clearly the electrical torque $\Gamma_{e, 1}$ is a complicated function depending on all of the machine angles and their derivatives. Equation (2.5) can be expressed in terms of the applied and delivered power, $P_{a}$ and $P_{e}$, respectively, by multiplying by 0 and defining the inertia constant $M$,

$$
M=I_{\omega}
$$

The torque multiplied by the angular frequency is just the poiver transserred, and we have

$$
M_{i} \ddot{\delta}_{i}=P_{a, 1}-P_{e, 1}\left(\delta_{i}, \delta_{j}, \ldots, \dot{\delta}_{i}, \dot{\delta}_{j}, \ldots\right)
$$

where the subscripts heve the same meaning as in Eq. (2.5).

To get some feeling for the power $P_{e}$ delivered, consider a simple example of a generetor driving a motor as show in Fig. 6. (Since there is only one motor, we can supprese the subecript i.) Then, for a purely inductive line $x$,

$$
E_{G}=z_{M}+j|X| I
$$

The real power $P$ delivered by the generator is just

$$
P=\operatorname{Re}\left(E_{G}^{*} \cdot I\right)=\left(\frac{\left|E_{G}\right|\left|E_{M}\right|}{|X|}\right) \sin \delta(t),
$$


ORNL-OWG 73-3685R

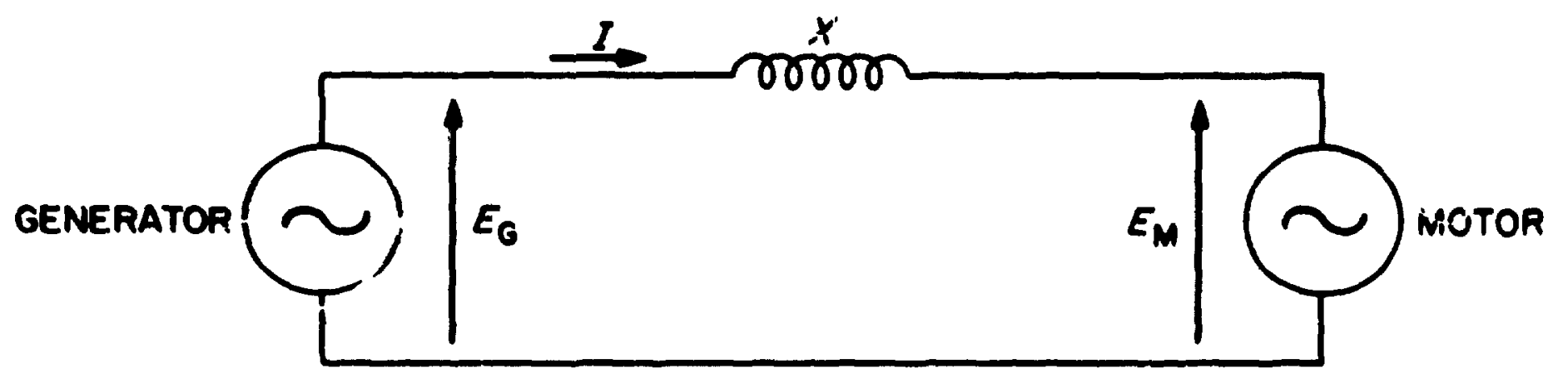

F18. 6. A Bchenatic Diagrea of a 81mple Generator-Notor Problem. 


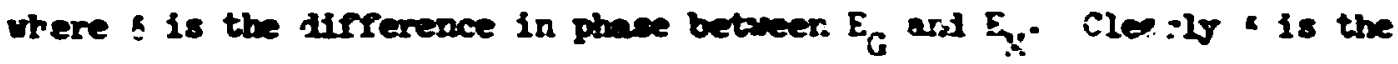
crucial angle since $P$ depends ipon the phese difference between $E_{G}$ and $E_{Y}$. In norml operation, $E_{G}, E_{Y}$, and $X$ are constants so that the power deifived by ine generator is proportiond to sin \&. Equation (2.7) becomes

$$
\because=P_{a}-P_{-} \operatorname{An}
$$

where $P_{E}$ is the maderr power tranefer. It is eary to urderstand wy aq. (2.10) has stable solutions. Figure 7 shours a plot of $P_{e}$ as a functiox of 6 . Aseune the equilibriur ariste is " 0 , ther if the load or. the motor is increased it vill decelerate or slor down with respect to the generator and s will tharefore increace. Correspondingly, the telivered power $P_{e}$ will increase until it exceeds the new load, at rhich time the wotor will begin to accelerate until its rotational freysency approaches that of the generetor agais. Bithort darpirf, $a(t)$ would oscillate about s unleas $P_{g}$ is insufficient to wet the new load. (Astually the case is more complicated than this of ince last charge sign, not just $\ddot{b}$. However, the basic idea is not nodified.) If the increase in load is too great, the motor will stall. At the nodes of $P_{e}(5)$ where $P_{m}$ sin s changes sign (at 0 or $x$ ), the generator no longer delfvers power, but, in fact, acts as a notor. It must be rew red frow the system; it cannot regain synchronisa. A repent of the rivore analysis will show that if the inftial angle vere $\&_{11}$ (Fig- 7), then the notor-generator would not be stable. In prectice in sulti-machine netvorks, a machine is considered to be out of synchronian when s differs by more than 1200 from electrically "close" machines.

We can $r$ return to our orlofinal question noncerning ine resporise time of the system. For simll perturbations, the system will oscillate about of and Eq. (2.10) can be linearlzed. Then, for simlle

$$
\begin{aligned}
\sin \left(s_{0}+e\right) & =\sin \theta_{0} \cos e+\cos b_{0} \sin e \\
& =\sin b_{0}+e \cos \theta_{0}+U\left(e^{2}\right),
\end{aligned}
$$




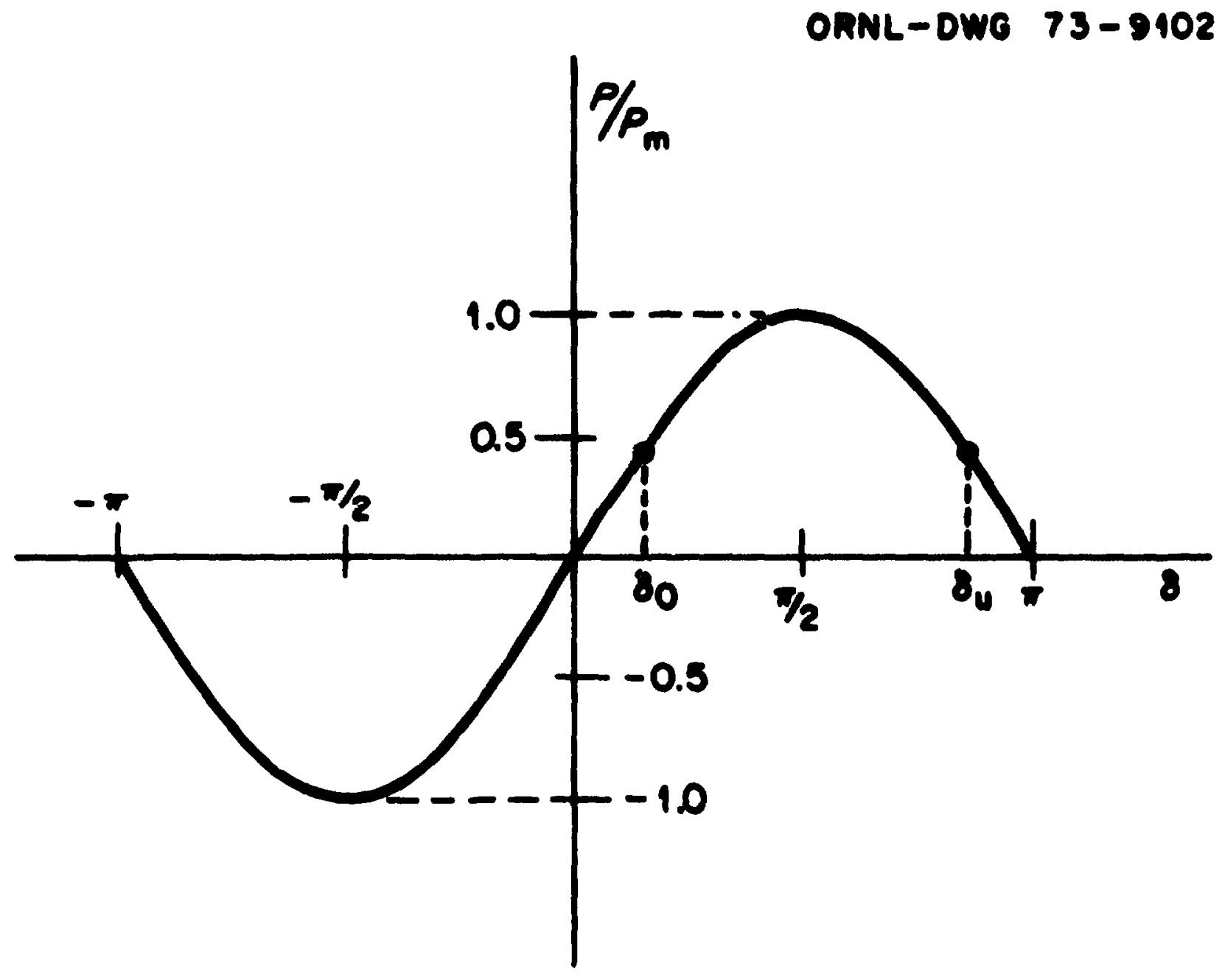

P1g. 7. $P_{e}$ a a Function of a for aenerator Driving a motor. 
where

$$
s=\Sigma_{n}+\vdots
$$

Squatior: (2.10) becoses

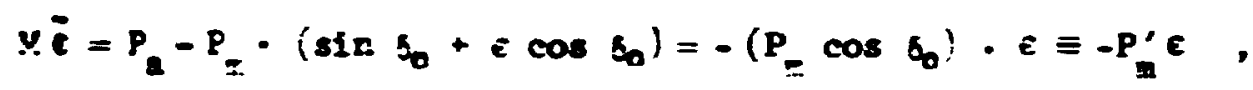

where ve bre ased the equilibrium sdentity

$$
P_{\mathbf{a}}=P_{\mathbf{z}} \sin \mathrm{C}_{\mathbf{2}}
$$

Equatior: $(2.12$ is fust that of barmonic oscillation with natural frequency

$$
\sigma_{m}=\sqrt{P_{I}^{\prime} / M}=\frac{2 x}{I_{I}}
$$

liote that

$$
P_{E}^{\prime}=P_{E} \cos \delta_{0}=\frac{d}{d t}\left(P_{t} \sin 6\right) I_{t} \cdot \delta_{0}
$$

is just the increwental power gradient (frequentis called the synchronizing power). For typical wachines the period, $T_{n}$, is or the order of a second, so that arter a perturbation, stable: mchines will oscillate or sing, with and oscillations, about their equilibriun velue with roughly

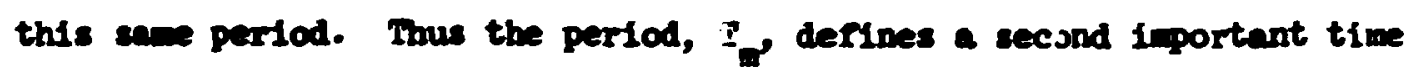
scale for stability studies and is directly related to the mechanical response tim of the wahines.

A third ifportant tive scale is the response time of the generator and land control circuitry. The effects of the generator governors becowe important about one or two seconds arter a perturbation since the 
governors resford rather slouly and gradinlly. The governor resporse is difficult to matel, and it is therefore agur. courenient to consider the response in each of two intervals: (1) the short tire transient response, which is that before geserator coctrol becomes siexificant, and (2) the laier time dyanic resposse, utich is strorgly dependent on the generator soutrol systens. As earlier nentioned, the tripping ji circuit breakers is ar. isportant class of perturbations wich car affect the transient response since relas response tize is betweer 1 and 15 sreies. Typical generator tripping gelays excite jreakers wher there is a $60 \%$ or wore valtage reversal for a time of 20 creles, witt the excited breakers opening about three cycles later.

One cannot coppletely rartition a remponse ifto trarsiest and dymanic stability components. Certaing boir appects aust be consilered since a system which is quite stable during the transiest period, int which is completely unstatie draadically, results is just as infortirate a collapse as if stability were lost very eariy. تowever, ore car. be certain that \& system which has an urstable trarsient respouse will rot ifkely regain syachroriss. A study linited solely to the carly time response car, therefore be quite informative if sct, almays corislissire, and this is the nrimary lindtation or this study. icwever, soce knjuledge of the dynandc resporse car be gained, as will be seer.

\section{Method of Solution}

Because of the nonlirearity of $\mathrm{Eq}$. (2.7), ore wat solve the coupled equation muserically. We have lsed the versatile digital conputer program of the Philacelphia Electric Compard.

Inftially the low flow of the network at equilibriur. nast be found by solving Kirchhorf's 1 iws 9 for the gi"en electrical retwork using as iterative technique. This determines the voltares, power nows, and initial equilib:ium angles of the wachines. For the complete load flow of $n$ machines, there are $n$ equations with $n+1$ unicnowns; and, with the specification of an indtial reference phase $j_{i} \mid t=0$, a unique solution for all cther $\delta_{1}^{\prime}$ 's can be obtained (i.e., again it is not the 
sboolute angles mict are ifortant, but the relative areles . D:.e

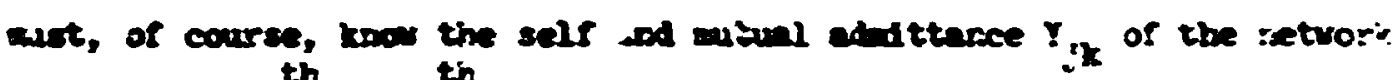

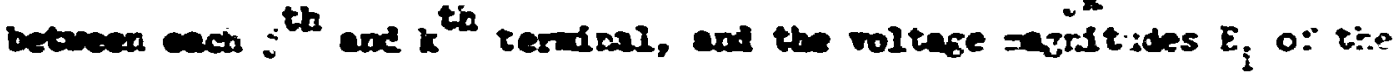
nchines. The deternined $f_{1}$ 's then copletely speciry the pourer outp:t for each nehine at equilibriva.

Hore epeffically ireaulify that the electrical piartities are coplex! we have for the porer output for the $1^{\text {tis }}$ anchine

$$
P_{i}=E_{i} I_{1}
$$

and

$$
I_{t}=\sum_{i} Y_{j k} \cdot E_{k} .
$$

Then derfaing the phase of between $E_{1}$ and $J_{1}$

$$
E_{1}=\left|E_{1}\right| e^{16}
$$

Equatior. (2.17) can be used to ellaimte if in (2.16), expressire tixe power of each wachine in terms of $Y, E$, and 8 . Fine angle " can be fourd by Iteration. (An example is given in Section 3 of this chapter.;

Ir: this study, a solved base cese representing the peak sunner power now of a profected 1977 transulssion network is ised. The digital stability progran could be used once a suttable model for the ERP faults was determined. Chapter III discusses the nodel in detail.

\section{Sulns Curves - An Illuatrative 2xarple}

As an illustrative exauple of stabilits calculations, consicier the simple tro-machine problem 1llustrated in Pig. 8. The pover delivered by each generator is a function of the difference in angies of the two wchlnes, 1.e., of $b_{3}-\phi_{4} \Delta$. The power delivered by each anchine for the two-machine prob!en is of tise form 


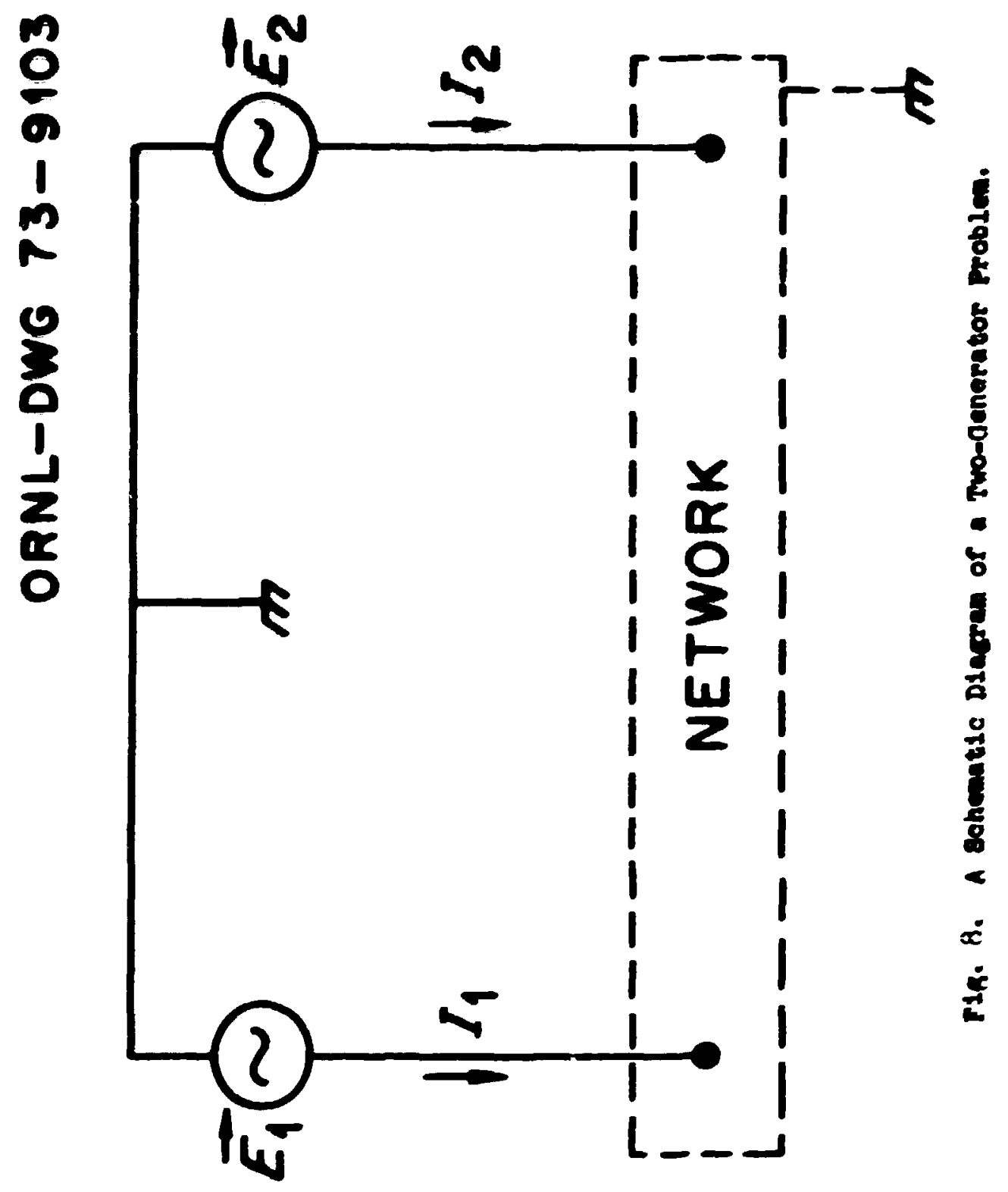




$$
\begin{aligned}
& z_{e, 1}=a_{i}-b \cos i+a_{1}-s_{2} \quad \because-1 ; a \\
& z_{e, 2}=a_{a}-b \cos 1=-5_{1}+a^{\prime} \quad \therefore .1 \%
\end{aligned}
$$

where $\exists$ is related to the fmpelance phese of the circult. Fe ar.iles ; are fourd by using Eqs. (2.16i through (2.18). Dirfirs equilitriur ? $e$, i and the argles $s_{1}$ and to are contant. Fowever, a perturbation sicis as a fault soiffies the orfoinal clrenit charfics a, b, ard $\Rightarrow$, ard therefore $P_{1}$ and $P_{0}$ change reaulting in a net torque or the machires. The argles $S_{2}$ and so thas begin to change as given by Eq. (2.7).

The effects of the perturbation, of course, deperd upor. sars factors such as the duratior of the rult, its location, its severity, etc. zo typical results for the change in the s's as a fur.ctior of time are illistrated in. Fig. 9. The achine arigle curves labeled i represert ar. irstable case in which the fault was not cleared vith surficient rapidity. The case labeled $B$ is the resporse for a wore sapid clsaring of the isult, and the curves indicate that the generators rewair. ir. syschrorism sir.ce the wachines swing back to equilibrium. Appropriately, the curver are called sing curves and show the deviation of the mahine argies irom equilibrisu as a function of tire.

$\therefore$ gereral criterfor, for loss of syrchronisa is that wher. two electrically close machires differ in phase angle ty nore than $12 \sigma^{\circ}$, the machines are said to be out of step. Thus, when the angular difference Ir. the s's of wo such machires exceeds this angle, the machines will rot be in sychronis with each other. The restoring torque vill not be sufficient to resychronize the achines. A loss in synchronism is quite apparent from the owing curves. 


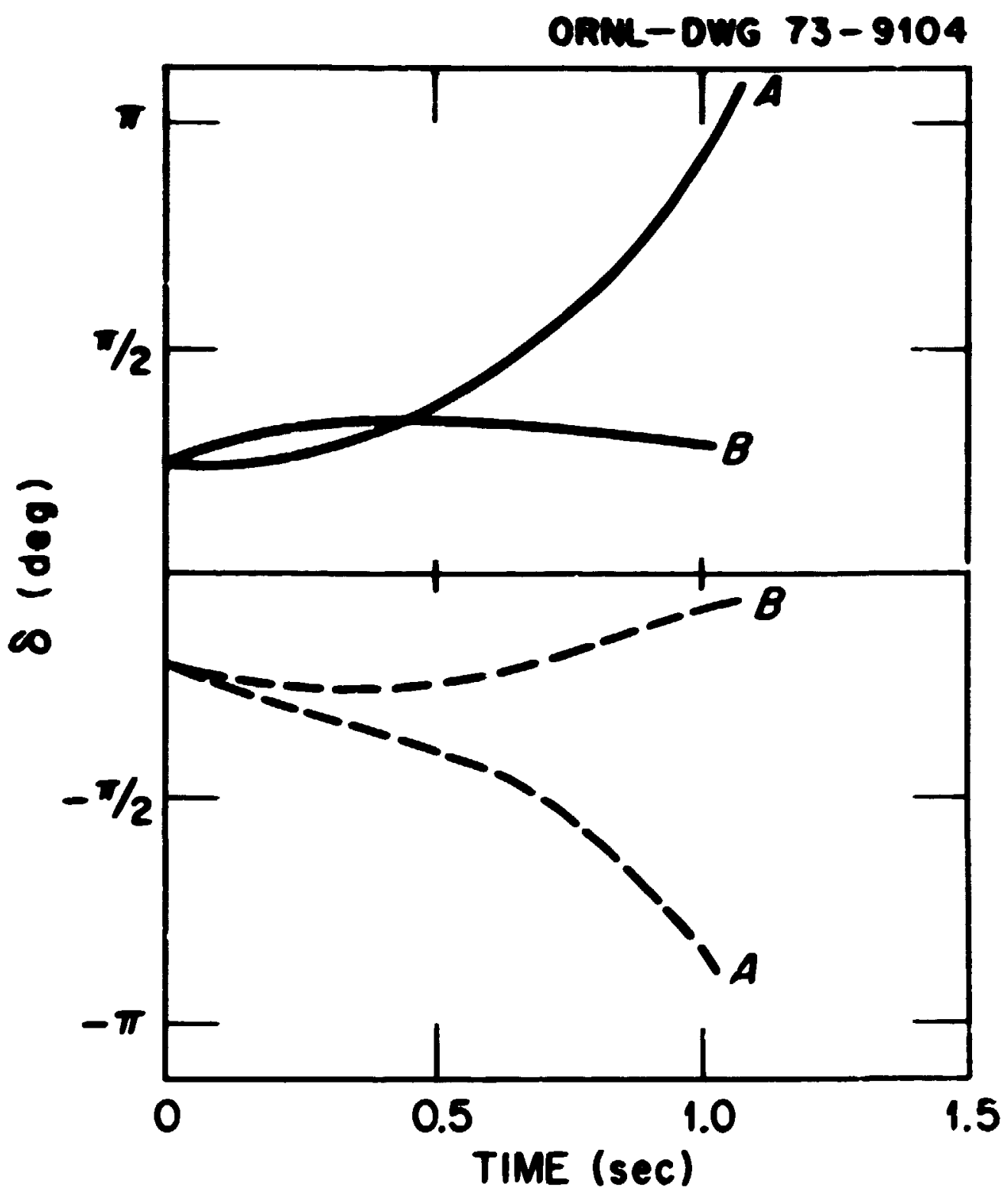

F18. 9. Typical Buing Curves for the Two-Generator Probiem. 
Cistring III

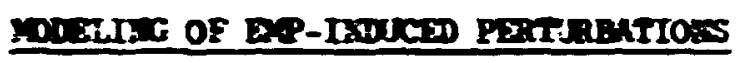

A. TSE DSCRIPTIOA OF THE GRTPPE-EATE SOREL

The general charecteristics of DP-indiced perturbatioss vere discrssed in Choter I, Section D. There it was coted that, witioin the linftations snd simplification sentioned, the prineipal Iisturbance affecting the transient response is zultiple failts on the listribution systen. The response fron the perturbation cas. be calesleted bs using standind digital copputer stability progres. Fionerer,

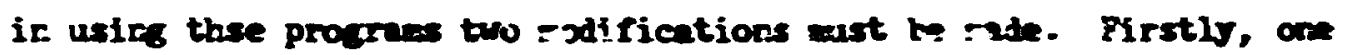
nust simalnte the rauls vifich occur on the distributior systess (not

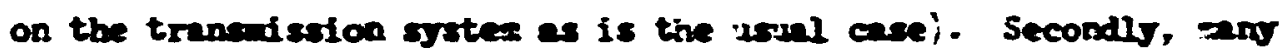
faults mut be simultancousis applied on the distribution systes connected to the traneassion networt over a larce area. Fortiuntely both of these sodifications can be ensils handled with ro reprocezerite of the besic stebility procres of Rer. 10.

A fault on a distributioc sstea will couple to the connectin transission network through sose affective imperience 2 , with $Z$ deterained by the locetion and nature of the particular fault on the distribution syetea. Paults should occir primalif or the lou voltare side of the =jor substation tranformers shown in Fig. 3. The characteristic iapedarce $\mathrm{Z}$ will then be teterained primarily by the priveryto-secondary impedance of t.u transformer at that point, i.e., a fault on the low voltage side of the transformer will couple to the transis sion nystems with en effective inpedance $Z$ nearly equal to that of the typical transformer. This iapedance is due to the leakage nive of the non-ideai transformer and is almost pure reactance. Faults occirring on the distribution systexi far from the rajor substation will have a much larger effective impedance. Consequently, the faults close to the jor substations will produce the most severe pertidrbation, of the transmission system. We are assuming that the voltage insulation of the 


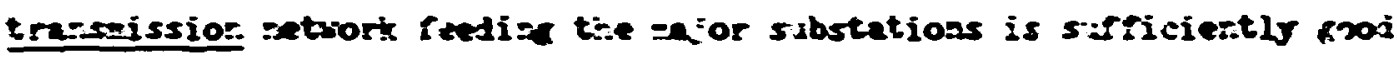

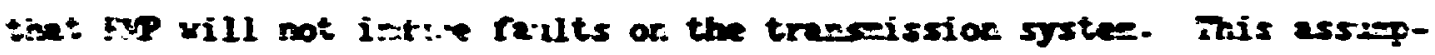
tion is sot vitiont: istificetior as earlier tiscussed.

Firive 10 illistrates the sodel for sijslating the exfect of

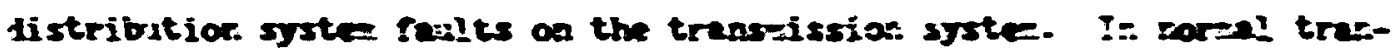
siert stidies, the laet is corsitered to be on the pior sibstation. bess labelet 5. :jonever. by deficiac en siditiosel bus, 0 , we cen siculate

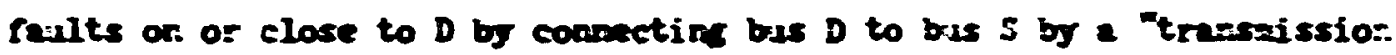

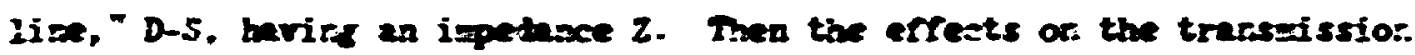
setunst proticed by a reult or or mar $D$ cer be calculated sisply is faulin D, a stacker option in the stability propar.

The procedure is essentielly as follours. The bas 2 is crounded 0 ?

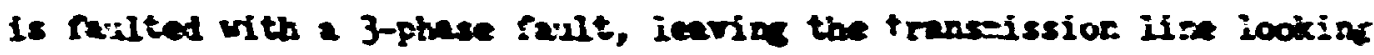
at the predomicantly reactive loed froe the leakece nix of the non-iten:

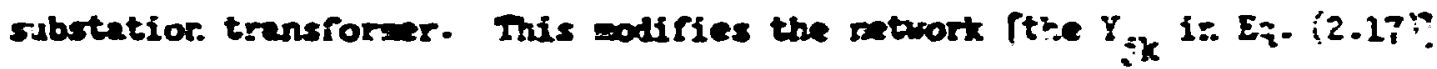

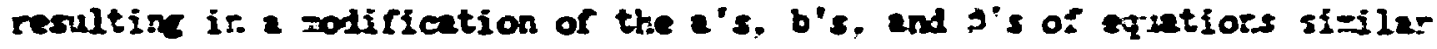
to $(2.19)$. The suin ancles ${ }_{i}(t)$ are ther calculated frea Eq. $\vdots \equiv-7$

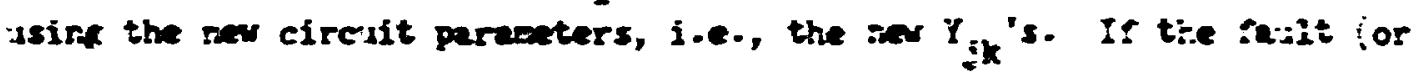
failtsi are then rescoed or sodified at a later $t i=t_{1}$, a rew set of circuit parenters will specing the power trersfers. The sacicice ereles $y_{1}(t)$ can be celculated for $t>t_{1}$ ising the wew power transfers the value of $\mathrm{g}_{1}\left(\mathrm{t}_{2}\right)$. and $\mathrm{Eq}$. (2.7). Even if all fallts are reoved ard the circuit is retprned to its initial configuretion, 'he gechine areles will vary in time since $i_{i}\left(t_{1}\right)$ are non-zero and the $s_{i}\left(t_{2}\right)$ are not at their equilibri:r: values. Thus the net torque or eack rotor vill still be ro:zero. The swing curres $s_{i}(t)$ will then show if the $i^{\text {th }}$ zachire loses stebility. We are not directly interested in. the effects of the periurbatior on bus D, itself, nor on the line D-S: these circuits are introduced rerely to simulate the effect of distribution rajls o: the transussior. network.

Hiltiple raults an be approximated in a simple manser. Sirce ve are rot interested in the distribution syster except for its effects or. the transuission system, all distribution buses winich are to be faulted ray be connected together. Equivalently, we represent all fa:lted 


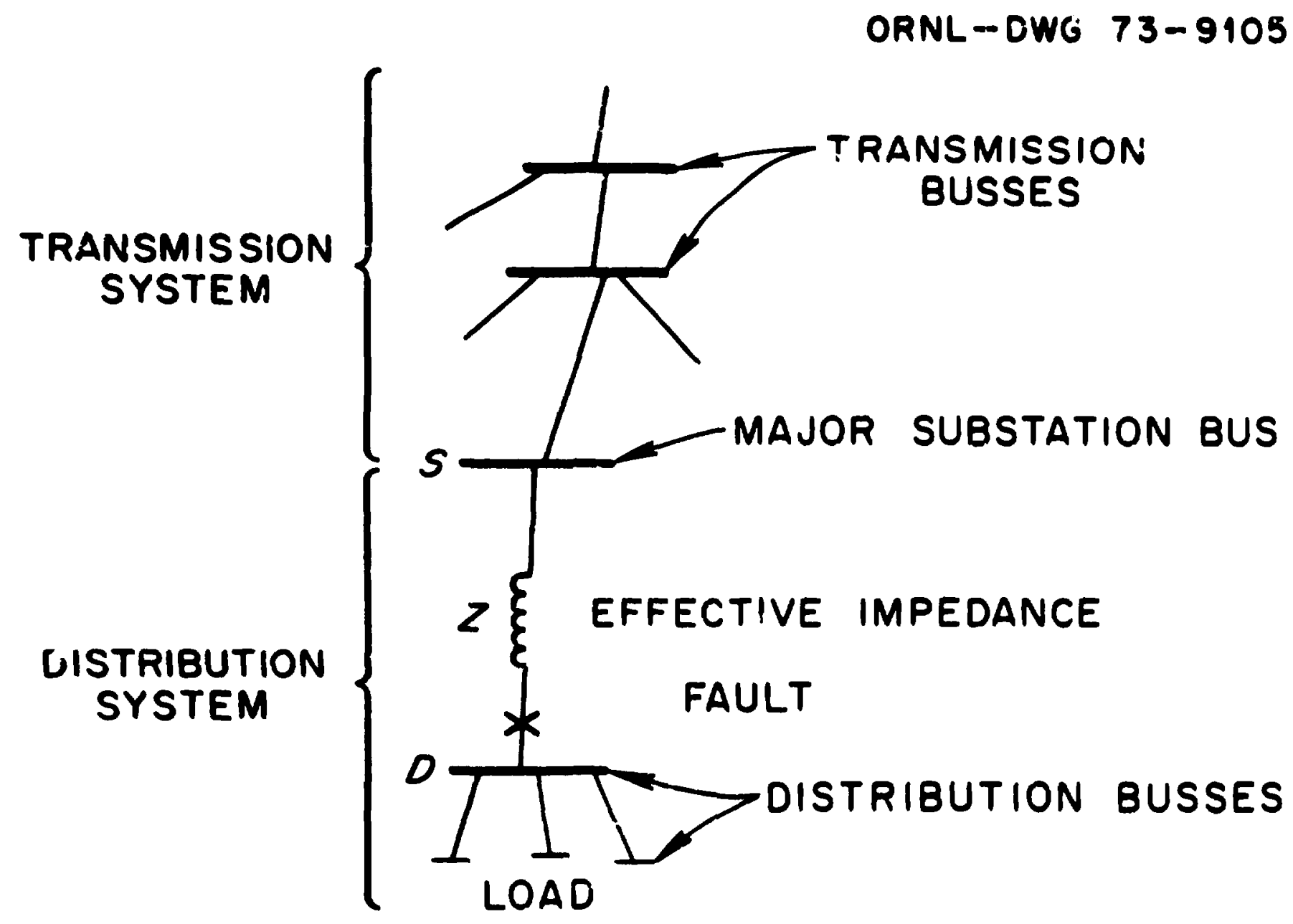

Fig. 10. A Network DIagram Illuntrating the Interconnertion of the Iransmiselon Syatem and the Diatribution system. 
distriblition points by a single bus on which one fault is placed. (This bus is designated by $\tilde{\mathfrak{D}}_{\text {.) }}$ Then the various points $T_{i}$ of the transeission network that are to be connected to faulted distribution lines are modeled by connecting each $\mathrm{T}_{i}$ to $\tilde{D}$ with a characteristic impelance $Z_{i}$. The model is illustrated in Fig. 11 . The effect on $T_{i}$ by faulting $\widetilde{D}$ can then be calculated in the sare manner as describel above.

A number of important parameters must be specified. In particular, we must ascertain what points on the transmission network should be connectei to faulted distribution systems, i.e., which transmission buses should be included in the set $T_{i}$. Both the number of ?wlts per unit area within the faulted area, as well as the geographical exient of the perturbed region, mast be specifled. We refer to this complicated variable as the fault density function, $P(\vec{r})$. The density is speciried by the number of faults within the faulted area per unit area, not by the total number of faults averagea over both faulted and unfaulted areas. Thus $o(\vec{r})$ is zero outside the faulted area.

The fault density function $O(\vec{r})$ depends on the severity of the DNPinduced currents, which, as pointed out earlier, is difficult to estimate. The density was estimated in the following manner. Within the perturbed area of the transmission network (such as the TVA network) we first arbitrarjly assumed that all major buses having a load of 100 mecawatts or more would be connected to faulted distribution systems. These buses specified the set $T_{1}$, thus specifying a particular fauit density. Ther. calculations were done using different densities in order to determine the change in the system's response. The size of the perturbed area is uetermined by the height of burst of the detonations. In order to determine the inportance of the grographical extent of the perturbations, several stability runs were made with the perturbation applied to increasingly larger areas.

Another iuportant paranater set which must be syecified is the impedances, $Z_{j}$, ronnecting each $T_{i}$ to $\tilde{D}$. We refer to this set as the effective fault impedance, $z(\vec{r})$. The dependence of the response or $z_{i}$ was determs ned by tise following procedure. First, all $\mathrm{z}_{i}$ 's were chosen as equal and fixed at the impedance of a typical major substation 


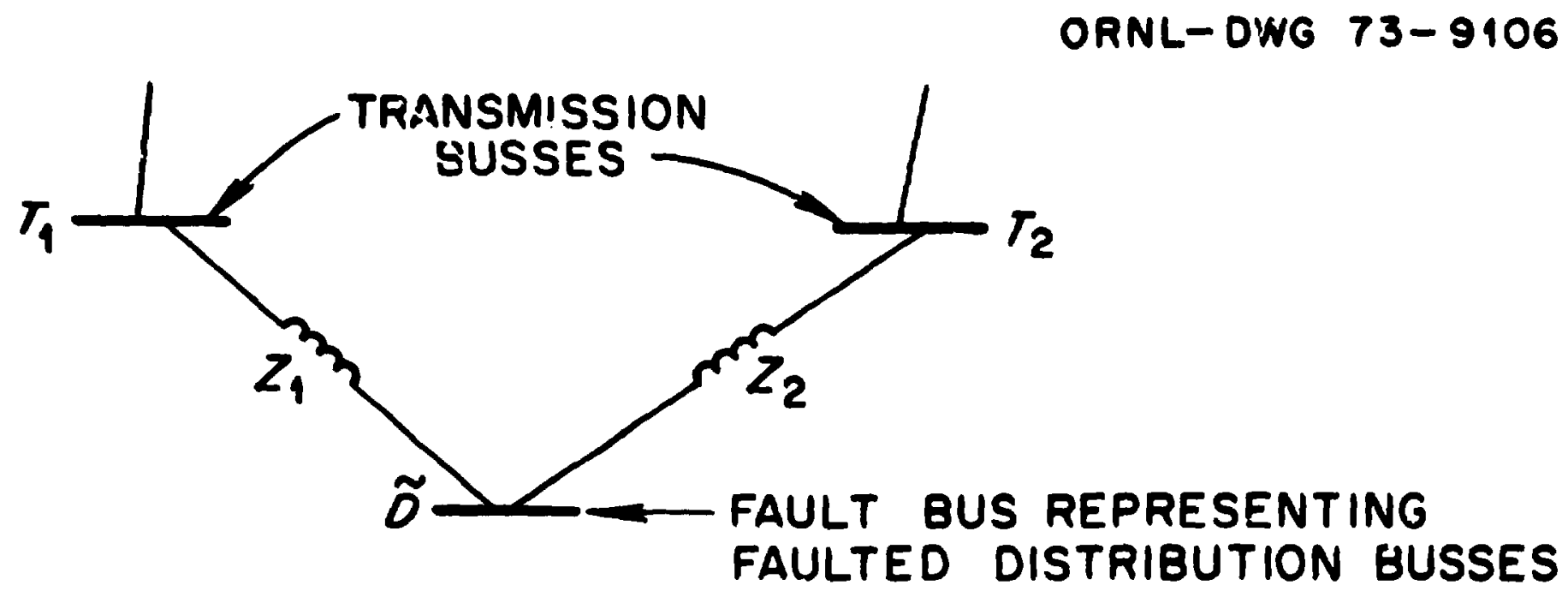

Fig. 11. The Model Used to 81mulate the Parturbation of the Tranomianion syatem from Multiple Faulte Occurrisos on the Diatribution syater. 
trensiormer. (The impedance is very nearly purely reactive.) Then calculations for different values of the impedance vere made. Firsll;, to be certair that using the same imidance for all $\mathrm{Z}_{i}$ 's is a reasonable approximation, $Z_{i}$ was randomly chosen betweer specified limits with the average of the set corresponding to a previously used value. A couparison of the calculated responses (i.e., of the swing and voltage curves) then allows one to determine the dependence of the response on the impedances.

Repetitive sets of multiple faults vere easily modeled by reapplying the single set model after the desired time delay from the previous pulse. The duration of the repetitive faults was chosen to correspond to typical distribution relay times as in the non-repetitive fault case. A detailed discussion of the importance of relay tires for multiple pulses is given in Chaftar IV. For two or wore repetitive pulses, the time separating the pilses gives an additional degree of freerion. fifter many trial calculations usiug different time separations, it we round that the response was not stroncly dependent on this time separation. A representative double pulse was tinen chnsen for further study of the effects of repetitive pulses. The detrilea characteristics of the pulses used are discussed in Chapter IV.

\section{B. THE HODELING OF OTTER PERTURBATIONS}

Many of the other EMP-induced perturbations mentioned in Chapter I, Section 4, can be incorporated in the stability studies using the digital program. Lock-out of distribution relays caused by mutiple pulses will affect the transmission system chiefly by reducing the lood on those buses feeding the affected distribution system. In order to simulate this effect and ascertain the importance of load shedding, the load on the buses $T_{i}$ was reduced. Several stability runs were made with this load reduced by 10 to $50 \%$, and the size of the area in which losd reduction occurred was also varied.

The stability program could also model both the opening of transmission lines (caused by elther proper or false operation of relays) and 
generator tripping. Honverer, as liscussed earlier, it vas assumed it. this study that Be would not initially cause the transaission circiitry to cpen.

An estimte of the magutude of reduction in geveration needed to counteract the increase in aster frequencs accompanving altiple faults and load shedilin can alsc te sade. The results and procedural details are discussed in the next chapter.

The computerized tie-line and load-flor sonirol asstens vere not modeled because of linted tine and resources. However, the effect which tie lines have on comnecting astens was studied. The stability progran allows one to model openine of tie lines at an time during the stability run. We vished to deterdine vhether significant effects are introduced because of the tie line comections and also if the opening of the tie lines before or shortly arter the EP-induced perturbation oceurs significicantly affects the response.

Ir. Crapter IV we present the reaults and analjses from scures of stability runs which were ade in order to deternd ine the inportance of the saranters discussed in this chapter and elsenhere. 
GinPTis IV

\section{RESULTS OF RURERCAL STABIIITY CLLCURATIOIS}

\section{A. InTODUCTION}

This chapter discusses the results of ihe ctability calculations using the model previcusiv described. In Section. B we present the results for perturbations consistirg of single sets of ultiple faults. Perturbations consisting of repetitive sets are discussed in Section c. By calculating the response from a vide variety of perturbations one can deternat ne both the possible range of EP-producs 1 effects or the systex's transient response and the inportant parametes s speciffirf the EMP pulse. This approach is recessary since one cannot quantitatively specify a unique and universal DAP perturbation.

The urmodified transmission network used throughout this studu for the base case was a projected peak summer pover flow network jor 1977 , provided by the Tennessee Valley Authority (TVA). Over 1500 buses 2600 lines, and 300 generators were modeled. The transient resporse vas calculated using the transient stabilfty program and the solved base case of the projected 1977 power now.

Several test runs of the model illustratsi in Fig. 11 were made to ascertain wrother or not the connection of the tranimission buses $T_{1}$ to the bus $\widetilde{D}$ representing the distribution system through the impedances $z_{1}$ would introduce a false perturiation even when no faults were applied. No significant perturbetion was in fact introduced.

The network was modified as specified, and the transient response was then calculated without faulting the distribution bus $\tilde{D}$. No aignificant deviations from equilibrium were produced, so that the circuit modifications of the model to not perturb the system by significantly modifyting the load now.

Several "representative pulses" for both the aingle set and the repetitive sets of pujses were chosen and defined by specifying the impedances, fault densities, area of coverage, and duration. Table 1 lists 
Table 1. Several of the Representative sets or Faulte, Fach Comprialng a Perturbetion

\begin{tabular}{|c|c|c|c|c|c|}
\hline Number & Label & $\begin{array}{l}\frac{\text { Number of Buses }}{\text { Paulted In the }} \\
\text { Perturbed Ares }\end{array}$ & $\frac{\text { Geosrephlc Area }}{\text { Covered by }}$ & $\begin{array}{l}\text { Effective } \\
\text { Impedence }\end{array}$ & Comment \\
\hline 1 & $\overline{\boldsymbol{F}}$ & $\begin{array}{l}\text { Approximately } 1 / 3 \\
\text { (78 out of } 264)^{1 / 3}\end{array}$ & Area 10 only (TVA) & $10 \%$ & $\begin{array}{l}\text { All busen with } \\
100 \text { MW or mure } \\
\text { load on TVA were } \\
\text { faulted. }\end{array}$ \\
\hline 2 & $\mathbf{F}^{\prime}$ & $\begin{array}{l}\text { Aa in No. } 1 \text { above } \\
\text { plus } 58 \text { additional } \\
\text { In areas } 12 \text { and } 13\end{array}$ & $\begin{array}{l}\text { Areas } 10,12 \text { (MO \& } \\
\text { AR), and } 13 \text { (IL \& } \\
\text { MO) }\end{array}$ & $10 \%$ & $\begin{array}{l}\text { Approximately anme } \\
\text { denaity in il of } \\
\text { faulted area an in } \\
\text { above. }\end{array}$ \\
\hline 3 & $F^{\infty}$ & $\begin{array}{l}\text { As in No. } 2 \text { but } 24 \\
\text { moro buses on } 4 \\
\text { additional nelgh- } \\
\text { boring notworks }\end{array}$ & $\begin{array}{l}\text { As in No. } 2 \text { plus } 4 \\
\text { more networks }\end{array}$ & $10 \%$ & $\begin{array}{l}\text { Same dansity in } \\
\text { aroas raulted in } \\
\text { No. } 2 \text {, but with } \\
\text { lower denaity in } \\
4 \text { added areas. }\end{array}$ \\
\hline $4^{-}$ & $\widetilde{F}$ & As in No. 1 & As In No. 1 & $\begin{array}{l}z_{1} \text { chosen randomly } \\
\text { between } 10 \text { to } 20 \% \\
\text { with average } z=15 \%\end{array}$ & As in No. 2 \\
\hline
\end{tabular}


four of the single-set pulses and also gives the notation ve ise it: identifying each. This is by r.s means a complete list of all pulses used in the study. These representative pulses vere selected becaise they illustrate the different syster responses for different perturbations as outlined in thapter I, Section D, and Chapter III. The pulses vere selected is "representative pulses" after scores of stabili'sy runs vere made using mand different fulses.

Four difierent grours of machines vere chosen to illustrate typical swing curves in order to facilitate the comparison of the rexponses fym different perturbations. Table 2 lists the different broups of machines, their locations, and their power outputs at equilibrium. The machire location names and area designations are giver for the comvenierice of those familiar with current Tennessee Velley Authority (TVA) rames.

The distribution relays are an important consideration ir. determining the effects of DPP. Typical distribution relays take about 0.133 to 0.25 second ( 8 to 15 cycles) to open wen clearing a faulted line. (One cycle is $1 / 60$ of a second.) The open relays will then reclose in about 0.25 second ( 15 rycles) after opening. If the line is still faulted, they will again open in an additional 0.133 second and remain open for about a second before reclosing. If, after reclosing, the line is still faulted, or if the line is refaulted withis the next winute or so, the relays oper. and remain opened intil manualir reclosed. They are said to be locked open. As a result of this programined sequence, repetitive bursts occiuring shortly after the initiation of the clearing sequence which also refault the lines will cause the relays to respond in the sare manner as if the lines had remained uncleared and consequently will lock the relays open. The relay time sequence will determine the duration of the faults, since DMP rerely initiates the paults which then remain until the ilnes are cleared. Since DMP will not fault a distribution line which has no voltage, open lires will probably not kc affected by EMP. Thus, a second EMP pulse arriving after the openting of a relay remosing the IIne will not affect, the line. There will, therefore, be about 15 cycles when a second DaP pulse will have little effect. We ignore this limitation of double pulses, but this simplification should have no significant effect. 
Table 2. Vachine Groups Used for C mparisor.

\begin{tabular}{|c|c|c|c|c|}
\hline$\frac{\text { inour }}{\text { I0: }}$ & $\frac{\text { Yachine Bus }}{\text { Iuter }}$ & Are & $\frac{\text { Yhohine }}{\text { Lochtion }}$ & $\frac{\text { Tachire }}{\text { Torque, }}$ \\
\hline 1 & 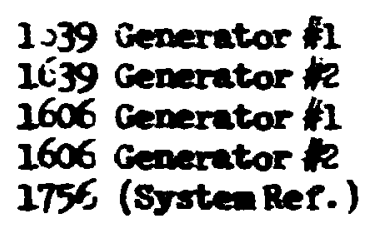 & $\begin{array}{l}10-\text { TVA } \\
10-\text { TVA } \\
10-T N A \\
10-T N A \\
14-\mathbb{A B P}\end{array}$ & $\begin{array}{l}\text { Paradise } \\
\text { Paradise } \\
\text { Bull Run } \\
\text { Bull Run } \\
\text { Ohio }\end{array}$ & $\begin{array}{r}535 \\
535 \\
i 13 \\
i 43 \\
1369\end{array}$ \\
\hline 2 & $\begin{array}{l}1546 \text { Generetor "1 } \\
1546 \text { Generetor it? } \\
1666 \\
1668 \\
1756 \text { (syuten Ref.) }\end{array}$ & $\begin{array}{l}10-\text { TVA } \\
10-\text { TVA } \\
10-\text { TVA } \\
10-\text { TVA } \\
14-\text { AEP }\end{array}$ & $\begin{array}{l}\text { Paradise } \\
\text { Paradise } \\
\text { Kingeton C } \\
\text { Cumberland } \\
\text { Ohic }\end{array}$ & $\begin{array}{l}675 \\
675 \\
195 \\
1268 \\
1369\end{array}$ \\
\hline 3 & $\begin{array}{l}1088 \\
144 i \\
1447 \\
1485 \text { Cenerater } " 11\end{array}$ & $\begin{array}{l}15 \text { - Carolin } \\
\text { and Virgina } \\
10 \text { - TVA } \\
10 \text { - TVA } \\
10 \text { - TWA }\end{array}$ & $\begin{array}{l}\text { URA } \\
\text { KY HY } \\
\text { SHAWF } \\
\text { COINI }\end{array}$ & $\begin{array}{l}260 \\
190 \\
294 \\
527\end{array}$ \\
\hline 4 & $\begin{array}{r}E \\
40 \\
251 \\
803 \\
1756 \text { (System Ref.) }\end{array}$ & 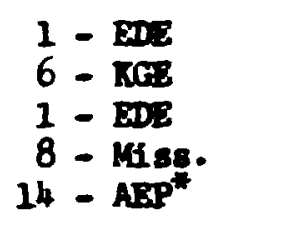 & $\begin{array}{l}\text { ASERI } \\
\text { GILL } \\
\text { SEMPP } \\
\text { WILSN } \\
\text { OhIO }\end{array}$ & $\begin{array}{r}200 \\
319 \\
450 \\
400 \\
1369\end{array}$ \\
\hline 5 & $\begin{array}{l}1666 \\
1669 \\
1676 \\
1699 \\
1702\end{array}$ & $\begin{array}{l}10-\text { TVA } \\
10=\text { TVA } \\
10=\text { TVA } \\
14=\text { AEPA } \\
14-\text { ABP }\end{array}$ & $\begin{array}{l}\text { Kingston C } \\
\text { CURE } \\
\text { ER FYG } \\
\text { KAM } \\
\text { TIC }\end{array}$ & $\begin{array}{r}195 \\
1268 \\
065 \\
800 \\
600\end{array}$ \\
\hline
\end{tabular}




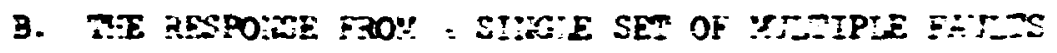

ie first discuss the tranient response obtained from a singie application of altiple faults (correspordice to the pertirbation caused by a single RP pulse: . The time duretion of the faults was choser. to be that of the opesing tise of typical distrioutior systea relays. III faults vere applie' simicheously since the difference in arrival tize of the EAP pulse over the network's aree is only a small fraction of a cycle, ard such a time ielay is of no consequerce.

The typical single fault iration was chosen to be 0.2 secord. Each of the representative sets of faults given in iable 1 was appliel for this duration and the network then returned to its original configuration. The sault duration time was then shanged in order to deterwine the dependence of the response upon this parameter. All faults applied were i-phase faults (the most severe case) since it was much easier to determine an effective impedarce for this situation. This is a reasonable assumption because 3-phase faults may typically occur if EXP induces faults at geometrical discontinuities. However, if the voltage on ore of the three lines is near a voltege node, it is possible that the EvP pulse iay fault only two of the three lines of tine 3-phase syster, creating a two-line-to-ground fault. But the basic characteristics of such a perturbation will not differ in principle from the 3-phase fault.

The system response from five different single pulse perturbatiors will be separately discussed with emphasis on the effect of changing the various puise parameters. We again remind the reader that the five cases are only representative of scores of pulses used in this study.

All voltages and impedances are given as per unit or percent quantities $^{9}$ (a per unit quantity multiplied by 100). Equilibrium values are typically near 1 per unit.

1. Faults Applied to the IVA Area Only

The perturbation $\bar{F}$ of Table 1 was applied for 0.2 second. The perturbed area was restricted to that of the Tennessee Valley Authority 
(IVA-Area 10). After 0.2 second fros the tiwe that the faults vere first applied, the network was returned to its normil configuratior, i.e., the $T_{1}$ lires, the faults, and the bus $\tilde{D}$ were rewoved. Calculations of the transient response was continued to 1.25 seconds.

The aring eurves of several wachines are shcwn in Figs. 12 through 15. Ail machines of Fig. 12 are in the TVA network except that labeled 1756, which is a far aray zeference whine located in Ohio (see Table 2). The numbers refer to the bus numbers to mich the machines are connected. Most IVA gachines remined in synchronism vith bus 1606 , and Fig. 14 shows a typical group. Recall thst a machine is considered to be out of step wher. its machine angle $A$ differs by more tivan about $220^{\circ}$ from the electrically "close" machines. Nost non-iVA wachines rewained in synchronism with the reference whine 1756 , as shown in. Fig. 15. Note the tendency for the IVA machines as group to separate from nor-TVA Eachines. Furtherwore, TVA generators at bus 1639 lost synchronisw with the rewainder of the IVA system, and the swing curves of Fig. 13 also indicate that the two generators at bus 1546 lost symchronism. Thus two effects can be observed. First, machines within the IVA system lost stability and second, the entire group of IVA machines have suing curves which differ in slope from the non-TVA machines. iie presently discuss this latter effect.

An increase in machine angle $s(t)$ implies that the frequency of the particular machine has increased which can be estimated in the following marser. A change in frequency af will result in $8(t)$ increasing inearly in time as

$$
R(t)=\delta_{0}+360 \cdot \Delta F \cdot t,
$$

where angles are measured in cegrees and $\Delta f$ is the increase in frequency in hertz. After the fault perturbation is rewoved, the swing curves tend to becowe IInearly increasing as the system daups to a new equilibrium frequency. They are only approximately linear not only because the transient oscillations take several seconds to daw out, but also because the power transfer does not depend ilnearly on 8. However, by 


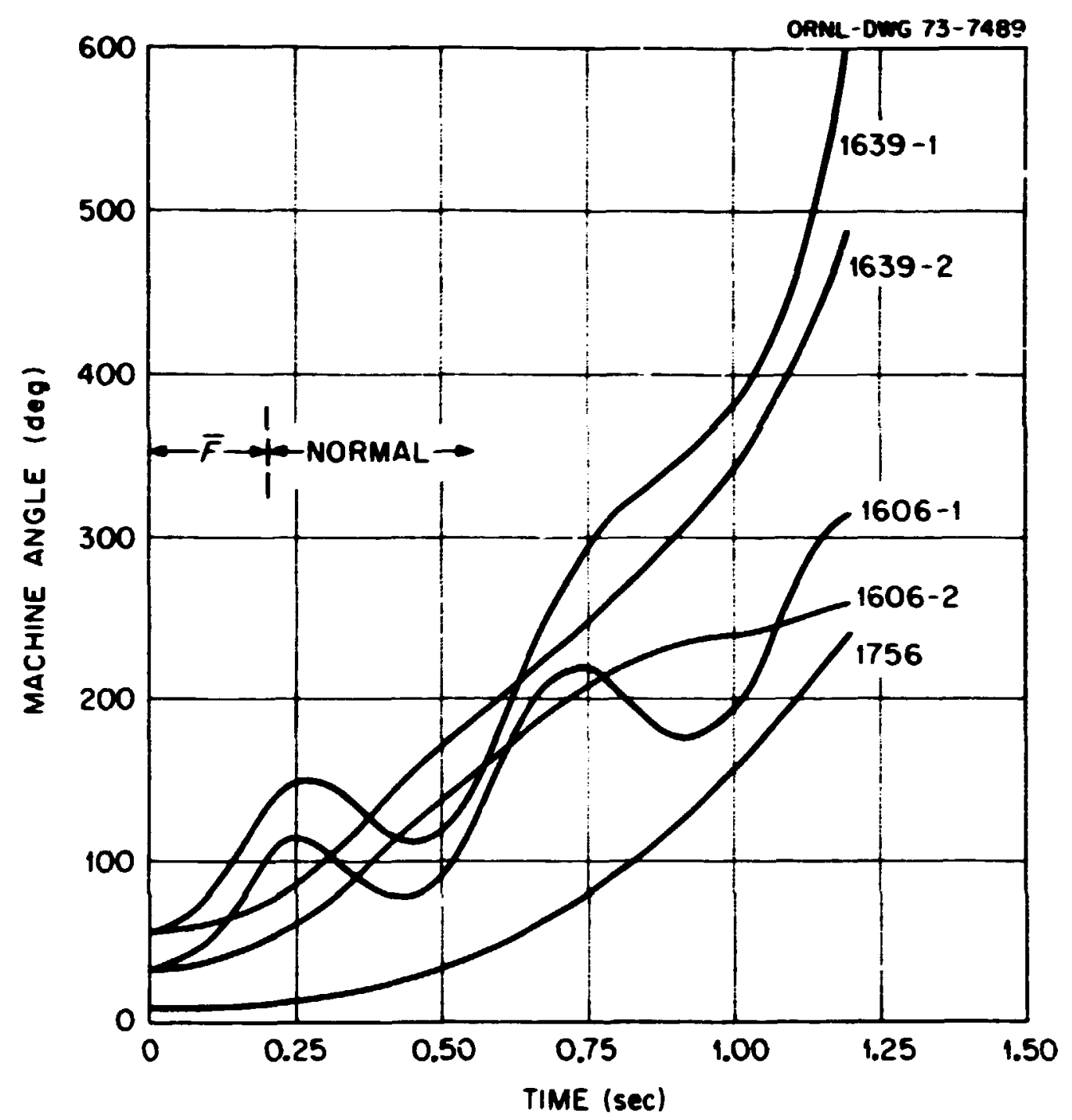

Fig. 12. Swing Curves for a single occurrence of Fault set $\bar{F}$ of Table 1 for Machine Group No. 1 of Table 2. 


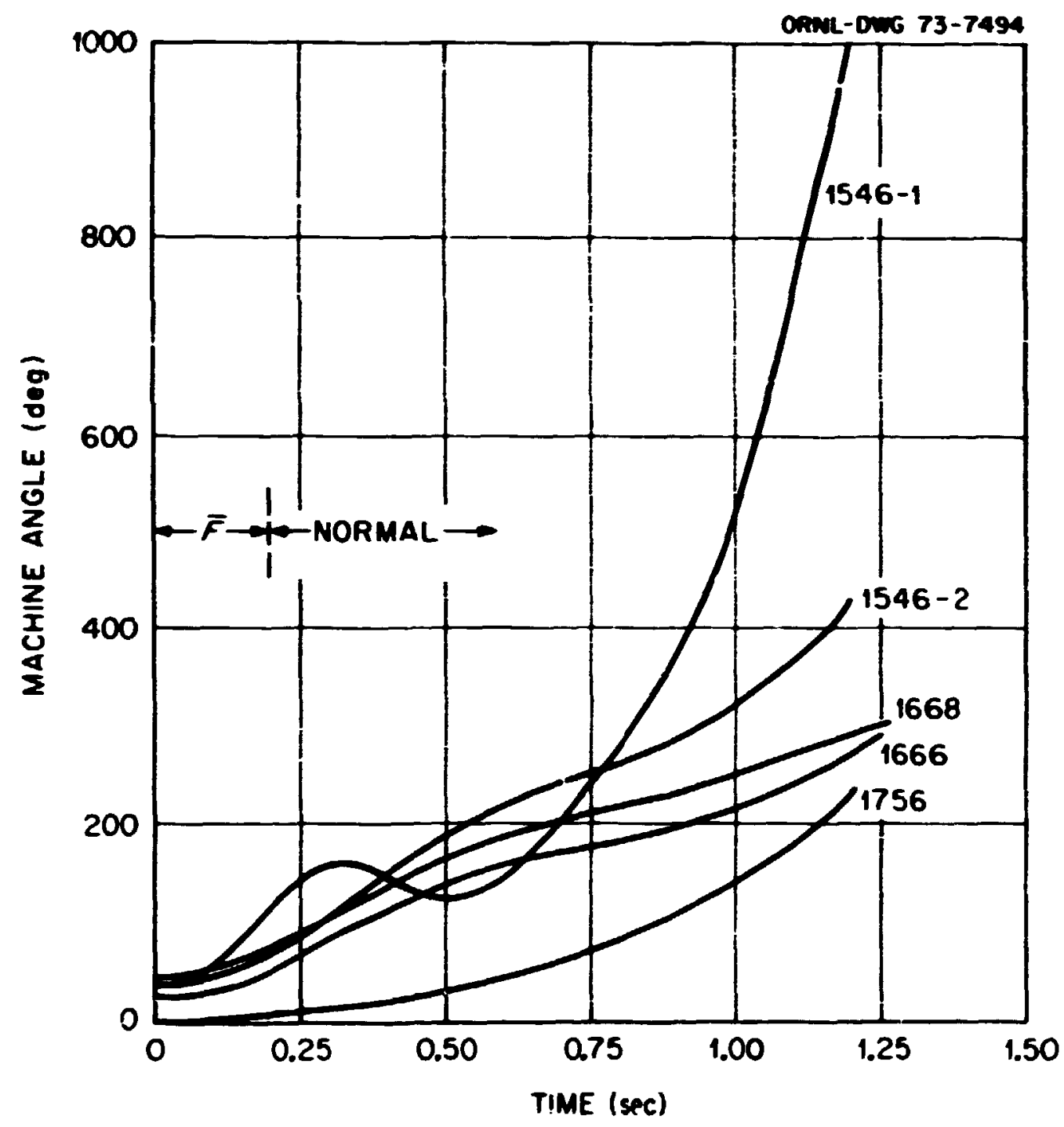

Fig. 13. Swing Curve for a single Dccurrence of Pault Set $\overline{\mathrm{F}}$ for Machine Group No. 2 . 


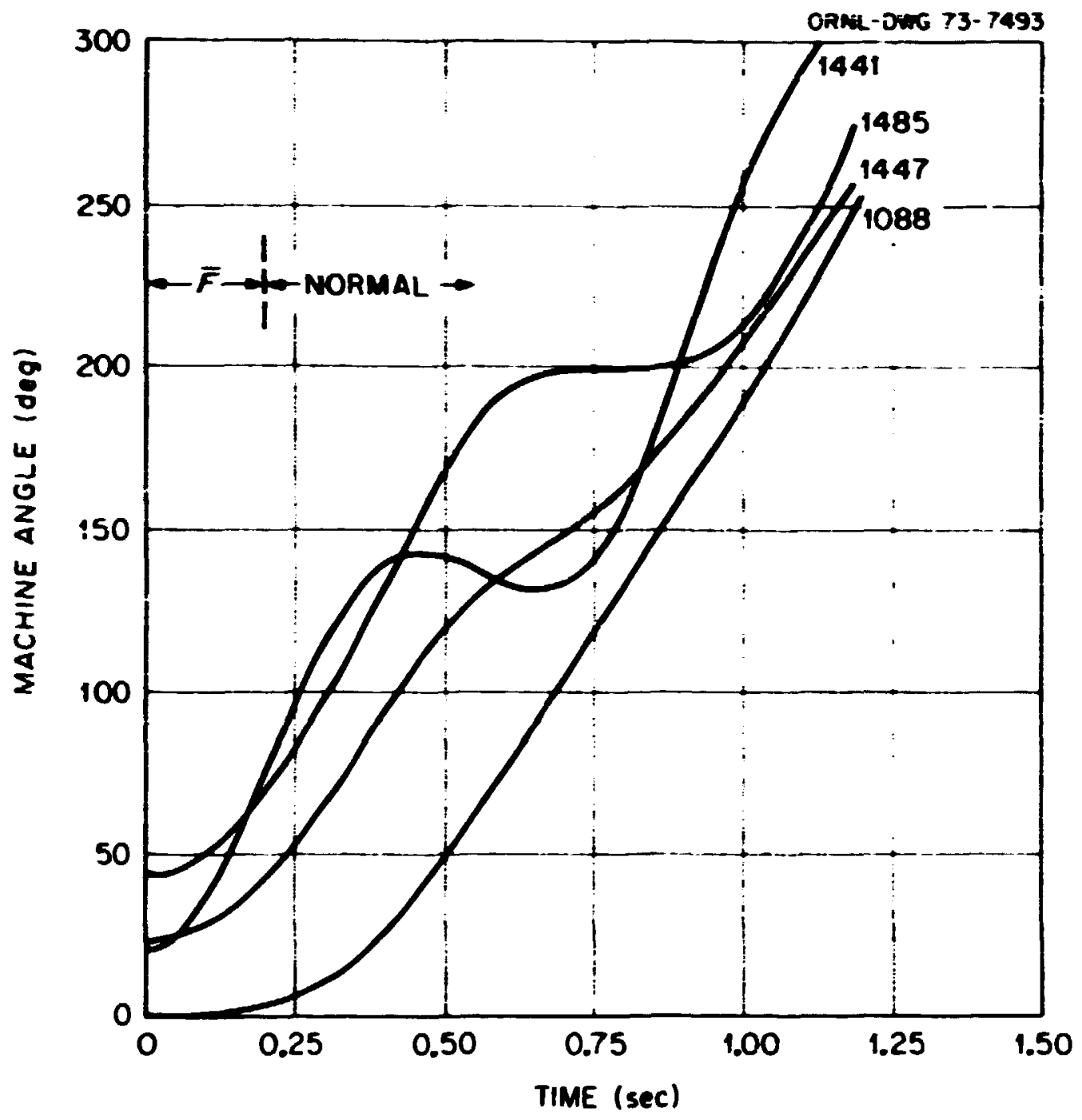

Fig. 14. Swing Curves for a single oscurrence cf pault Set $\bar{F}$ for Machine Group No. 3 . 


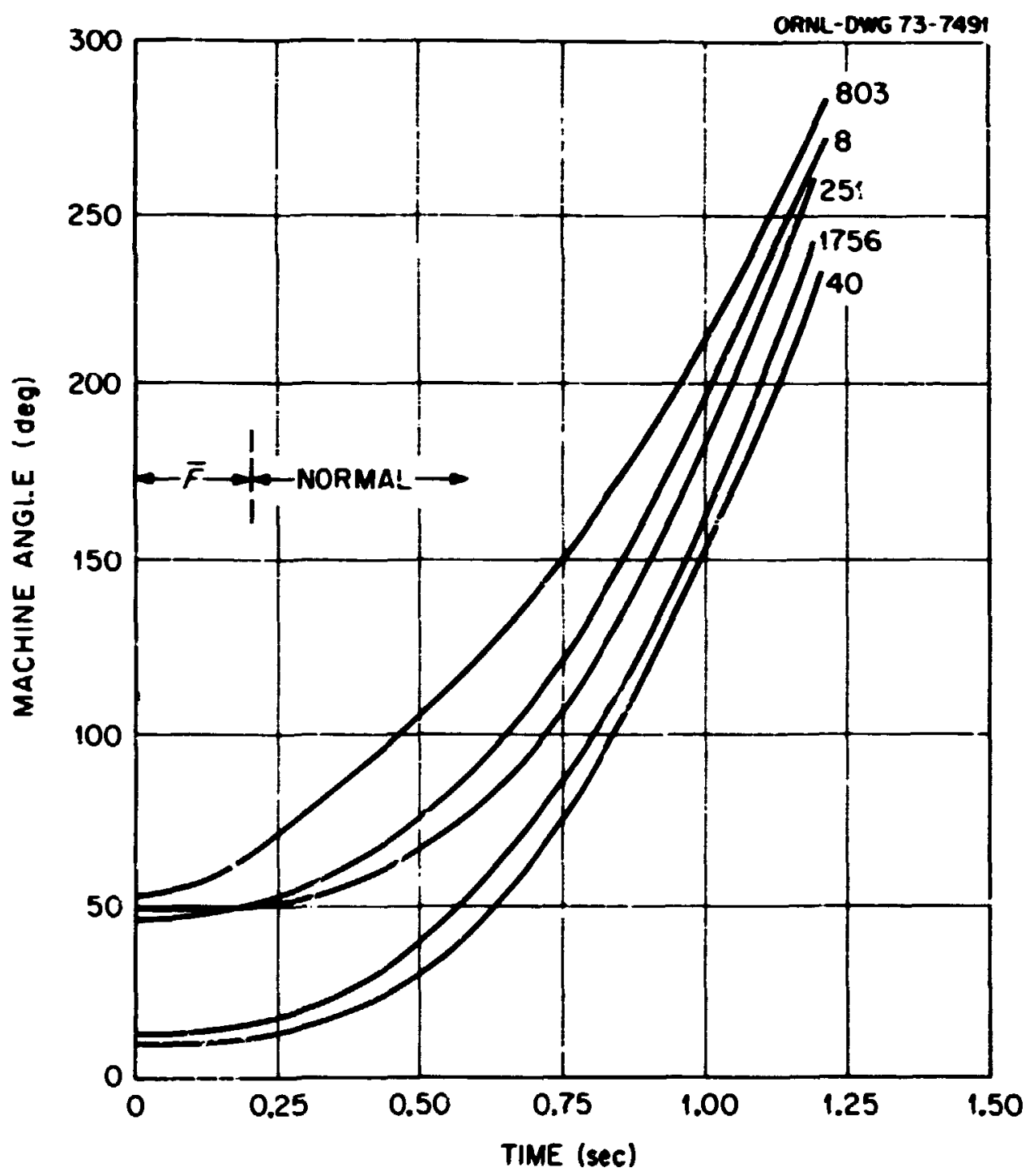

Fig. 15. Swing Curves for a single occurrence of Fault Set $\bar{F}$ for Machine Group No. 4 . 
averaging many swing curves together, an approximate $\Delta f$ can be obtaired from the "average slope" of the suing curves.

It is instructive to compare the change in frequency of the perturbed area, $\Delta f_{p}$ (which in the present case is the IVA retwork), with that of the unperturbed area, $\Delta f_{u^{*}}$. Ifnoring the machines which have lost syrichronism with their adjacent neighbors (as will always be done in calculating $\Delta f), \Delta f_{p}=0.75$ hertz while $\Delta f_{u}=2.1$ nertz. In this case, $\Delta f_{p}<\Delta f_{u}$, probably because several TVA generators lost syrchronism and therefore reduced the total IVA power output. The increase in $\Delta f_{, 1}$ shows that there is a significant coupling between the perturbed areas, and it will be shown later that this coungling is quite important.

The uniform increase in frequency of all machines is somewhat peculiar to multiple-fault perturbations. The system frequency increases primarily due to the change to a predominantly reactive Ined, resulting in a great decrease in power absorbed by the load, even though large current surges are produced, and there is a widespread decrease in voltage on the transmission lines connected to $\tilde{D}$. Thus, although the faults cause large current surges, the voltar,es decrease greatly (by as much as $60 \%$ at many machine buses) resulting $\therefore$ in a greatly decreased power output, of the generators for the duration of the faults. Since the applied torque of the machires is not decreased initially, the machines accelerate.

Unless the genorator governor systems can handle the increase in frequency, the entire system affected will speed up excessively, possibly resulting in the tripping of crerspeed relays which then disconnect the generator from the network. However, if the estimates of $\Delta f$ for the perturbation considered above are in the ball park, the goverror systems may be able to handle the overall frequency increase and prevent loss of synchronism. In any case, typical governor systems begin to have an effect at about one to two seconds after the initial perturbation occurs.

In summary, the transient response to a perturbation ccvering only the TVA network area results in (i) several IVA machines losing stability, (ii) an increase in frequency of TVA machines, and (iii) a somewhet greater increase in the frequenny of the unperturbed networks. 
2. The Effect, of Increasing the Size of the Perturbed Area

In the first case corsidered, the fawt perturbation was applied rather uniformly over the TVA transwission network. Generally, the transwission system consists of several groups of transmission networks (of which TVA is but one). Internally these networks have a strong electrical connection but are less strongly connected tc adjacent networks. Figure 16 pictorially shours some groups of networks close ts the TVA network. Not all networks of the base case are shown. The power flow between the different networks is given for the equilibrium case. (The number in each circle is used to designate the particular area and corresponds with that given in Table 1 and 2.)

In order to deterwine the effect of increasizs the extent of the perturbation, the size of the perturbed area was increased as specified by fault set $F^{\prime}$ of Table 1 , and was applied for a duration of 0.2 second, the sane duration as in case 1. The perturbation was extended to areas 12 and 13 of Fig. 16. Aree 13 (Illinois-Missouri exported about 1090 megawatts to TVA through connecting tie lines in the equilibrium load flow, while Area 12 (Missouri-Kansas) exported about 550 megawatts to Area 13. The three areas, 10, 13, and 12, comprising the perturbed area form a connected link. The average fault density 1 : the entire perturbed area ias about the same as case 1 . Figure 17 and 18 show typical swing curves.

The interesting difference between the responses of this case and the former is that the perturbed and non-perturbed area machines remained in symchronism much better when the perturbation covered the larger area. For instance, the four machines at buses 1639 and 1546 did not lose synchronism for the larger area perturbation. In fact, only one small machine (not shown) lost synchronism as compared to more than half a dozen machines iosing symchronism in the first case. Thus for the second case, even though the inrturbation was more severe, covering a much larger area and consisting of about $70 \%$ more faults, the system remained more stable in the transient time interval. 


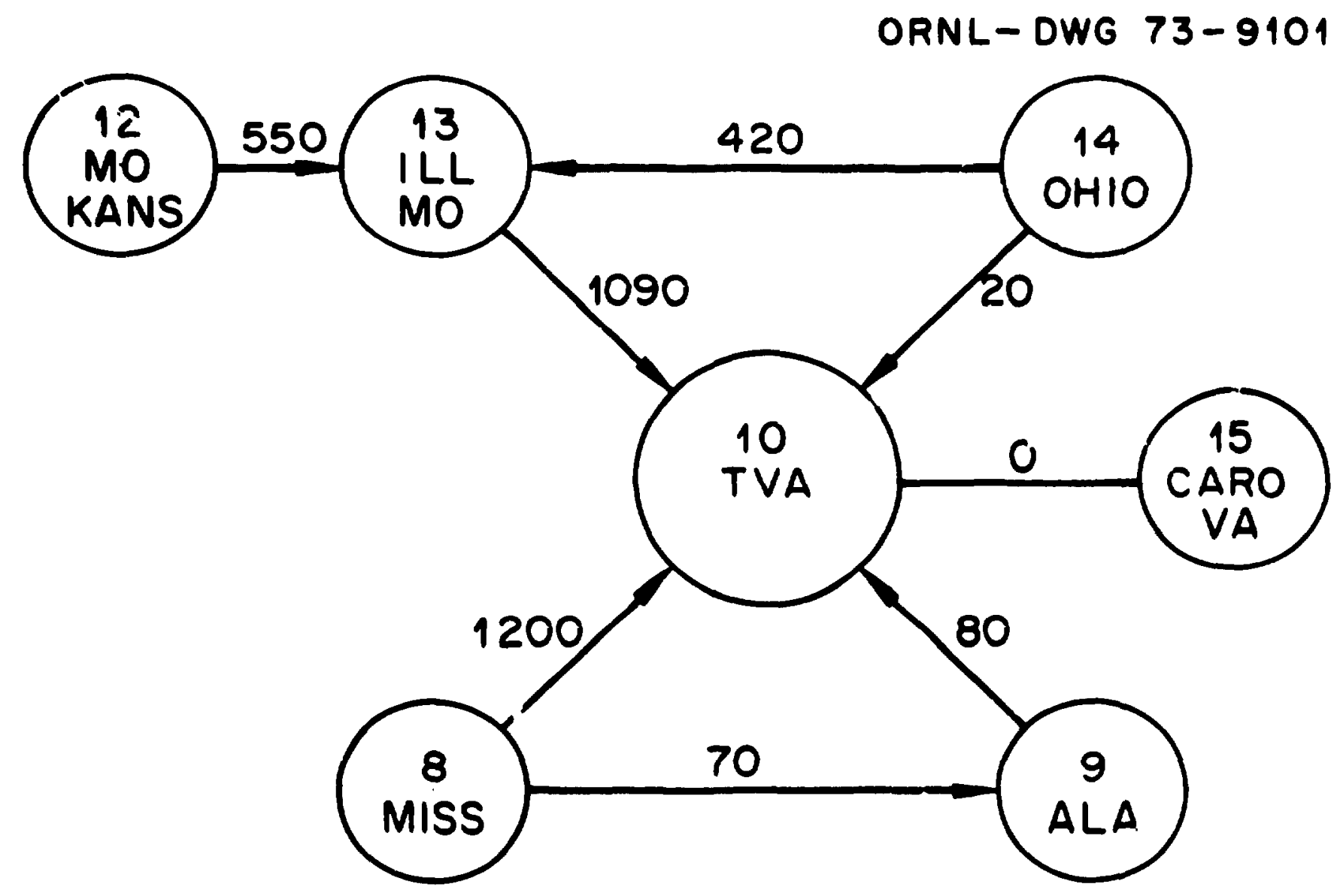

Fig. 16. Several Groups of Networks in the Vicinity of the TVA Network. 


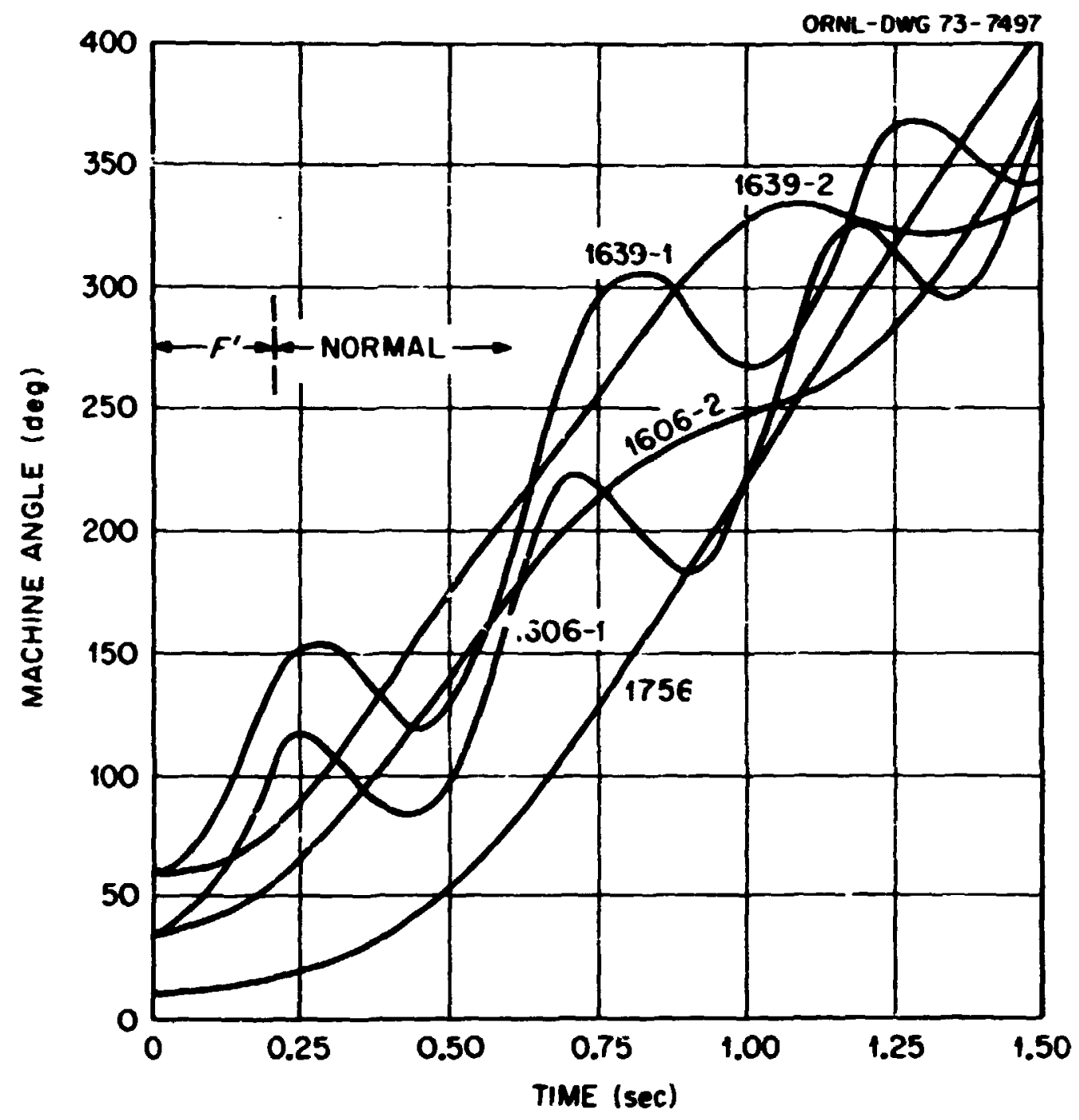

Fig. 17. Swing Curves for a single occurrence of Fault Set $P^{\prime}$ of Table 1 for Machine Group No. 1 of Table 2. 


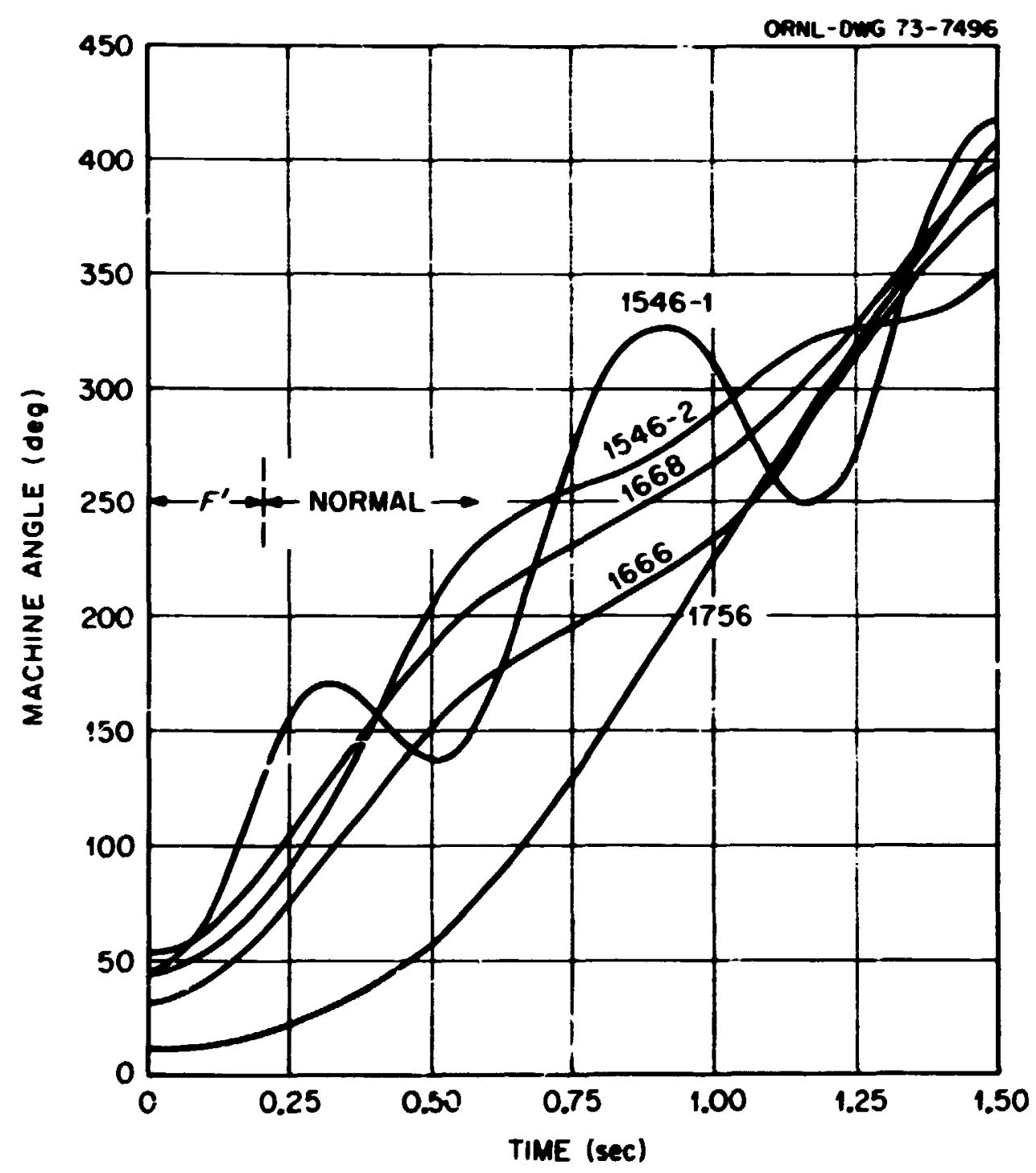

F1g. 18. Swing Curves for a single occurrence of pault Set $\boldsymbol{F}^{\prime}$ for Machine Group No. 2 . 
At 1.26 seconds after applying this perturbation, the charee ir. I (not $\mathrm{AI}^{\circ}$ ) of the TVA buses was rearly the sare ir case 2 as ir. case 1 , but the reference bus angle changed by about $50 \%$ more in case 2 . Sote aiso that the suirg curves for the second case are much wore linear thar. in the first. Fron Eq. (4.1) the linearity would ingly that the machires in case 2 are no longer accelerating and rave somewhet stabilized at a "new equilibrium" system frequency. The contimued acceleration observed in the first sase, even after one second, would indicate that the perturbed and umperturbed areas were still interacting or interfering vith each other. The net change in rrequency, if, calculated by linearly extrapolating the late time part of the sring curres, is about the same for both cases.

The difference in response of the two cases given so far can be partially understoal in a simple way. In case 1, the perturbed area (TVA) is strongly connected internally and less strongly connected with its neighbors, as pictorially illustrated in Fig. 16. Consequently, when the perturbation is applied solely to IVA, the rrequency of this area tends to separate from the adjoining areas causing the perturbed and unperturbed synchronous regions to interfere or beat with each other. Since there are so many ties with other areas which are unperturbed, the interference is sticng. The result is that machines within the perturbed area lose syncixonism. However, as the size of the perturbed area is increased to irclude adjacent, areas, the connecting perturbed networks hang together much better since there is less adjacent unperturbed areas with which to interact. We shall return to this phenomenon when the results for double pulses are given.

3. Faults Applied to a More Extensive Area

In order to further verits that the difference in response observed in the previous two caves was the result of increasing the size of the perturbed area, the size was increased still further to include four additiona: areas, all connecting IVA. Because of practical limitations the 
fault density in the four added areas was considerally less than or. areas 10, 12, and 15, but the anior loads were still faulted. Figure 19 sbows the resporse froa such a perturbation (fault set F' defined in Table 1).

The effect $::$ the additional faults was winimal. The swing curves of the IVh sechines showr. and the cther machines were quite siatlar to case 2. The change in frequencies wa nearly the save as the prerious two cases: $a_{u}=1.1$ hertz and $\Delta f_{p}=0.6$ bertz. The =esponse of the IVA network itself is therefore not strongly dependent on very far-any perturbations once the adjoining areas are perturbed. Thus as the size of the distiurbed aree is increased, the effect on the interior of the perturbed aree "saturates" so that the response there does not change greatly.

4. Dependence of the Response on the Effective Inpedarice $Z$

In the examples presented above, the effective impedance $\mathrm{Z}_{1}$ fros the distribution inis $\tilde{D}$ to each transusission bus $i_{i}$ was set at $10 \%$.

Other stability calculations vere wade both vith ifferer.t average values of the effective impedance and with all $\mathrm{z}_{i}$-andomly chosen between fixed limits. There was minimal difference between the responses of cases with randowly selectad $Z_{i}$, and cases with all equal $Z_{i}$ when the average of the $Z_{i}$ of the forre: case was the same as $Z$ of the latter.

Figurer 20 and 21 show the swing curves for fault set $\widetilde{F}$ given $i r$. Table 1. The fault duration time was $0.2 \mathrm{sec}$, and the fault density and area were identical to $\bar{F}$ in case 1 , except the $Z_{i}$ 's were chosen randoriy between 10 and $20 \%$ with the average value of $15 \%$. Comparison should be made with Figs. 12 through 15.

All of the machines remained in symchronism during the transient period, including those which lost aymchronism in case 1 when $Z$ was equal to 10\%. Note, however, the very large amplitude of oscillntions of sowe machines, e.g., on bus 1546, ind1cating tix.t these machines were strongly affected and nearly lost atability. The change in the frequency of the unperturbed area was about the same as case $1\left(\Delta f_{i s}=0.95\right.$ hertz). 


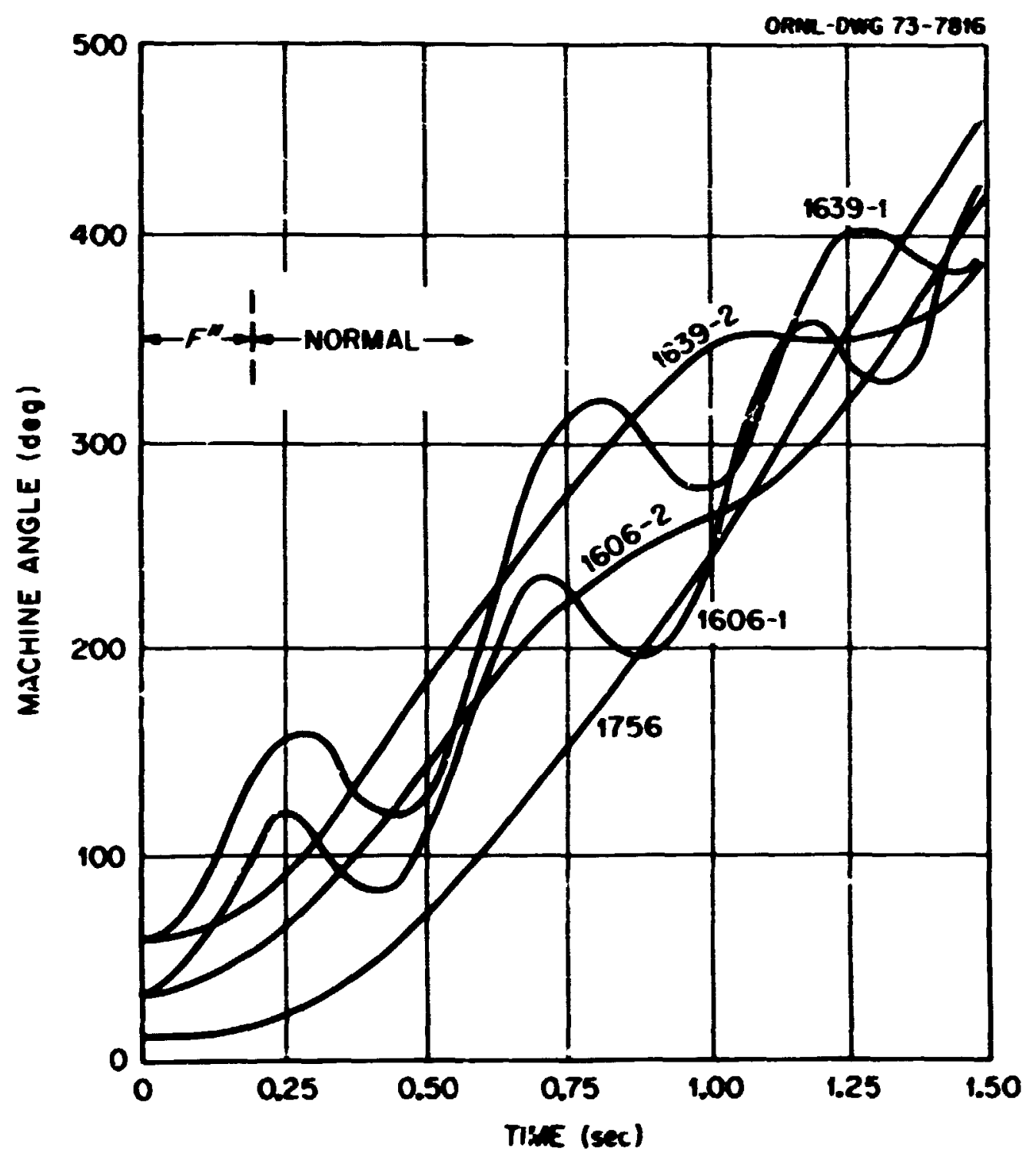

Fig. 19. sulng Curves for a single occurrence of pault set P'" for vachine Group wo. $t$. 


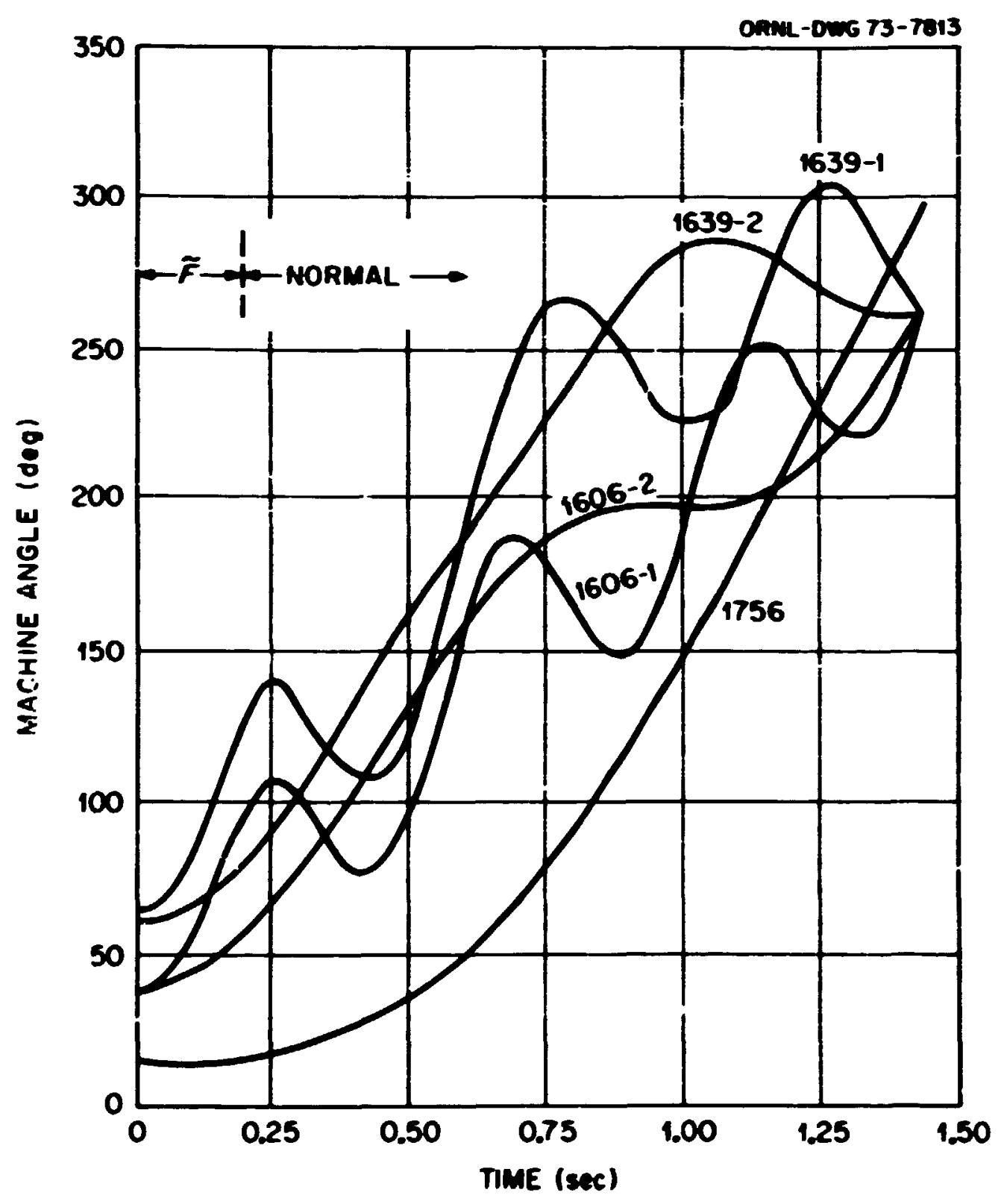

Pig. 20. Suing curves for a single cecurrence of pault set $\bar{F}$ for Mibine Group no. 1 . 


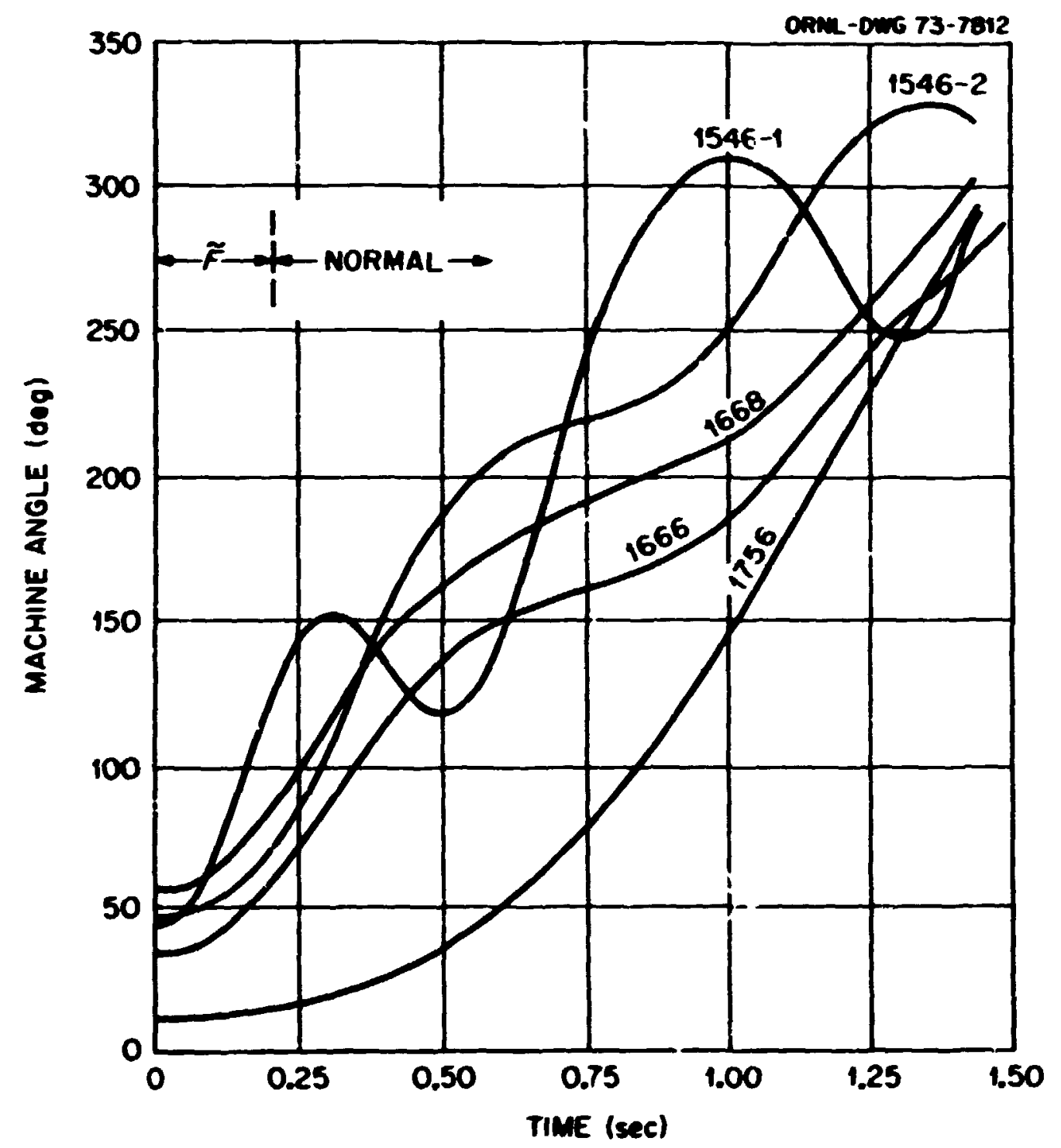

718. 21. Suding Curve for a 8ingle occurrence of Pault set $\tilde{P}$ for mahine Group No. 2 . 
For a sile 1: pulse perturbetion, the effective impedance strorely affects the syster: response, as one would expect. By changing 2 eff fros 10 to 156 , the syster kept in synchronisr much better. Consequentiy, if EAP produced faults only on the very low voltage lines (which heve much greater impedance to the transmission lines) ard not close to the mejor substations, then the effects of EPP on the transient stability would certainly be less severe.

\section{Dependence of the Response on the} Tine Duration of the Faults

The duraticn of EXP-induced faults should be about 0.2 second since the distribution relays take ihis long to inftially open. Howner, one stability run was wade with fault set $\bar{F}$ of Table 1 applind for only 0.12 second in order to determine the dependence of the response on the fault duration time. A typical set of swing curves are shown in Fig. 22. The mackines remained in synchronism nuci better than for the longer fault duration as one would expect for the shorter fault time. Yet some of the marhines had large amplitude oscillations, irdicating that they neariy became unstable. Clearly, a rapid clearing of faults is desirable; riator turately, the longer ( 0.2 second) fault luration tiwe corresponds more closely to preser.t actual relay times. The more realistic time $(0.2 \mathrm{sec}-$ ond) was used in the rewaining calculations.

c. TLE RESPONSE FROM REPETTTIVE SETS OF MILTIPLE PUISES

In the previous section the response to a single set of multiple faults was calculated. We presenily turn to repetitive sets of multiple faults. Since the occurrence of two or more sets of repetitive faults introduces several new variobles such as the number of pulses and the time separaition of the pulses, the problem must somehow be simplified. If our study is limited to the transient response of the network, then quite natural restrictions can be applied to the parameters. For instance, with this linitation we are not interested in two or more 


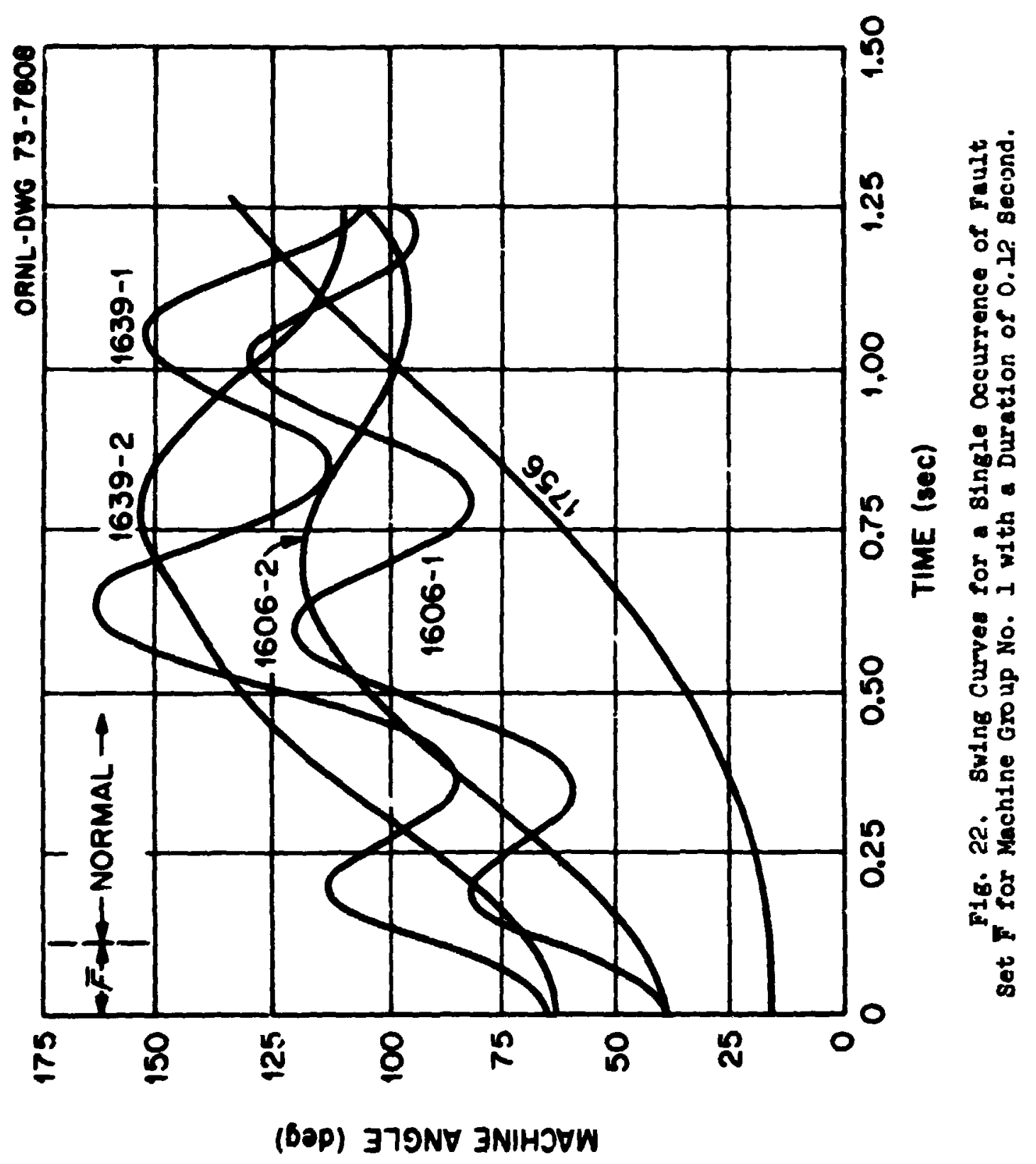


pulses separated by a time greater than tine trarsient and trnacic resporse times, i.e., in pulses separated by a ti=e greater thar that for the system to return to equilibrium. The rekstior. of the syster to such widely separated pulses would be no different fro: its reaction to indiridual single pulses.

Multiple pulses all occurring within the transient tise period vili prodice the most serio:ts perturbations, and ve will henceforth likit this study to such cases.

The mechanical design of the distribution relajs provides a sizilar liwitatior. or the new parameters introduced by the mistiple pulses. The relay desigri was previously discussed in deteil in Sectior. A. It was noted chat a second EMP pulse occurring after the initial reclosing of the relays could refault the lines. The relays would ther activate ard reopen second time about 0.133 second after the occurrerce of the second set of faults. They would remain open for about one second before agair. reclosirf. A third EMP pulse occurring shortly after tile second closing would lock the relajs open until manually reslosed. If the thirt pulse occurs before the secord reclosing, the relays will elready be oper. so the lines probably will not refault. We furtiver simplify the probler. in stidying the transient behavior by representing multiple pulses by a 2-pulse model, with each pulse occurring within a second of eech other. Such a simplification is necessary since the stability prograri cansiot faithfully calculate the systen response much beyond 1.5 secords after the initial perturbation unless the dyramical controls are modeled which was beyond the scope of this study. However, this 2 -pulse model should determine the primary disturbance from aultiple pulses, and the pulse parameters are then conveniently restricted so that they are within manageable ranges.

Using the above simplifications, a representaifive double pulse was chosen to model the primary effecis of multiple pulses. The iirst fauit was chosen to have a time diration of 0.2 second (for tise same reasons as in the single pulse cases, i.e., the relays take this long to iritially open;. Then the network was left unfaulted for the next 0.3 second. The second set of faults was then applied (after 0.5 second from the initiation of the perturbation) for a duration of 0.15 second. The second fault 
duration time is shorter than the first because the relays respond more rapidly on the second opening. In summary, a double pulse of chnsen fault density and area of coverage was used. The system was faclted for 0.2 second, back to the unfaulted configuration for 0.3 seconi, faulted for 0.15 second, and finally back to the unfaulted configuration (at 0.65 second). We refer to this configuration as the standard aouble pilse.

The intermediate time between the two pulses was latei varied to see if the response would differ significantly. The response did not, greatly change for somewhat longer separation times between pulses.

\section{A Double Pulse Appl'ed to the TVA Area}

Fault set $\bar{F}$ of Table 1 was used in the standard double-pulse conf'guration previousiy described. Typical swing curves are show in F.gs. 23 through 26. The effect of the perturbation was much worse than of the single-pulse perturiation of the same fault set (case 1 of Section B). Many more TVA machines lost symchronism. In particular, Fig. 25 shows 2 much greater angular spreed in 5 of the TVA machines than occurred in the equivalent single-pulse case (F1B. 14).

The average frequency increase of the stable TVA wachines, $\wedge_{p}$ was 14 hertz, more than four times greater than for tre single-pulse case: $\Delta f_{u}=1.4$ hertz. In contrast to the frequency increase of aachines which remained in synchronism, a typical frequency increase of a machine losing stability was 15 hertz. Such an increase would definjtely trip the overspeed relays of the generator.

Figure 26 shows a distinct separation between perturbed and unperturbed area machines (see Table 2 asd Fig. 16 for a list of the machine areas). This separation is merely a consequence of the difference in $\Delta f_{p}$ and $\Delta f_{u}$, which is much greater than for the single-pulse case.

\section{A Double Pulse Applied to a More Extensive Area}

In order to determine the effects of increasing the size of the perturbed area while keeping the fault iensity of the perturbed area 


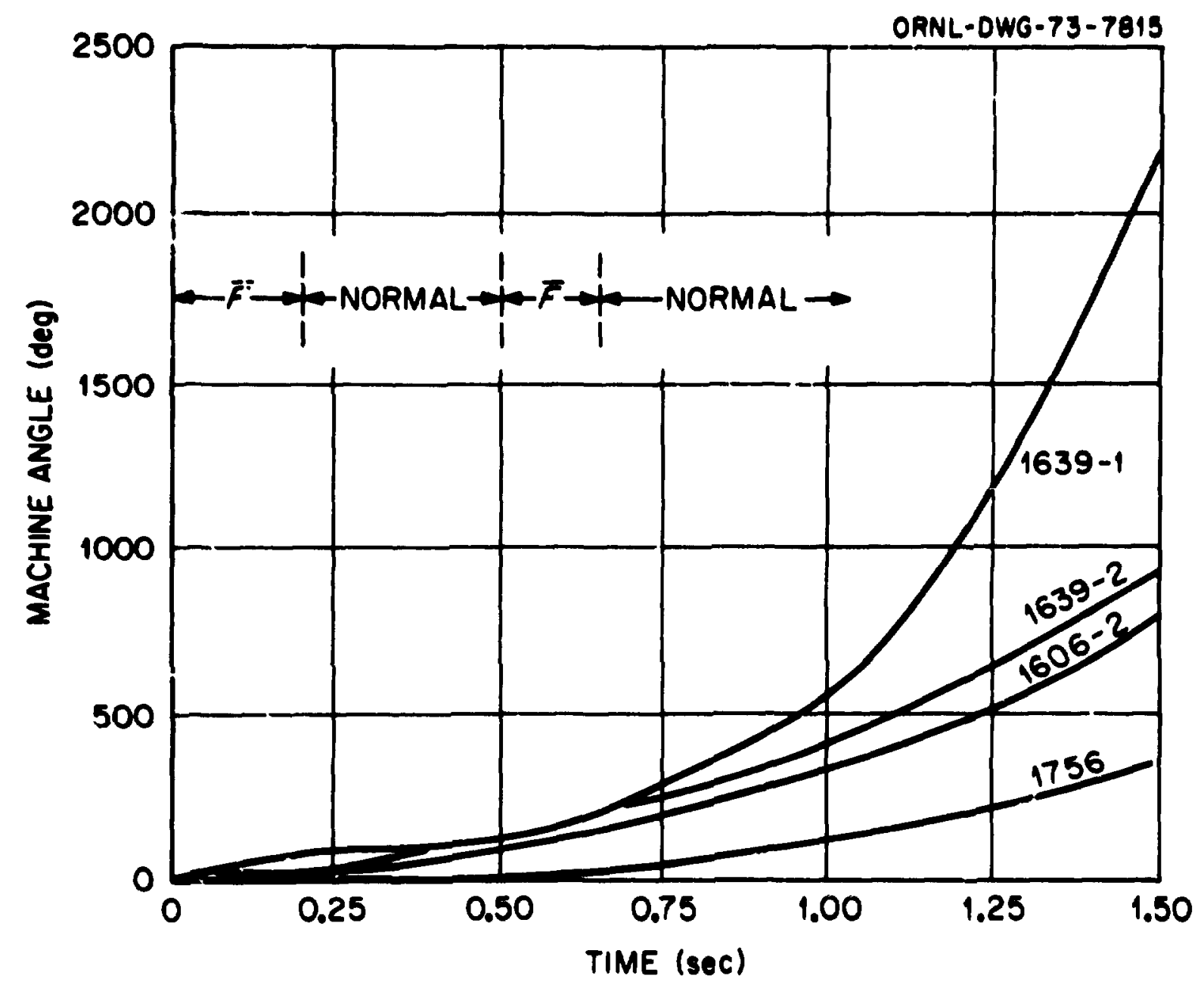

Fig. 23. Swing Curved for Two occurrences of Fault Set $\bar{F}$ for Machtne Group No. 1 . 


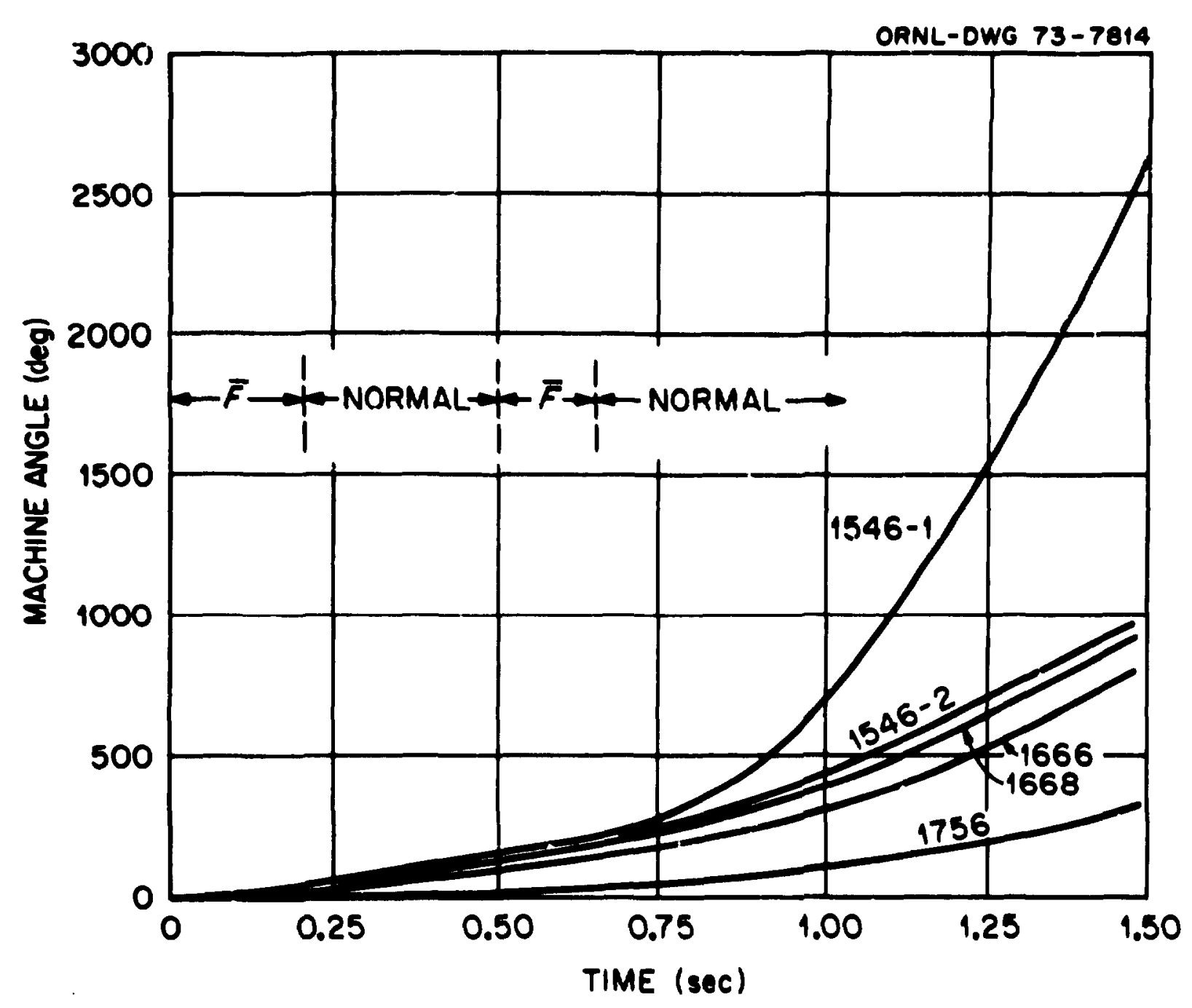

F18. 24. Swing Curves for two cceurrences of Fault Set $\overline{\mathrm{F}}$ for Machine Oroup No. 2. 


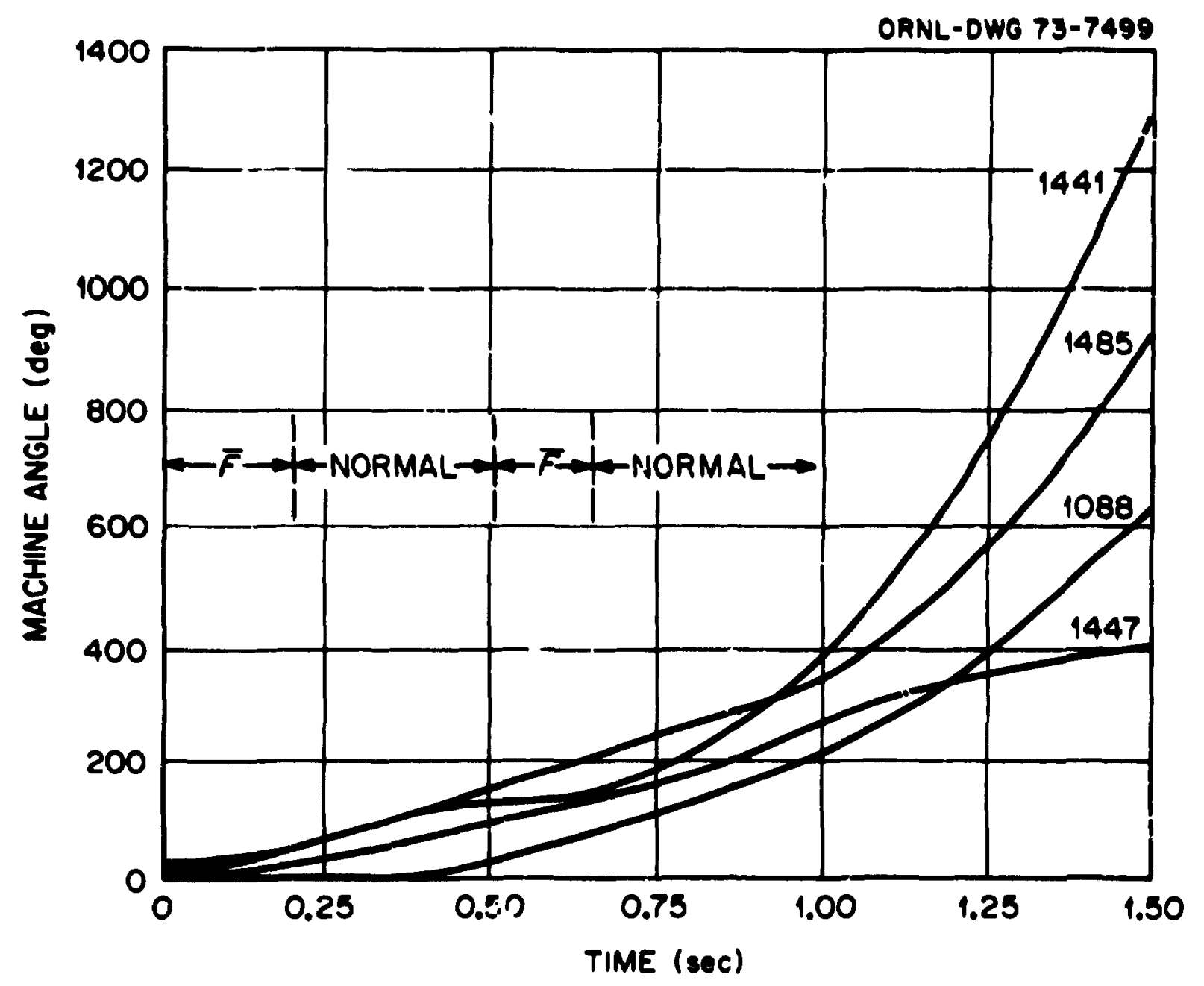

F1g. 25. Swing Curves for two occurrences of Fault set $\bar{F}$ lor Machine Group No. 3 . 


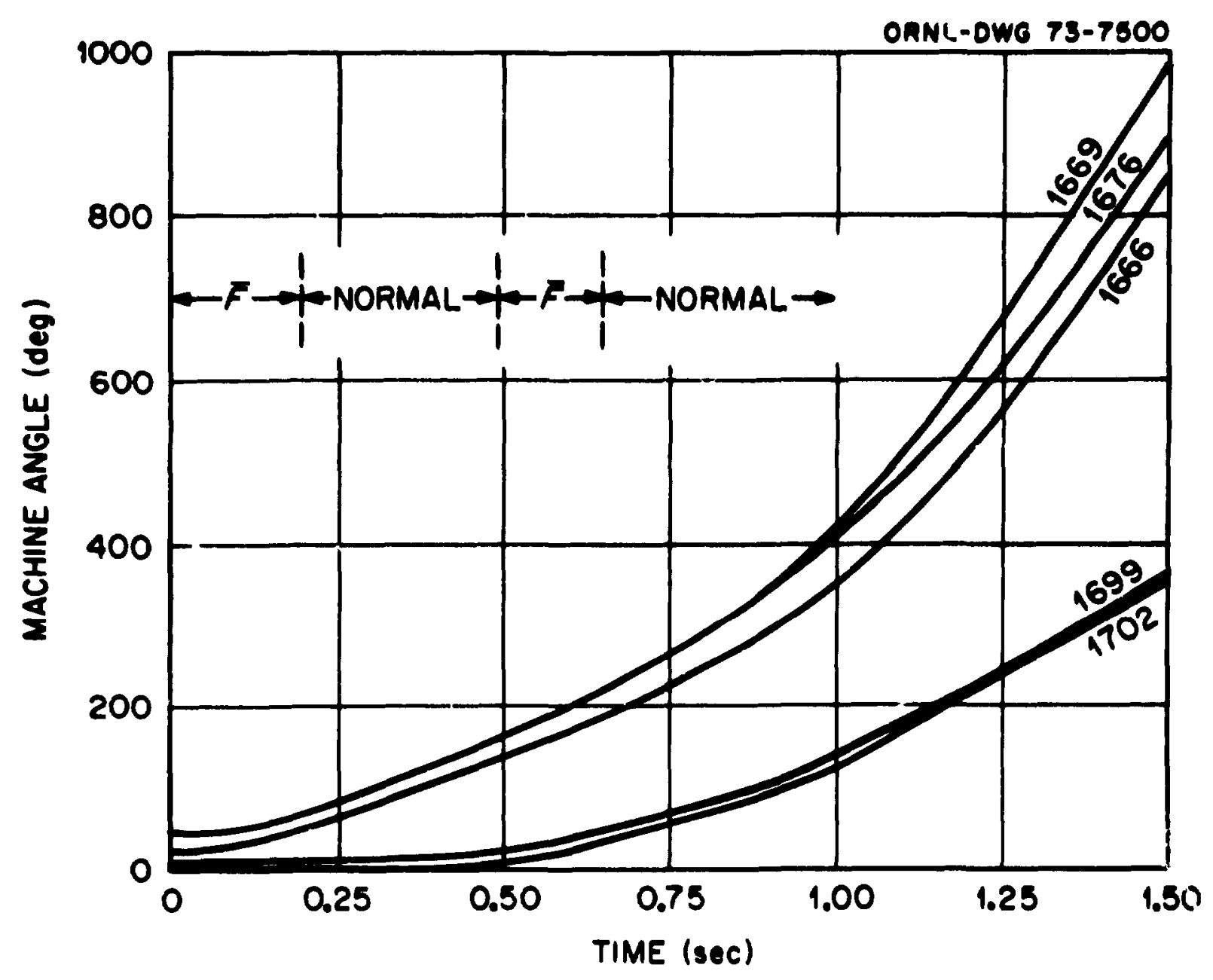

518. 26. Swing Curves for two Docurrences of rault set $\bar{F}$ for Machine Group No. 5 . 
constant, fault set $F^{\prime}$ was used in the coubie-pulse configuration. The compirative single-pulse calculation was giver, in Section B, case 2. Again, as in the single-pulse case of larger are coverage, the perturbed and unpert rbed areas remained in synchronisa wuch better, with fewer generators losing synchronism (cumpare Fig. 30 vith Fig. 26). Only bus :639 badly fell out of step. The increase in the average perturbed and umperturbed recquencies was $\Delta r_{p}=2$ hertz and $\Delta r_{u}=1.4$ hertz respectiprely, both nearly twice as great as for the single-pulse case. But $\Delta f_{p}$ was wuch swaller for rault set $F$ ' than for set $\bar{F}$.

In particular note the renarkable difference in the behavior of the group of machines shown in Figs. 25 and 29. In Section B, anse 2, a siuple explantion was given for the ilproved response from the perturbation of larger areas. This ilprovenent suggests that the trensmission system would be more stable to Bip-type perturbations if the aijecent transmission groups were not tied together. A test of this hypothesis will be given in the follsaring sample. In an case, the rachine control system must be able to damp the large frequency increases if the system is to remain stable during the tynaric time period.

\section{The Eerect of Opening the Tie Lines Before} Apg lication of the Perturbation

The original set of faults, $\bar{F}$, was again used in the double-pulse configuration to perturb the IVA area as in case 1 . However, the major tie lines connecting adjacent networks were opened before the faults were applied to see if the perturbed area's stability was improved. It was hoped that the opening of the tie lines might eliminate the interference between the perturbed and unperturbed areas and improve the stsililty. If this interference causas the loss of synchronism, then the effect of opening tie lines should be simlar to that of perturbing a larger area as done in case 2.

In all, seven major tie lines were opened imediately before the perturbation was applied. (It was iupractical to open all tie lines, w'it all high voltage, 500 kilovolt, connections vere opened.) Although sime locul areas were affected by the tie line opening, in general, the system was not severely disturbed. 


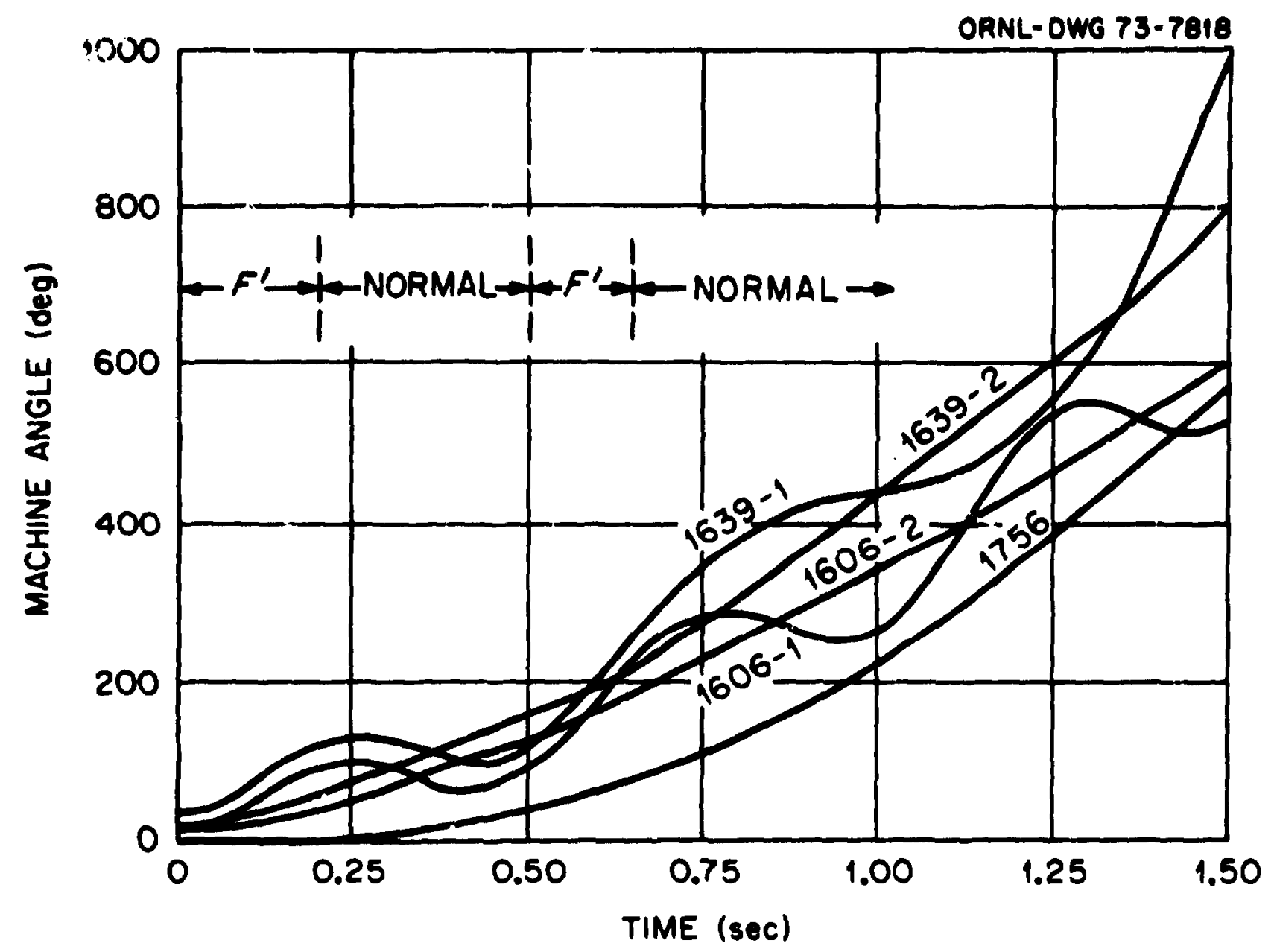

F1g. 27. Swing Curve for two ncisurrences of Fault set $F^{\prime}$ for Machine Group No. $\mathrm{l}$. 


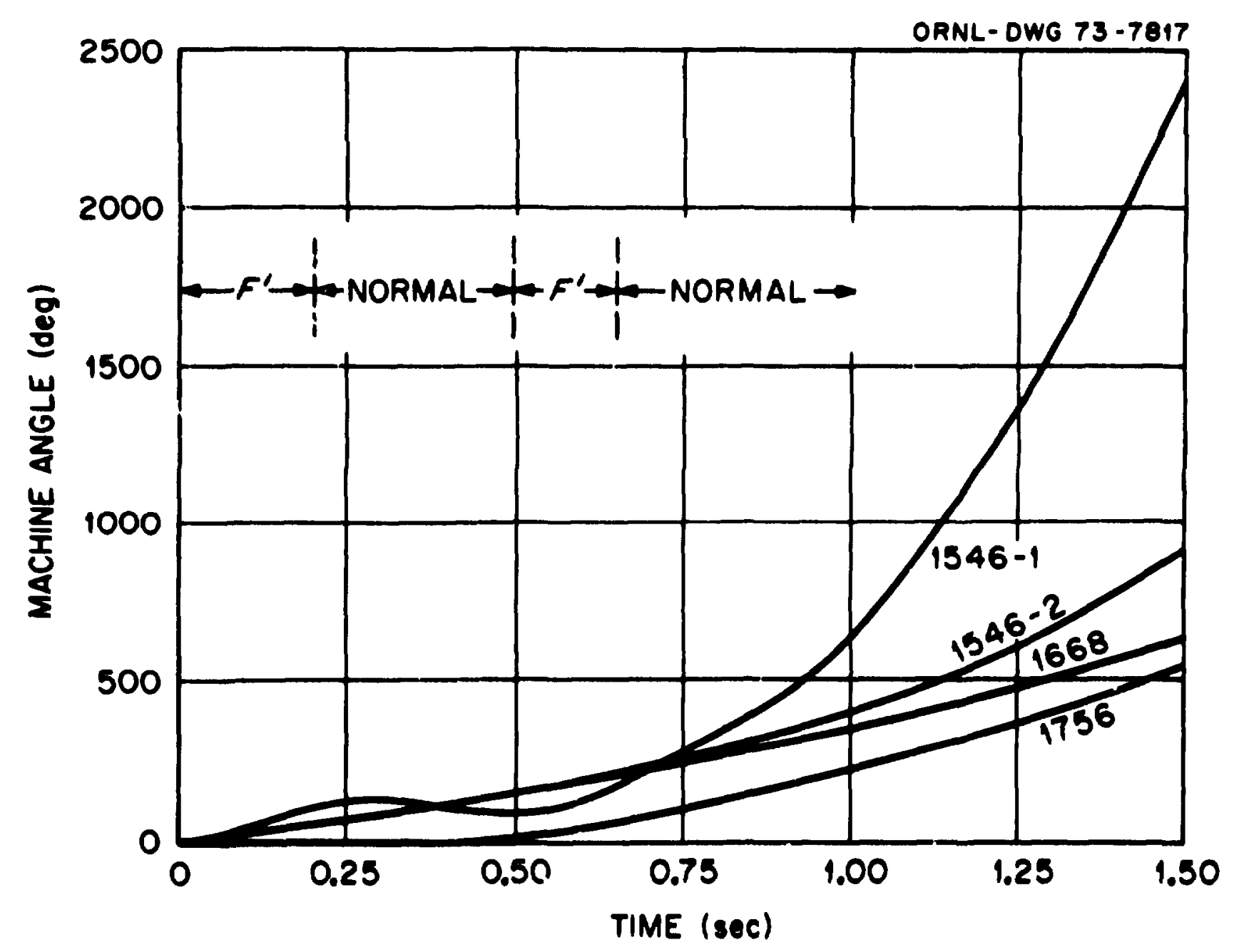

\$

F1g. 28. 8wing Curves for two cocurrences of Fault set $f^{\prime}$ for Machine Group Mo. 2. 


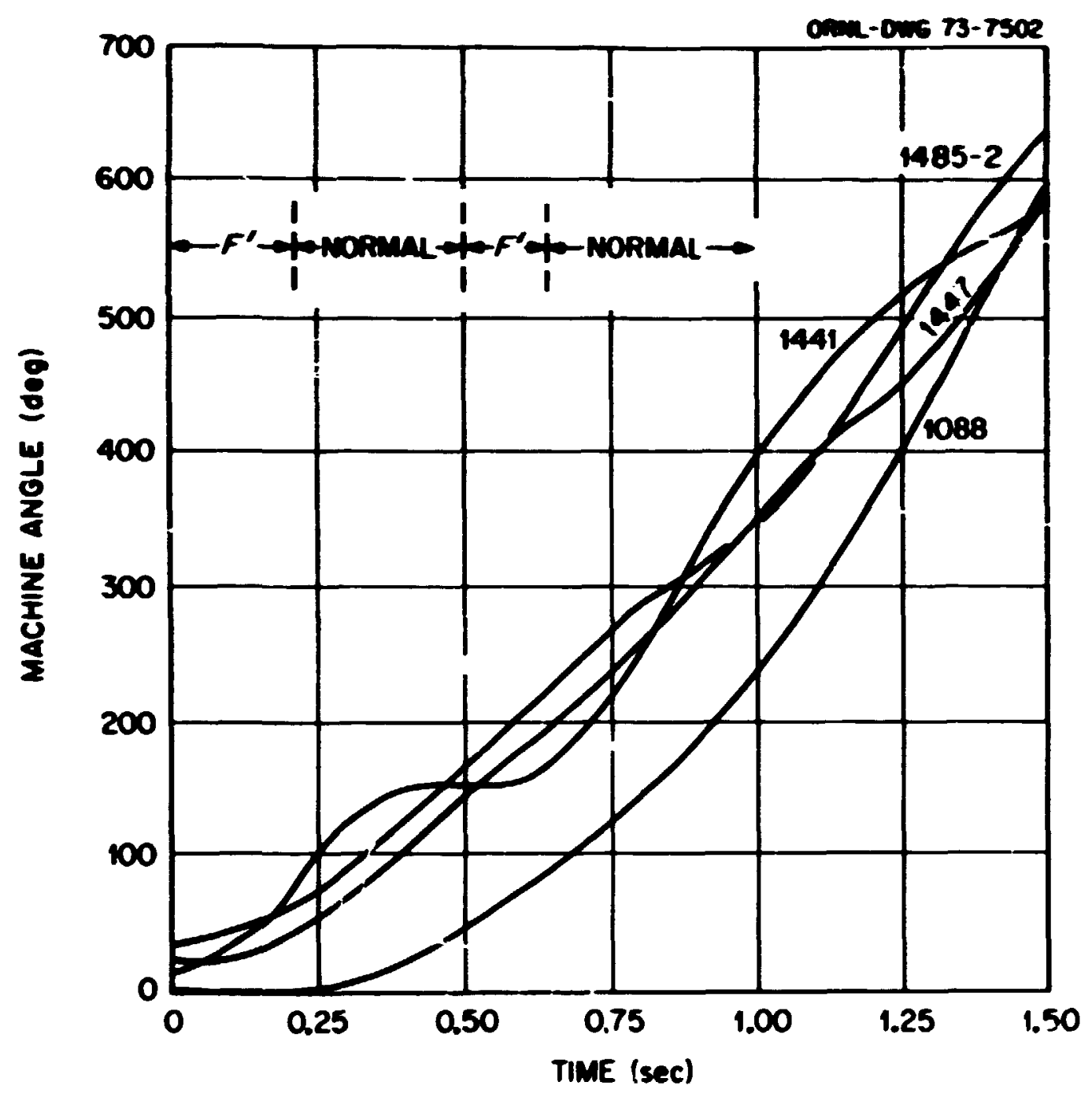

P1g. 29. 8uing Curves for two occurresuces of Pault set $P^{\prime}$ for Wachine Group No. 3 . 


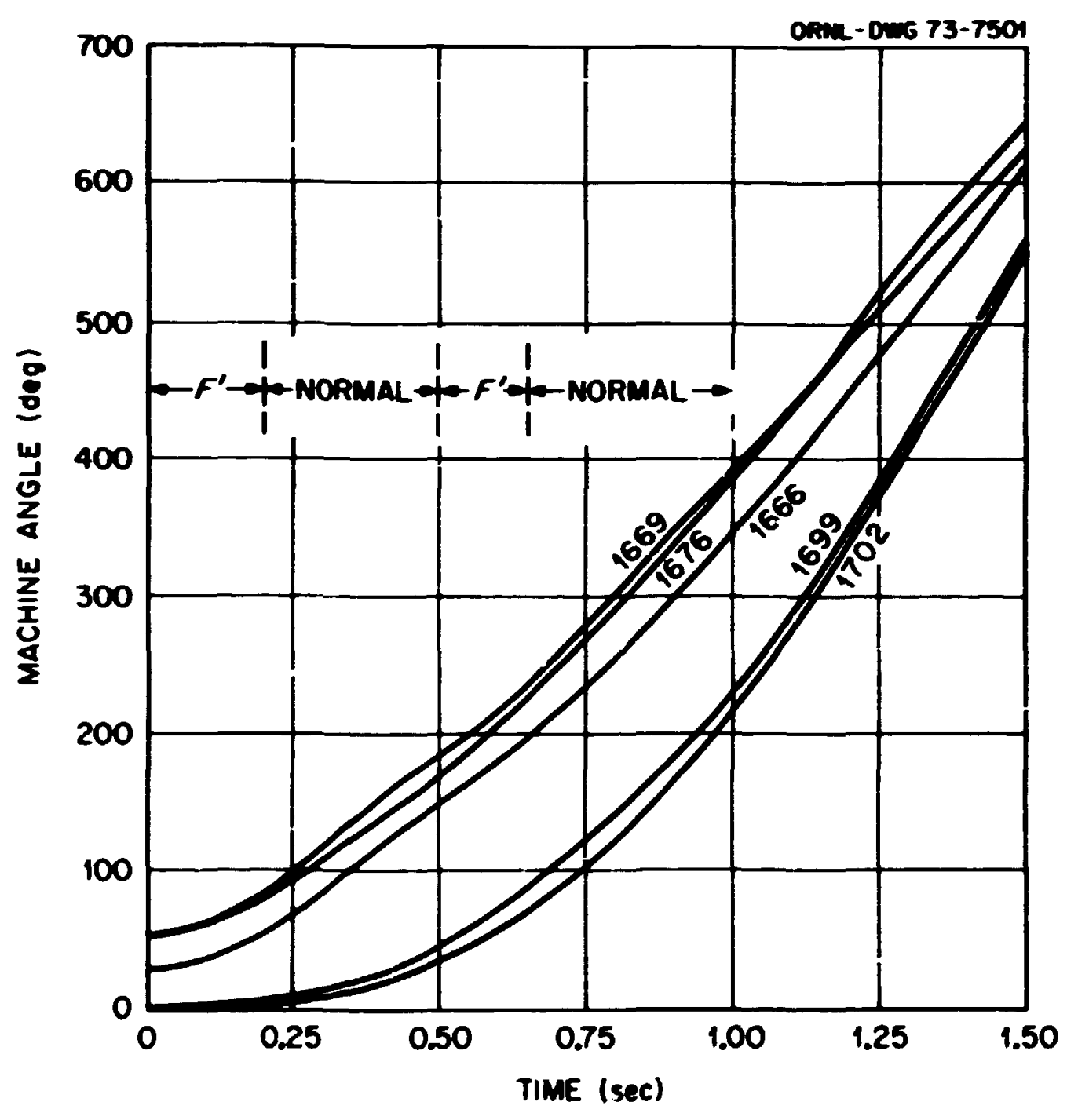

F1g. 30. Swing Curves for Two occurrences of Fault Set $\mathbf{F}^{\prime}$ for vachine Group No. 5 . 
Sigures 31 and 32 show the results of the double pulse during fault set $\bar{F}$, except with the major TVA tie lines open. The TVA syster held together auch more strongly tinan in the comprative case with the tie lines clased (compare Fig. 3 and Fig. 23 and Fig. 32 and Fig. 26; - Oris one zujor WA sachine (not shown) lost syachronisa. Both figures illustrate that the TVh network sings separately from the umperturbed aree, as one would expect since the two areas are no longer conrected. (This also shors that the removal of solely the hich roltage tie lines is sufficient to renore wost of the interaction.) The frequency change if of the perturbed and umperturbed areas can now differ greatly since there is no interaction between them. The average frequency increase for the TVA machines was ${ }^{f_{p}}=4$ hertz with the tie lires open. This is not to mach greater than for the case when the tie lines were closed (ther: $\Delta F_{p}=3$ hertz).

In sumary, a wltiple-fault perturbation has a much less severe effect on the perturbed area when there are no unperturbed areas connectirs and interacting with it. This partitioning of the system by the opening of tie ines before BaP severely perturbes the system may provide 3 means of minimizing the effects of DAP on the transmission system.

\section{The Dependence of the Response on the Effective Impedance}

Tre dependence of the response on the effective impedance was discussed in Section B, sase 4, using a single pulse. We now present the results for the dorble pulse using the same set of faults and effective inpedances. The fault set $\widetilde{F}$ previously defined was used. Figures 33 and 34 show typical owing curves. In contrast to the single-pulse case, this double-pulse case using the larger effective impedance set $\tilde{F}$ did not differ substantially from the original set $\bar{F}$. The average frequency increases were about the same for both double-pulse cases as was the overall instability.

The single-pulse perturbation was probably more affected by the impedance increase because the system was then just on the verge of 


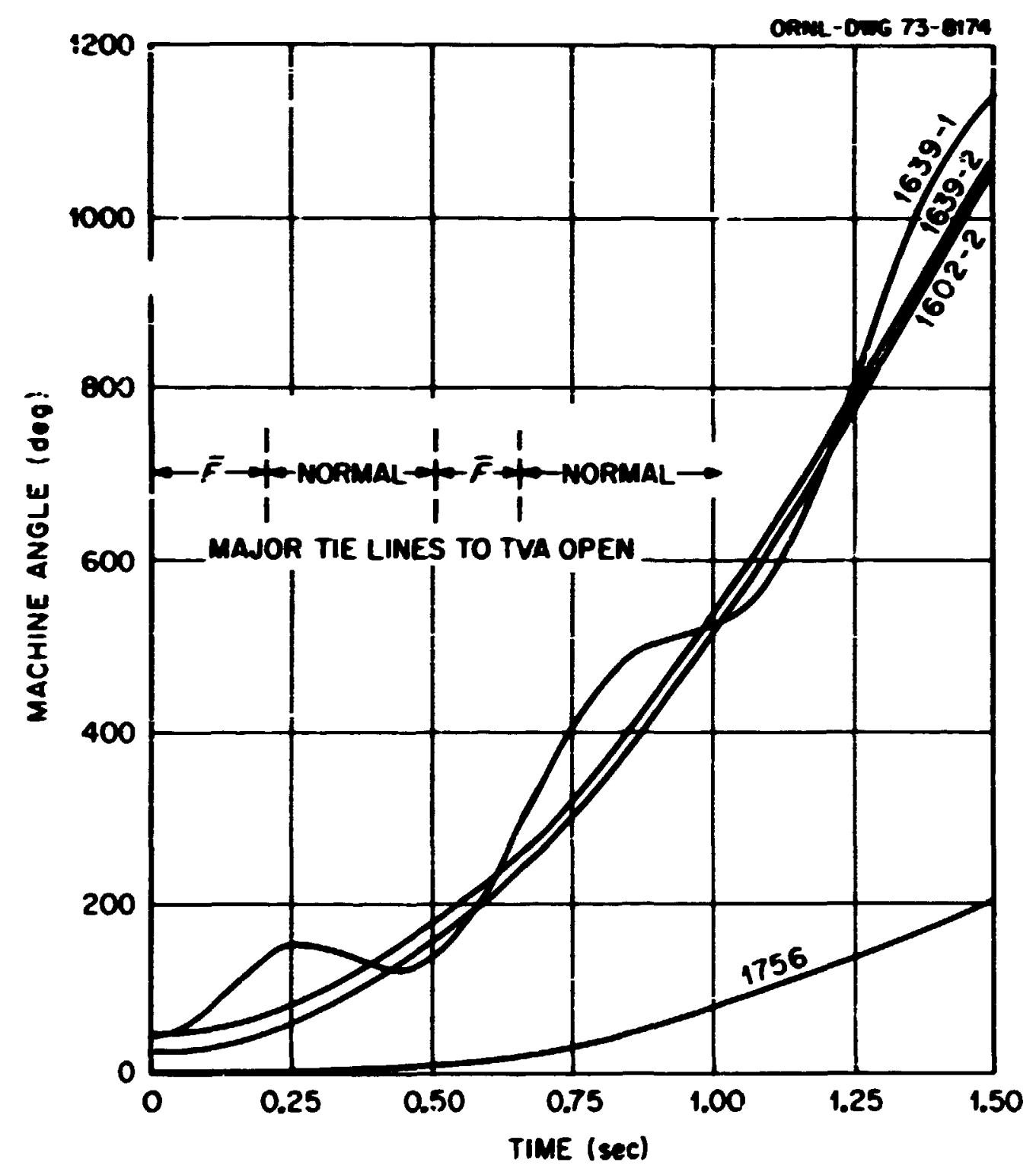

P1g. 31. Suing curves for Two Occurrences of Pault Set $\bar{P}$ with Major TVA Tie Ifines Initially open for Machine Group No. 1. 


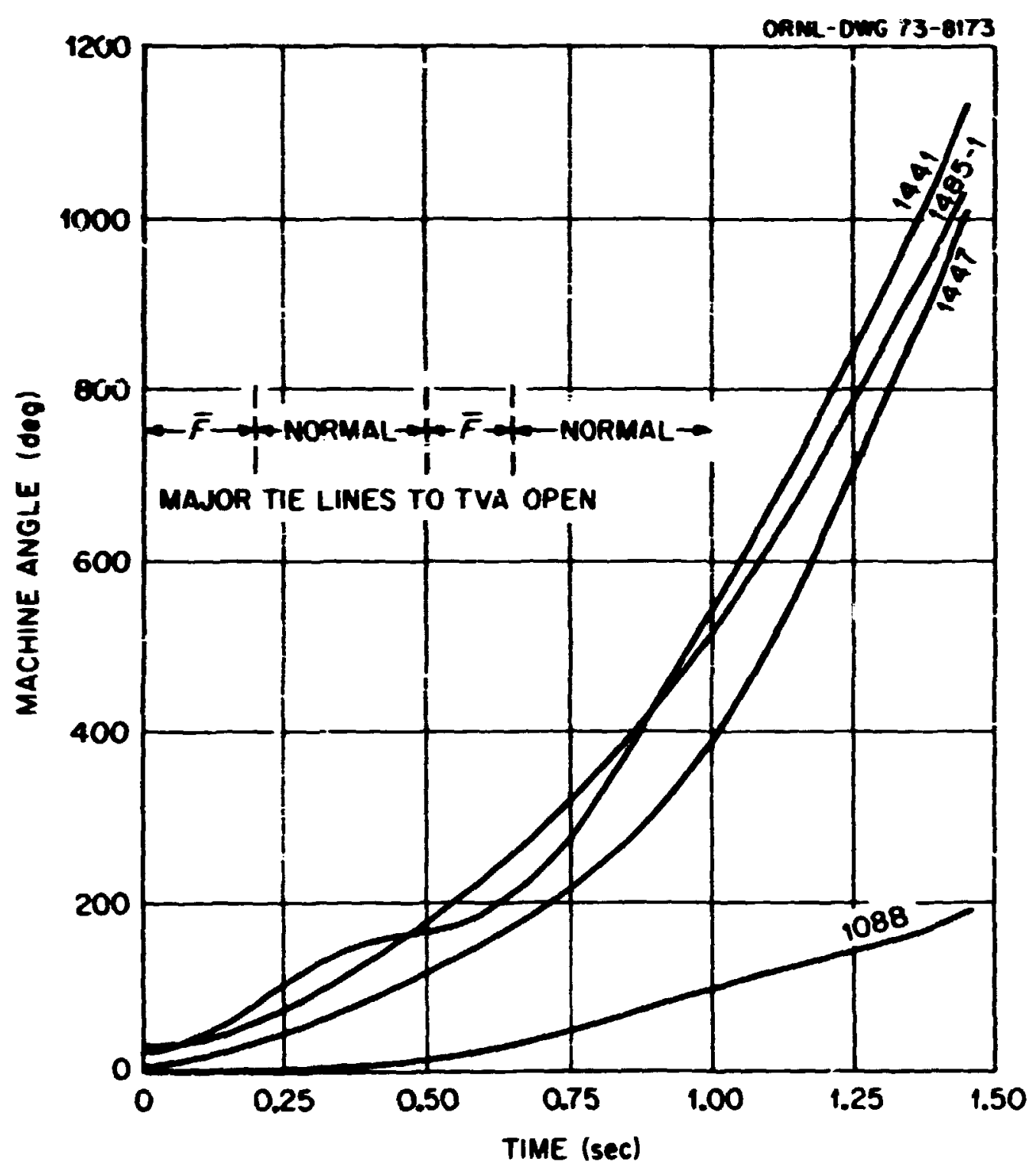

P1g. 32. Sulng Curves for Two occurrences of Pault

Set $\overline{\mathrm{P}}$ with Major IVA Tie tines open for Machine Group Wo. 3 . 


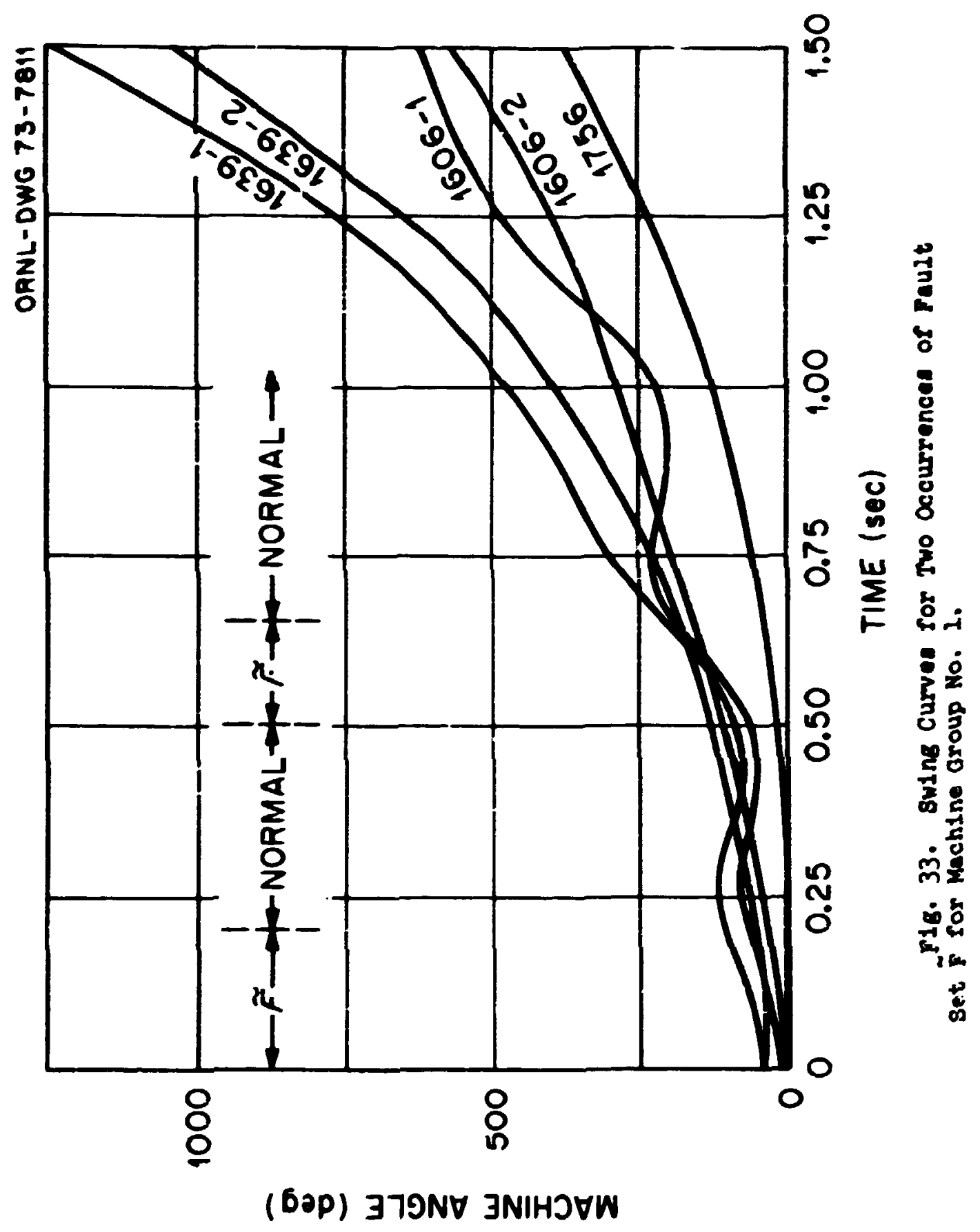




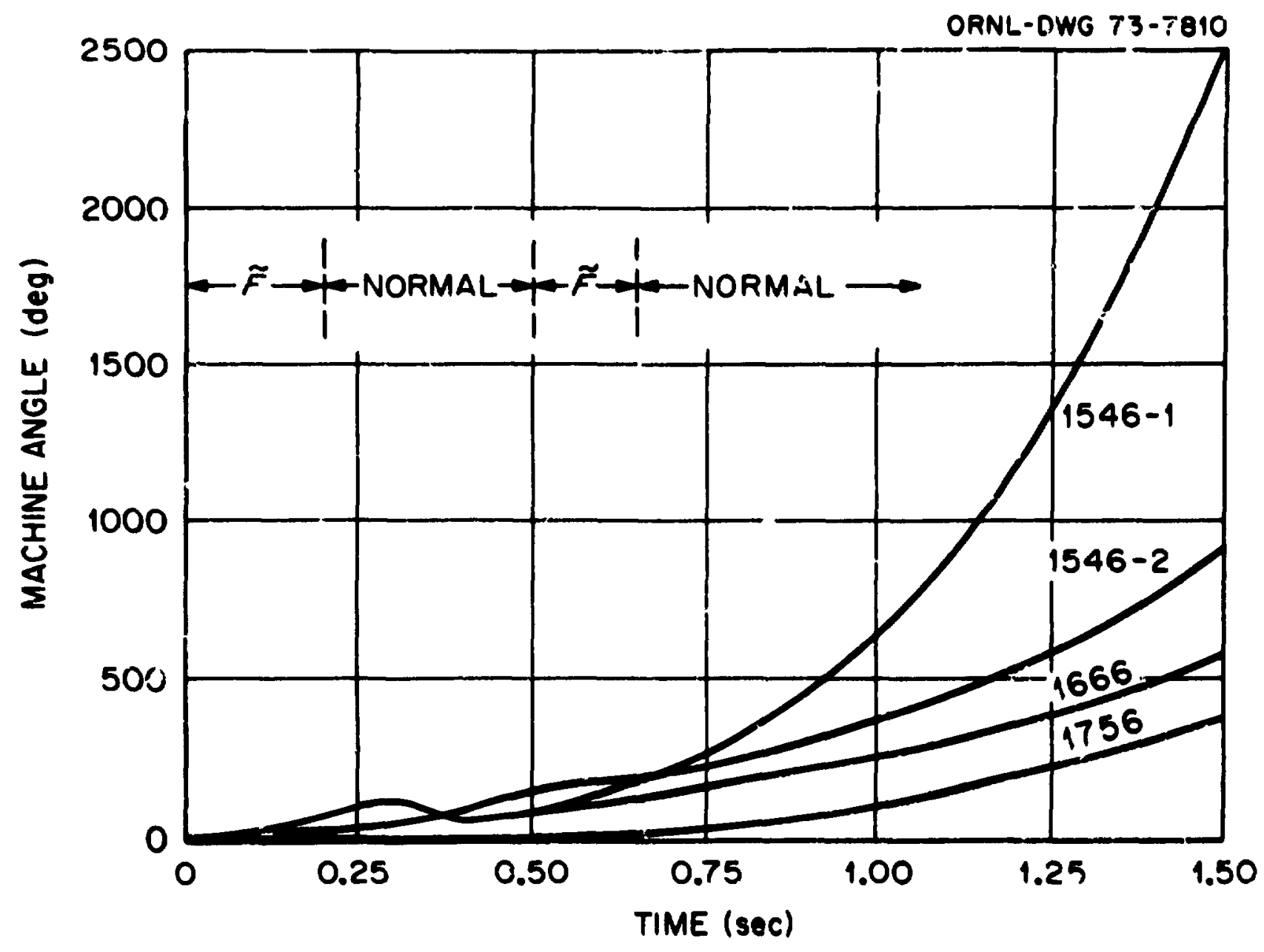

F18. 34. Swing Curves ror Two occurrencas of Fault set $F$ for Machine Group No. 2 . 
having jor instabilities, i.e., the higher $Z$ perturbation was then about the most severe that the transmission system could experience without having many wachines lose stability. But when the pertiurbation consists of a double pulse, it so disturbs the systen that it is unstable even for the larger effective irpedance, and consequently the response is not strongly dependent on the irpedance in this instability range.

\section{The Effect of Mor Load Reduction}

In the introduction of this section, we discussed how multiple pulses car lock open the distribution system relays until they are later manually reclosed. With the relajs open, the load or the isolated ifres will be renoved from the transmission network resulting in a net reductior of lcad. Since the generators cannot react instantaneously to such a load reduction, the machines will accelerate. A load reduction will affect the response primarily in the dramic, rather than the trarsient time intervi. However, stability olculations were made to determine if a major load reductio: might exacerbate the instabilities produced by a double-pulse perturbation. The distribution load on a line is rewoved yhenever the relays are open to isclate that line. Since the clearing time following the first fault is shorter t! in that following the second, It is reasonable in our model to reduce the loak after tire second fault.

The standard double-pulse perturbation was applied to the network using fault set $\bar{F}$, and the load was reduced on a chosen subset of transmission buses after the removal of the second fauit a -; (at 0.5 second). The impostant variable 15 the fraction of $100 \mathrm{~d}$ reduced, and the reaults do not vary greatly for a reduction in load on different sets of transmission buses as lone as this reduction occurs sver a reasonably large aree (and not, on fust a sew buses:). Figures 35 and 35 show typicil swing curves for a $3 \%$ reduction on bus set $F^{\prime}$, 1.e., on areas 10,12 , and 13 of Fig. 16. fibcit 11,000 megawatts of load was removed unf formly over a multi-state area. After 1.5 seconds, the increase in average syotem frequency was about the same (just a Ittle more) as the comparative double pilse with no loed shedding (Section $C$, case 1). Surprisingly snne machines seemed to aring together better then in the comparative 


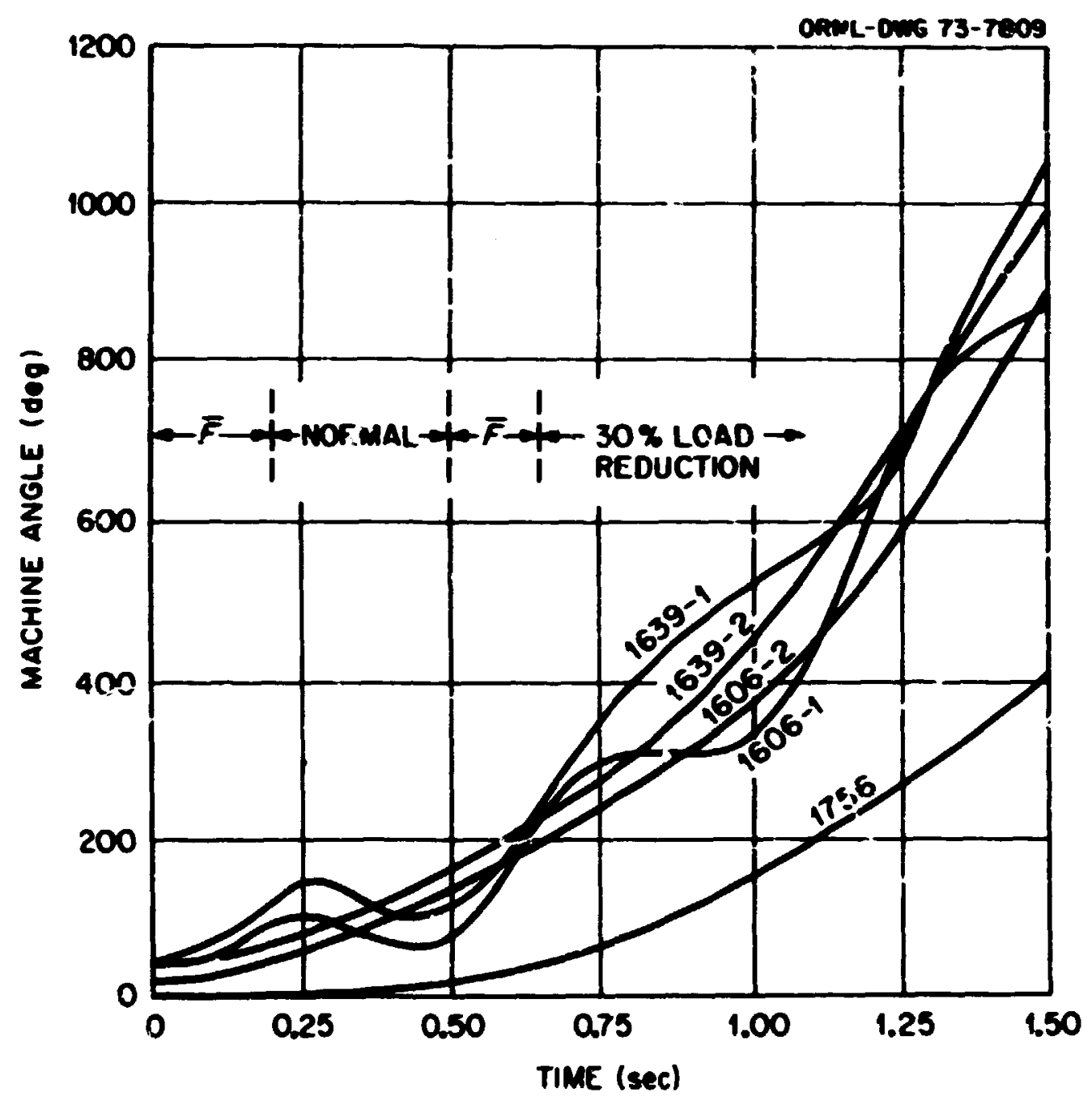

P18. 35. 8wing Curves for two occurrences of fault Bet $\bar{F}$, Followed by a $30 \%$ Reduction in Ioad, for Machine Group Eo. 1. 


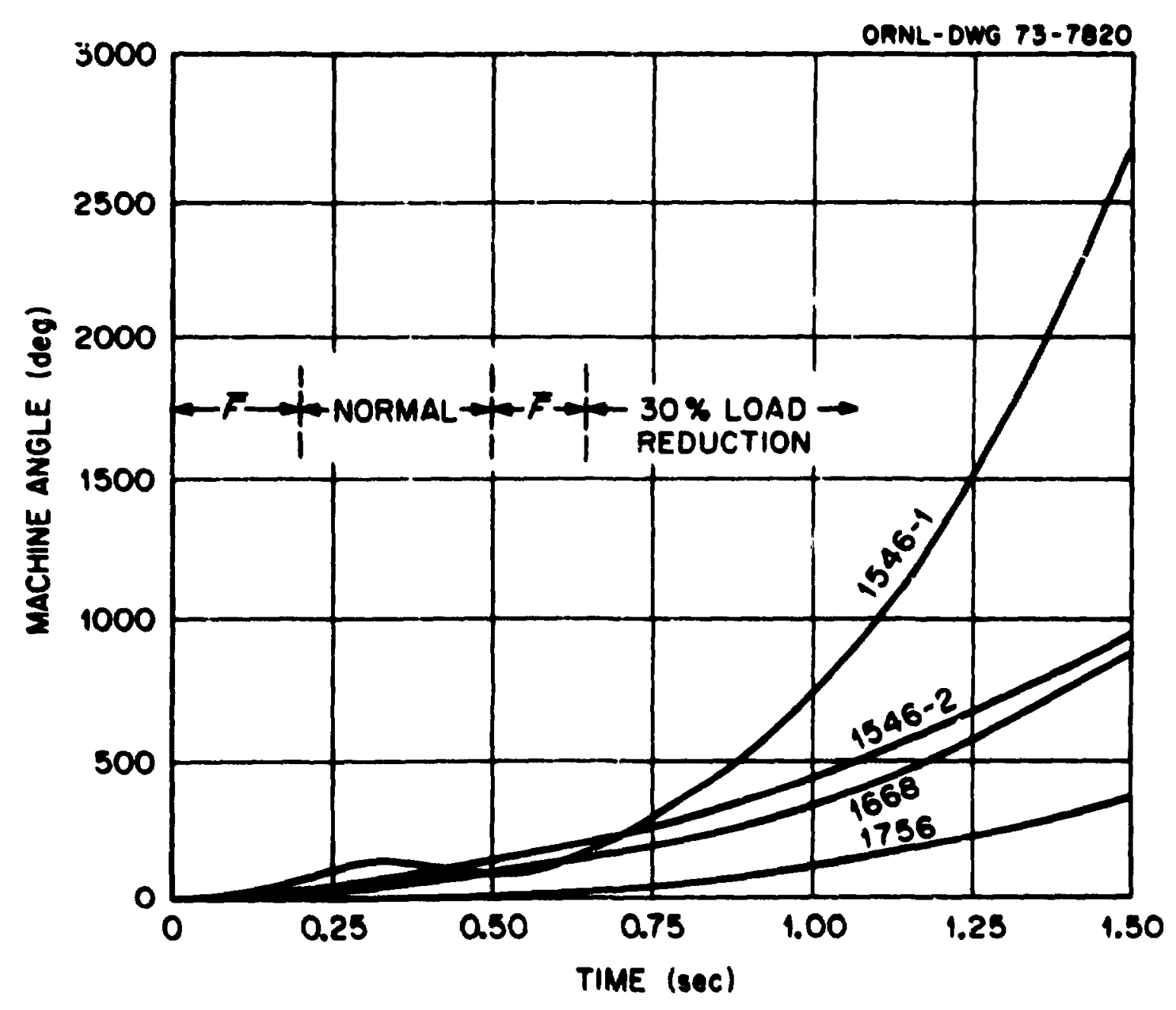

Fig. 36. Swing Curves for two ocourrences of Feult Sat $\bar{F}$, Followed by a $30 \%$ Reduction in Load, for Machine Group No. 2. 
case with no load reduction, a rather peculiar result since even without load reduction the entire systen accelerated considerably. But even though some of the machines vere more stable, about the same total number of generators lost synchronisin as in case 1 .

Apparently a mor load reduction does not greatly affect the transient stability, but it my pose a serious threat to the dymanc stability which is beyond the scope of this study to determine. The load reduction results in a frequency increase which differs in principal from tinat procuced by the autiple faults. The latter is caused hy the extensive drop in voltage during the curation of the faults, vich the average acceleration being reduced after the clering if ine faults. But because of the slowess of generator control action, a uniform load reduction will result in a pet accelerating torque on the machines for a longer time, so that the total net frequency increase may be greater. In case $?$ below, the frequency increase caused by multiple faults will be cospared to that caused by a reductior in zeneration (which is just the opposite of, but anelogous to a load reduction).

\section{Effect of Changing the Fault Density}

All of the previous calculations of Sections B and C were made using the same fault density in the perturbed area but differet in the size of the perturbed areas, the effective impedancer. the number of pulses, etc. Many studies usine ifferent fault densities were also made, dns: we presently give af, illustrative example. The representat tre double pulse was used. The fault density was reduced by randomly removing one-third of the buses from fault set $\bar{F}$ of Table 1 , thue reducing the fault density applied to the TVA area to two-thirds of thai in case 1 of this section. Figures 37 and 38 show typical swing curves for this case.

The difference in responses of the two cases was not surprising. Sone TVA machines remained in synchronism much better for the redixced density pertirbation (compare Fig. 27 wth Fig. 23), while other machines (F1gs. 38 and 24) st: 11 f'ell out of step. The change in average frequency of the TWA macinines, $s_{p}$,was about 1 hertz for the low density 


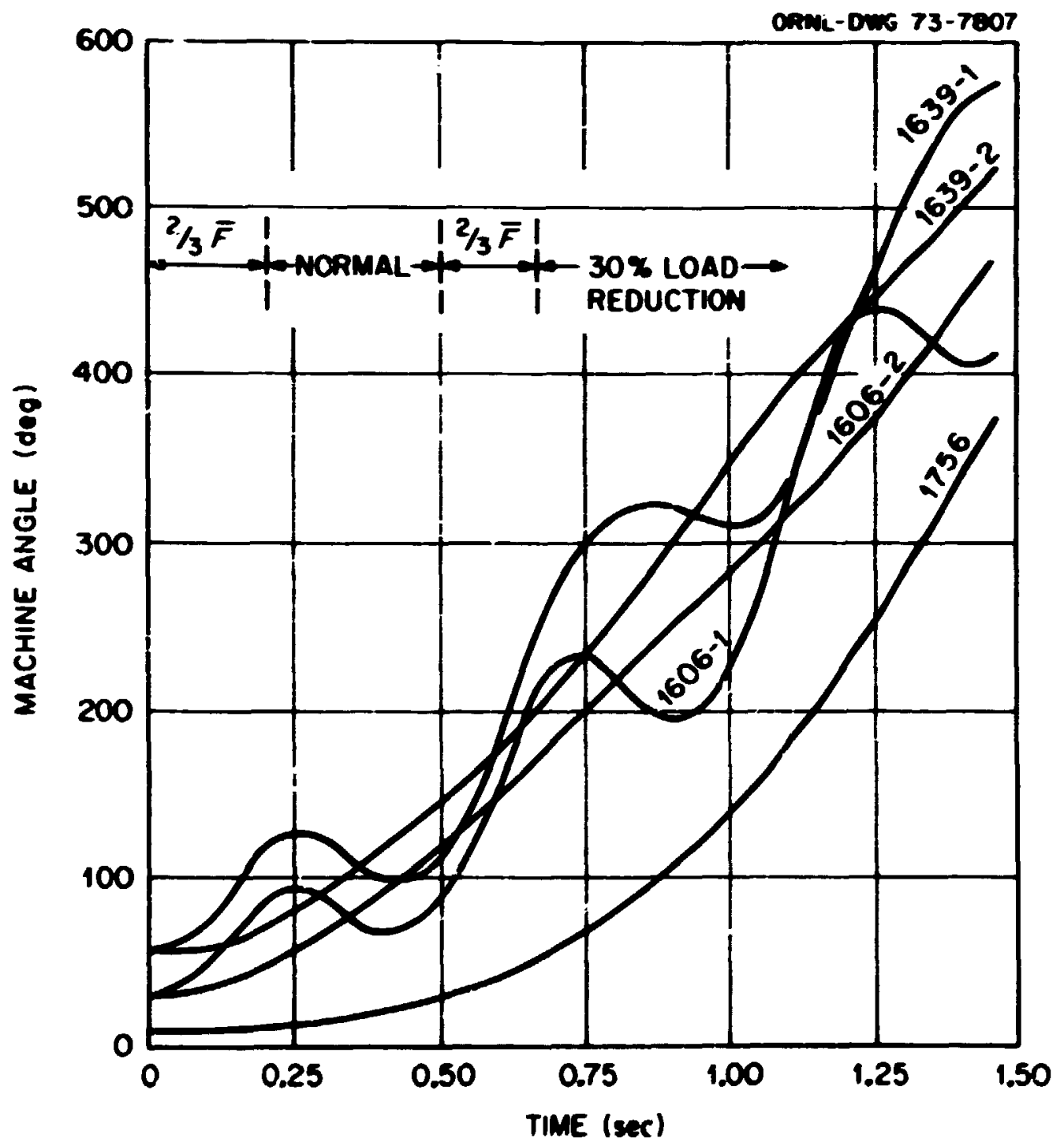

P18. 37. Bwing Curves for Two Occurrencel of a Fault set of Eniller Density, Pollowed by a 30\% Reduction In Ioed, for Mistine Group Ho. 1. 


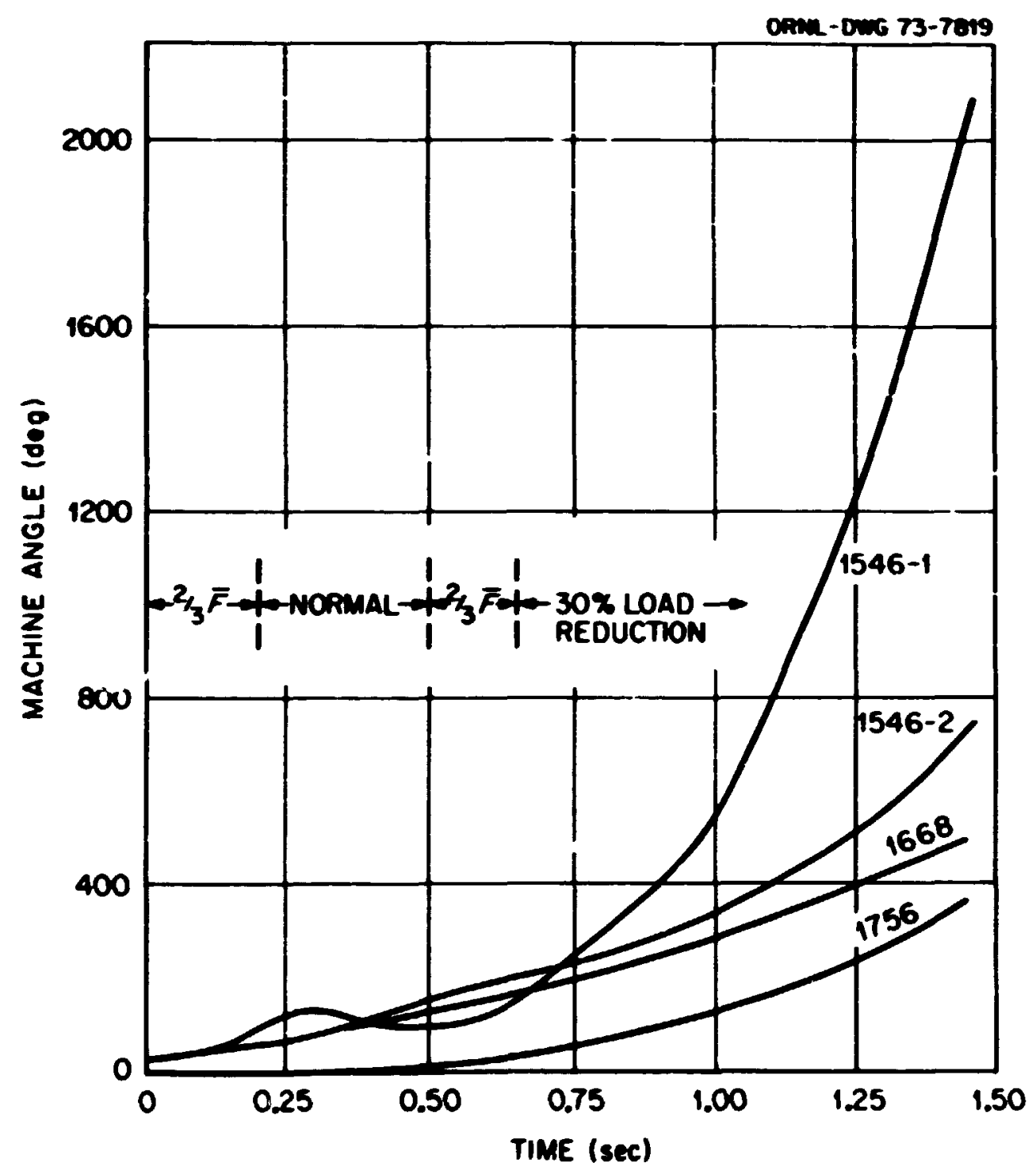

Pig. 38. Swing Curves for two occurrences of a pault set of sinller Denaity, Followed by a $30 \%$ Reduction in Ioad, for Machine Group No. 2. 
pertiubation as compared to 4 hertz for that of higher density. But the increase in frequency for machines outside of the perturbed area was nearly the same for both dencities.

The fault density is certainly an important factor in determining the effect of BPP on the transwission systen's stability. Unfortunately it is not presently known what range of fault densities BAP mas produce. The density used in the majority of cases of this study sbould not be too unrealistic if the distribution lires electrically close to mor substations are faulted. These calculations would be more realistic if, instead of the sharp cutoff between perturbed and unperturbed areas, the density decreased gradually at the outer boundary of the perturbed area (i.e., the edge of the line of sight of the detonation). The gradual change would occur near the perimeter of the circles of Fig. 2 since the : MP field decreases there for increasing distance from ground zero. Hr sier, this modification of the fault density should not change the response significantly; the important parameters are the sizt of the faulted area and the average density within the faulted area, as previously discussed.

\section{The Change in Average System Frequency}

Barlier, we briefly discusser how EMP-induced perturbations result in. an increase in the arerage syatem frequency. It is ingortant to know the aeriousness of the frequency increase during the dynamic time period resulting from multiple fauts. One measure of the severity of the effect is the decrease in power generation necessary to counteract the frequency increase. But the present stability program cannot reliably calculate the dmamic time period response. A crude estimate or the arcunt of generation which wust be shed to counteract this frequency increase, $\Delta f$, can be made by determining the change in frequency for a

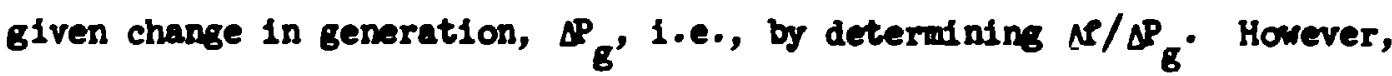
one cannot merely reduce generation by $\Delta P_{B}$ in a particular transmisoion Broup (such as TVA) and measure $\Delta f$, for then a large amount of power will be supplied by the tie lines (ar illustrated in Chapter II, Section $A$, and P1G. 5). 
We used the stability program to estimate $s / \Delta P_{B}$ for the dymanical tiwe period in the folloring manner. First, the principal IVA tie lines were opened. Then a number of TVA generators with known total megarattage $\Delta P_{g}$ were tripped. The swing curves were then linearized and the increase in frequency from equilibrium $\Delta$ was obtained from the slope of the extrapolated curves [see Eq. (4.1)] thus giving $1 \mathrm{f} / \mathrm{AP}_{\mathrm{G}}$. One great difficulty in this procedure is that it is difficult to linearly extrapolate the sring curves. After a sudden reduction in generation, the suing curves oscillate about a line of negative slope for only a second or less, but then the curves swing upward, sometimes quite steeply. The upswing occurs because the voltage drons on the machine buses reducing the electrical torque and results in a net accelerating torque.

If the swing curves are linearly extrapolated in the intermediate region before the uparing (1.e., before the machine angles start to increase) and $\Lambda f / \Delta P_{B}$ is determined as described in this section, the following results are obtained. With the major TVA tie lines open, $24 \%$ of TVA generation was tripped (6,200 megawatts out of a total of 25,500 megawatts), and the frequency decreased by about 0.55 heriz. This gives $\Delta f / \Delta P_{g}$ equal to about $9 \times 10^{-5}$ hertz/megaratt. For a generation reduction of $45 \%$ (about 11,000 megasatts) the frequency changes by about 1.1 nertz, which is reasonably proportional to a $24 \%$ reduction.

For case 1 of Section B, Chapter IV, this approximation gives the frequency increase from the ExP fault perturbations which would be roughly equivalent to a $30 \%$ decrease in the load using the above determination of $\Delta P / \Delta P_{g}$. Wote that in this estimate ve have tacitly assumed that $\Delta F / \Delta P_{B}$ resiliting from a reduction of $\Delta P_{g}$ of generation is of the same magnitude (and of opposite sign) as that resulting from a $\Delta_{G}$ decrease in ioad. We remind the reader that this is a very crude estimate as 1llustrated in the following example. If we use the above procechure to estimate the equivalent decrease in $1 \mathrm{sad}$ needed to cause the frequency increase of case 1 (Section $C$, Chapter IV) where $\Delta f_{p}=4$ hertz, one yould need to terminate about, 24,000 megawatts or nearly all of the generation, a clearly absurd result! However, the above estimates may five some indication of the serfousness of the frequency increase in 
the dynamic tive interval resulting from simultaneoss multiple faults over a large geographical area.

\section{A SURMARY AITE COAPARISON OF BRP-INDUCED AND RON-DAP-IMTUJCED PERTURBATIOLS}

We brierit summarize the results of this chapter. Both a single set and repetitive sets of multiple faults severely perturb the transmission system, the latter disturbing the system wuch more severely than the former. Loss of stability of a signifzcant number of generators in the perturbed area may occur from expected EM-induced porturbations. The size of the perturbed area is a crucial factor in determining the manitude of the aisturbance of the system. An interaction or interference occurs between umperturhed and perturbed areas which tends to exacerbate the instabilities. Consequently, the system may be more stable if tie lines between perturbed and unperturbed networks are opened prior to the disturbence in order to reduce such interactions. Other iaportant parameters of the perturbations affecting the sransient response are the fault density and the effective impedances (determined by the location of the faults).

Two examples of norral perturbations were given in Part 1 of Chapter II, Section A, with a discussion of the differences between EMPinduced and natural perturbations presented in Part 2 of that section. It should be clear that the two types of pertirbations are really quite different, as are the responses from the perturbations. Certainly EMP may lead to a cascading type of failure not unlike the Northeast Power Failure. However, the inftial EM-induced perturbation affecting the transient response is quite different. The second example of Chapter II should also be contrasted with EMP perturbations. In the former case, the effects of the power deficit resulting from the loss of generators was greatly reduced by the power tranefer from the adjacent networks as illustrated in Fig. 5. Thus the connecting networks help stabilize the system from the local perturbations. Hovever, for DMP-type perturbations, the perturbed area is so extensive that a ctabilizing effect fromadjacent 
netwo:ks is not nearly as significant. In fact, a significant and destructive interference can result. Consequently, one should not naively compare the effects of EMP-induced perturbations with those of "natural" perturbations.

In conclusion, it is possible that may induce a serious pertirbation on the distribution networks whict can cause a large portion of the transmission network in the perturbed area to lose symchronism, and consequently result in an imediate and massive power failure. 
CHAPTER V

THE LIMITATIONS OF THIS STUDY AND SJGGESPIONS

FOE FTJRTHER WORK

The philosophy of this study was to determine the transient response from ERP-generated perturbations using standard calculational techniques. Because of the limited scope of this report, necessary limitations were made. In this chapter, my of the approximations and limitations are discussed, and suggestions for further work are made.

\section{A. DIFFICULTY IN DETERMIIING A REALISTIC EMP-INDUCED PSRTURBATION}

Many different forms of perturbations were studied in this work. Clearly a large number of parameters are needed to specify the perturbation, $a_{i}$ of which are dependent on the nature of the EMP pulse (or pulses) as well as on tine coupling mechanism of the BMP field to the electric power system. Needless to say, it is difficuli to specify "the representative disturbance." One must therefore be cautious about taking any of the representative disturbances used in this study as "the real thing."

Because of this uncertain:y, preliminary calculations were made, varying ine parameters specifying the perturbation over $a$ wide range in order to determine which variables were important. Secondly, we hopeu to determine the effect on the stability for different. choices of parameters to provide some intuition for the possible range of effects that could be produced by different types of conditions. In this way, a ger:eral understanding of the synchronous behavior of the system when subjected to the unusual EMP-produced perturbations has been gained. 
B. LIMTTATIONS OF THE STIJY ANE RIADEZUACTES

TN THE NETWORK MODEL

Due to the great corplexity in calculating the system response, several simplifications were made which somewhat limit the applications of this study. Most important, machine excitation and voltage regulation were not modeled. The response could thereiore not be calculated for times greater than $1-1 / 2$ to 2 seconds after the initial perturbation. Consequently, the later tiue dyramic responr? could not be salculated at all. Because of the lack of realistic damping in the system, the later time trarsient response (between 1 to $1-1 / 2$ seconds) may also be somewhat overly pessimistic. But the apparent major luss of synchronism found using this model, particularly for the multiple pulse cases, cannot be ignored. However, one should not expect this study to have precisely determined the behavior of the traismission system when subjected to expected EMP-induced perturbations.

Other insufficiencies were discussed elsewhere. We aquin mention the critical need to determine the effect of EMP on (1) the load tis line and control systems, (2) the generacor control systems, and (3) the solid state transmission relayrs. Further study of these sub-jstems is needed tefore any sinal conclusion concerning the effects of EMP on the power system can be drawn.

It is possiole that high altitude nuclear detonations could occur without having any blast darage. It was not the purpose of this paper to discuss virious sceriarios. however, if many low altitude or groundburst nuciear detonations occur causing significaint blast damage to a significant part of the transmission network, then the transmissior. system will certainly lose stability. Moderate physical damage accor. panying EMP would only enhance the instabilities calculated in this paper. Consequently, the transient disturbance as calculated for EMP perturbations alone should be considered as a minimal perturbation.

A further difficulty in all stability studies is the difficulty ir. representing the load, which is frequently expressed as a constant impedance load, and occasionally as a constant current or a constant 
megavolt and load. :towever, all of these represertations are simolifirations since the sature of the loed is not precisely known. In. this study, the load was modeled as a constant impedarice load. Fovever, some calculations we:e made using the other two load representations in. localized areas in wich machines lost stability, in order to see if the different representations significantly affected the response. The results were negative. The locel response changed very little. Machines which jost stability for the local lood, modeled as constant impedance, also lost stability when the local load ins modeled as constant current or constant megavolt amp load.

If SMP perturbations produced transmission line surges of sufficient magnitude to open relays, the effect on the stability would be severe. However, the powe: flow in the major lines in the perturbed area was mitored in most, of the stability calculations. There were significant power surges, but they were not large enough to trip relays. Consequently, the transmission lines were not openeil at ary time, except for the tie lines in a few cases. If additional effects resuit in excessive power surges, such as might occur if tring generators were tripper, then the possibility of the opening of transmis: on lines sholild be incorporated. The limited szope of this study coild not estimaite the likelihood of such events. 
CHAPTER VI

GENERAL UNNCLUSIG:E:

The results of this study indicate that the electric transmission system way be disturbed by EMP-induced perturbations sufficiently tc sause wuch of the system to lose stability, resulting in a iarge power failure. Although the effects from DAP are complex, a model vas defined which should reasonabiy represent the effects on the transmission system fron induced perturbations on the distribution system.

Both a single set and repetitive sets of waltiple faults sererely perturb the transmission system; the resetitive sets of faults disturb tine system much more severely. Loss of stability of a significant number of generators in the perturbed area can occur from expected DMPinduced perturbations.

The severity of 5xp-type perturbations can perhaps be reducei by separating perturbed and unparturbed areas by opening the tie lines connecting these regions. The interference between the two areas would then be minimized. Furthermore, a rarturbed area losing synchronism would then not result in the collapse of the areas which were not directly affected. However, further consideration of possible effects from such a tie line opening mast be nade before such a procedure is adopted.

As outlined in Chapter $V$, further study should be made of other possible EM-induced perturbations which were rot included in this worr. only then can final conclusions be drawn concerning the severity of disruption which EMP may induce. 
REFERENICES

1. W. I. Karzas and I. R. Latter, Phys. Rev., 137, 1369 (1965).

C. D. B. lielson, A Progren to Counter the Effects of Nuclear Electromagretic Pulse in Commercial Porer Systems, ORiL-in4-3552, Part 1, October 1972.

3. J. K. Marable, J. K. Baird, and D. B. Ilelson, Effects of Electromagnetic Pulse ni a Power System, ORNL 4836, December 1.

4. James K. Baird and Nicholas J. Frigo, Effects of Electromagnetic Pulae (EMP) on the Supervisory Control Equipment of a Power Sy ster, ORN-4899, October 1973.

5. C. W. Toss and T. A. Green, "Djrandc Performance Eveluation of 2 Cong iter Controlled Electric Power System," Paper 71-TP-593-PWR, IFAE Simmer Meeting and International Symposium on High Power Testing, July 1971.

6. Federal Power Comission, "Prevention of Pover Failures, A Rer רrt to the Presidsnt," Volumes I, II, and III, July 1967.

7. F. Levi, M. Panzer. Electronechanical Power Conversion, McGrawtilill Book Co., (1966).

8. E. W. Kimbark, Power Supply Staility, Vols. I-III, John Wiley \& Sons, (1948).

9. Westinghouse Electric Corporation, Electrical Transmission aud Distribution Reference Book, 4th Edition, (1964).

10. W. W. Maslin, S. T. Matreszek, C. H. Rush, and J. G. Irwin, "A Power System Planning Corputer Program Package simphasizing Flexibility and Compatibility," IERE Conference aper No. 70-CP-684-PW?, (July 1970). 